Aus der Klinik Gynäkologie und Geburtshilfe

(Prof. Dr. med. J. Gallwas)

der Medizinischen Fakultät der Universität Göttingen

\title{
Der Einfluss von GnRH-Analoga auf die Zellproliferation und die GPR-30-Expression in triple negativen Mammakarzinomzellen
}

\author{
INAUGURAL-DISSERTATION \\ zur Erlangung des Doktorgrades \\ der Medizinischen Fakultät der \\ Georg-August-Universität zu Göttingen
}

vorgelegt von

Eva-Maria Catharina Beer

aus

Roding

Göttingen 2021 
Dekan:

Referent/in:

Ko-Referent/in:

Drittreferent/in:
Prof. Dr. med. W. Brück

Prof. Dr. rer. nat. C. Gründker

Prof. Dr. rer. nat. D. Kube

Prof. Dr. hum. biol. M. Schön

Datum der mündlichen Prüfung: 01.09.2021 
Hiermit erkläre ich, die Dissertation mit dem Titel "Der Einfluss von GnRH-Analoga auf die Zellproliferation und die GPR-30-Expression in triple negativen Mammakarzinomzellen"

eigenständig angefertigt und keine anderen als die von mir angegebenen Quellen und Hilfsmittel verwendet zu haben.

Göttingen, den 


\section{Inhaltsverzeichnis}

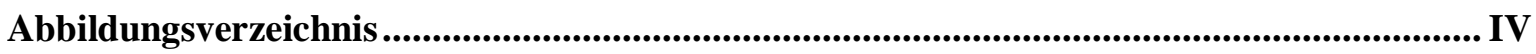

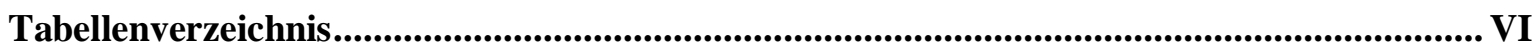

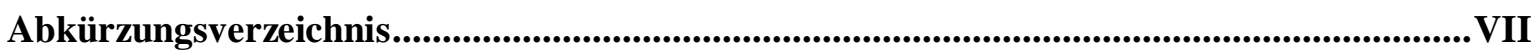

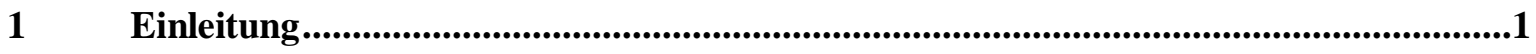

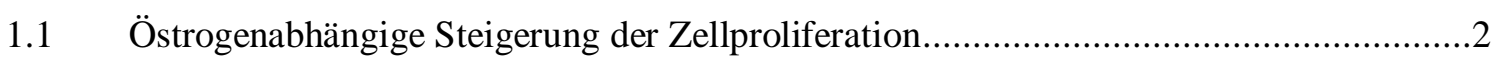

1.1.1 Der genomische Signalweg über den Östrogenrezeptor $\alpha$ und $\beta(E R \alpha, E R \beta)$..............2

1.1.2 Der nicht genomische Signalweg über den G-Protein-gekoppelten Rezeptor 30..........3

1.2 Der GPR30 in triple negativen Mammakarzinomzellen ..............................................

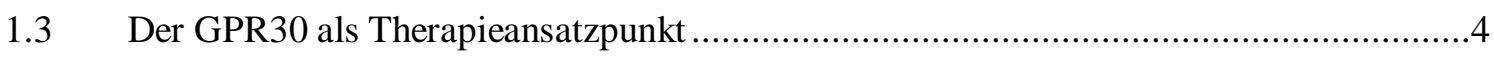

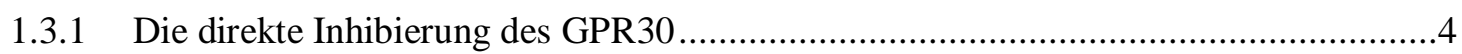

1.3.2 Die indirekte Inhibierung des GPR30 durch direkte Hemmung des EGF-Rezeptors ....4

1.4 Gonadotropin-Releasing-Hormon $(\mathrm{GnRH})$ und der GnRH-Rezeptor ...............................

1.4.1 Das Gonadotropin-Releasing Hormon I (GnRH I) in der Hypophyse (syn.: LHRH) ....8

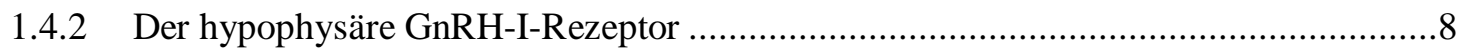

1.4.3 Die GnRH I induzierte Signaltransduktion in der Hypophyse ....................................9

1.4.4 Die GnRH I induzierte Signaltransduktion in gynäkologischen Tumoren....................9

1.4.5 Das Gonadotropin-Releasing-Hormon II (syn.: GnRH II, chicken GnRH II)............11

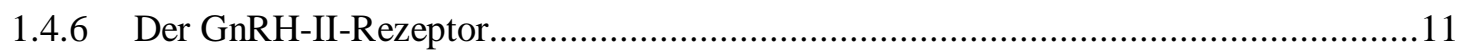

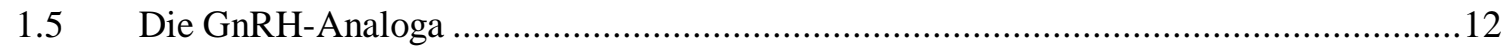

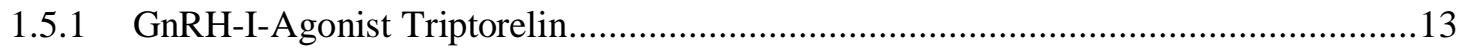

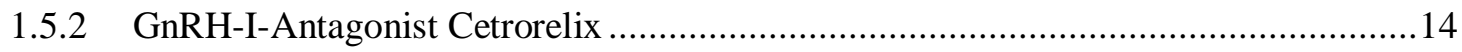

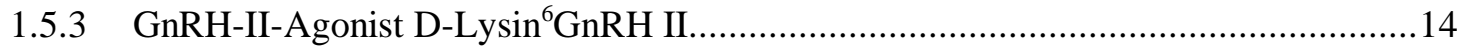

1.5.4 GnRH-II-Antagonist DNal-DCpa-DPal-Ser-His-DPal-Trp-Leu-Pro-DAla .................14

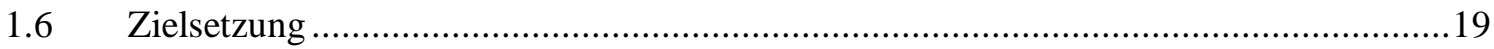

$2 \quad$ Material und Methoden.........................................................................................................20

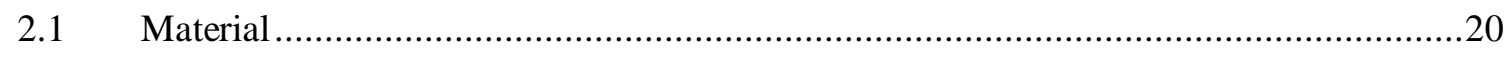

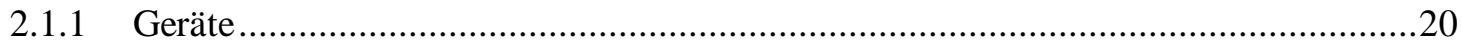

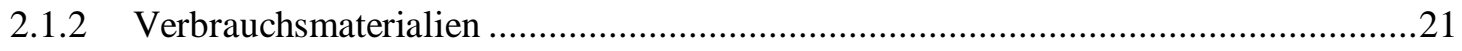

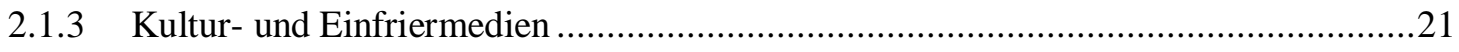

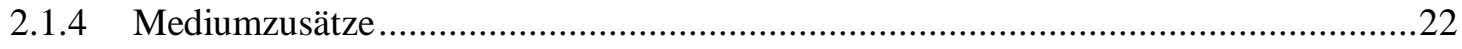

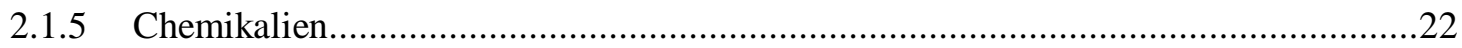




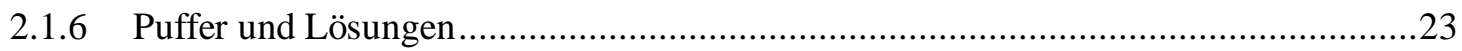

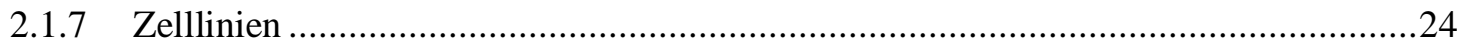

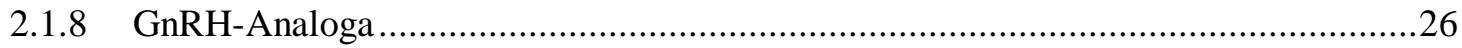

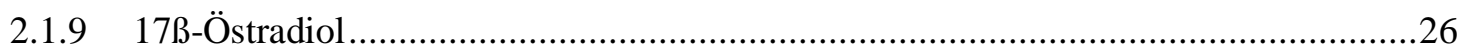

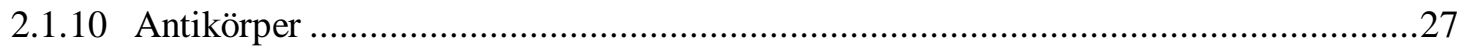

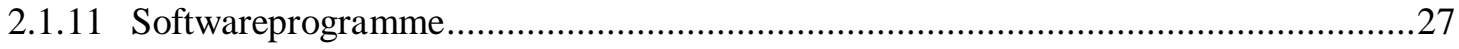

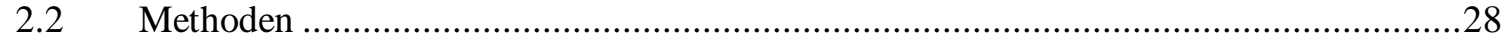

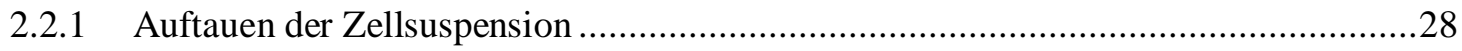

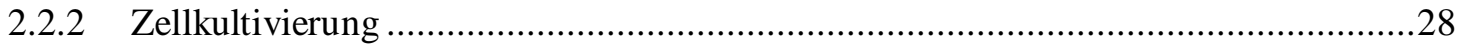

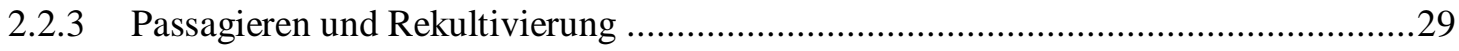

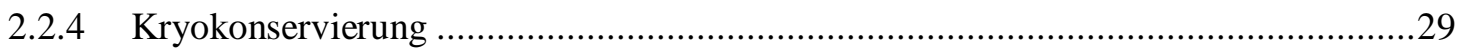

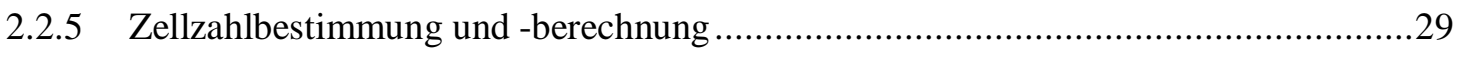

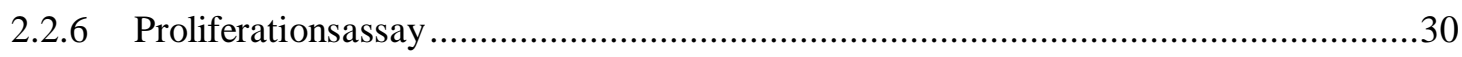

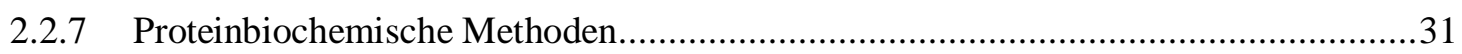

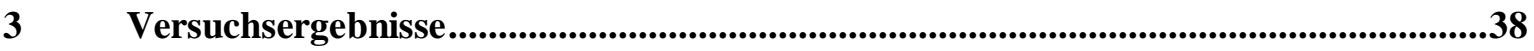

3.1 Beeinflussung der Proliferationsraten von vier TNBC-Zellpopulationen durch verschiedene Konzentrationen von 17 $\beta$-Östradiol $\left(\mathrm{E}_{2}\right)$......

3.1.1 Beeinflussung der Proliferationsraten der MDA-MB-435S-Zellpopulation durch

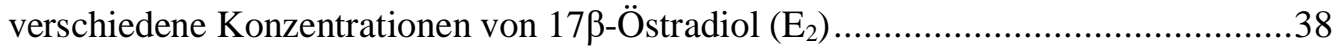

3.1.2 Beeinflussung der Proliferationsraten der MDA-MB-453-Zellpopulation durch verschiedene Konzentrationen von $17 \beta$-Östradiol $\left(\mathrm{E}_{2}\right)$

3.1.3 Beeinflussung der Proliferationsraten der HCC70-Zellpopulation durch verschiedene Konzentrationen von $17 \beta$-Östradiol $\left(\mathrm{E}_{2}\right)$.

3.1.4 Beeinflussung der Proliferationsraten der HCC1806-Zellpopulation durch

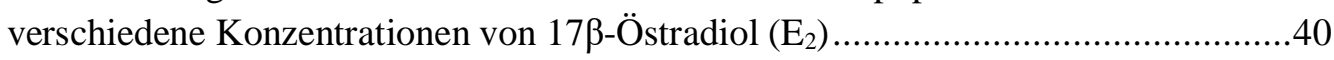

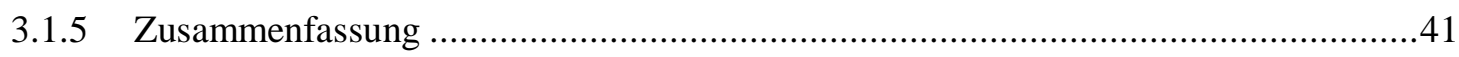

3.2 Vergleich der Wachstumsraten von $\mathrm{E}_{2}$-stimulierten und nicht $\mathrm{E}_{2}$-stimulierten TNBC-

Zellen unter Reduzierung des FCS-Gehaltes

3.2.1 Vergleich der Wachstumsraten von $\mathrm{E}_{2}$-stimulierten und nicht $\mathrm{E}_{2}$-stimulierten $\mathrm{HCC} 70$ Zellen unter Reduzierung des FCS-Gehaltes.

3.2.2 Vergleich der Wachstumsraten von $\mathrm{E}_{2}$-stimulierten und nicht $\mathrm{E}_{2}$-stimulierten HCC1806-Zellen unter Reduzierung des FCS-Gehaltes. .43

3.2.3 Zusammenfassung .44

3.3 Wirkung der GnRH-Analoga Triptorelin, Cetrorelix, D-Lysin ${ }^{6}$ GnRH II und N4 auf die relative Zellzahl der Zelllinien MDA-MB-435S, MDA-MB-453, HCC70, HCC1806 ..45

3.3.1 Wirkung der GnRH-Analoga auf die relative Zellzahl der Zelllinie MDA-MB-435S 45

3.3.2 Wirkung der GnRH-Analoga auf die relative Zellzahl der Zelllinie MDA-MB-453 ..45 
3.3.3 Wirkung der GnRH-Analoga auf die relative Zellzahl der Zelllinie HCC70.............46

3.3.4 Wirkung der GnRH-Analoga auf die relative Zellzahl der Zelllinie HCC1806 ..........51

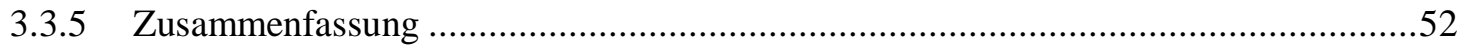

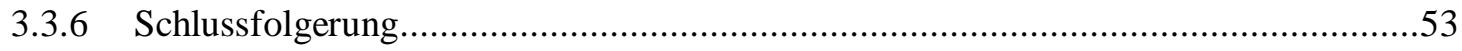

3.4 Wirkung des GnRH-I-Antagonisten Cetrorelix auf die GPR30-Expression bei den

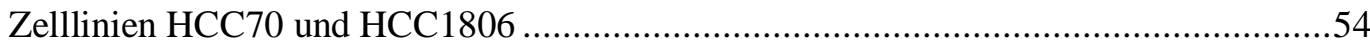

3.4.1 Wirkung des GnRH-I-Antagonisten Cetrorelix auf die GPR30-Expression bei der

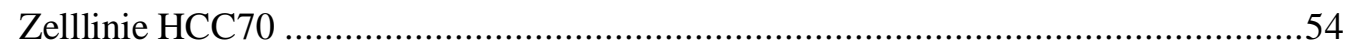

3.4.2 Wirkung des GnRH-I-Antagonisten Cetrorelix auf die GPR30-Expression bei der

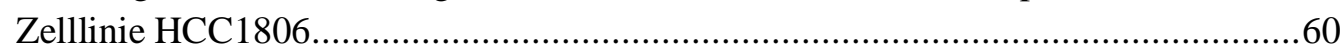

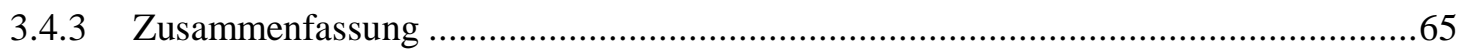

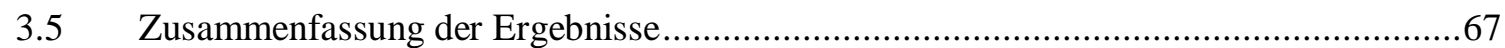

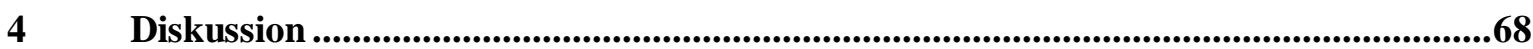

4.1 Die Beeinflussung der Proliferationsraten von vier TNBC-Zellpopulationen durch verschiedene Konzentrationen von 17ß-Östradiol $\left(\mathrm{E}_{2}\right)$.

4.2 Vergleich der Wachstumsraten von $\mathrm{E}_{2}$-stimulierten und nicht $\mathrm{E}_{2}$-stimulierten TNBC-

Zellen (zwei verschiedene Zellpopulationen) unter Reduzierung des FCS-Gehaltes......70

4.3 Wirkung der GnRH-Analoga Triptorelin, Cetrorelix, D-Lysin ${ }^{6} \mathrm{GnRH}$ II und N4 auf die relative Zellzahl der Zelllinien MDA-MB-435S, MDA-MB-453, HCC70, HCC1806 ..70

4.3.1 Vergleich der Zelllinien MDA-MB-453, MDA-MB-435S, HCC70, HCC1806 ........71

4.3.2 Vergleich der Wirkung der GnRH-Analoga GnRH I vs. GnRH II............................73

4.3.3 Vergleich der Wirksamkeit des GnRH-I-Agonisten Triptorelin vs. den GnRH-I-

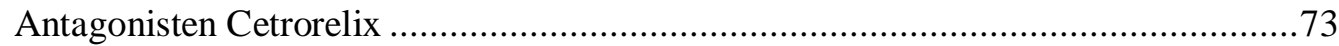

4.4 Dosis-Zeit abhängige Wirkung des GnRH-I-Antagonisten Cetrorelix auf die GPR30-

Expression bei den Zelllinien HCC70 und HCC1806 ................................................75

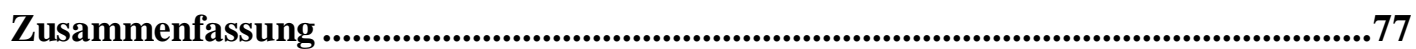




\section{Abbildungsverzeichnis}

Abbildung 1: Struktureller Aufbau des membranständigen humanen hypophysären GnRH-I-Rezeptors.. 9

Abbildung 2: Schema der GnRH Signaltransduktionsmechanismen in gynäkologischen Tumoren 11

Abbildung 3: Übersichtsgrafik einer triple negativen Tumorzelle ................................ 17

Abbildung 4: Einfluss von $\mathrm{E}_{2}$ auf die Proliferationsrate von MDA-MB-435S-Zellen ..... 39

Abbildung 5: Einfluss von $\mathrm{E}_{2}$ auf die Proliferationsrate von HCC70-Zellen ................... 40

Abbildung 6: Einfluss von $\mathrm{E}_{2}$ auf die Proliferationsrate von HCC1806-Zellen ................ 41

Abbildung 7: Vergleich der Wachstumsraten von $\mathrm{E}_{2}\left(10^{-8} \mathrm{M}\right)$ stimulierten und nicht $\mathrm{E}_{2}$-stimulierten HCC70-Zellen unter Reduzierung des FCS-Gehaltes ....... 43

Abbildung 8: Vergleich der Wachstumsraten von $\mathrm{E}_{2}\left(10^{-8} \mathrm{M}\right)$ stimulierten und nicht $\mathrm{E}_{2}$-stimulierten HCC1806-Zellen unter Reduzierung des FCS-Gehaltes ... 44

Abbildung 9: Einfluss des GnRH-I-Antagonisten Cetrorelix in verschiedenen Konzentrationen auf die relative Zellzahl von 17ß-Östradiol stimulierten Zellen der Zelllinie MDA-MB-453

Abbildung 10: Einfluss des GnRH-I-Agonisten Triptorelin in verschiedenen Konzentrationen auf die relative Zellzahl von 17ß-Östradiol stimulierten Zellen der Zelllinie HCC70

Abbildung 11: Einfluss des GnRH-I-Antagonisten Cetrorelix in verschiedenen Konzentrationen auf die relative Zellzahl von 17ß-Östradiol stimulierten Zellen der Zelllinie HCC70 48

Abbildung 12: Einfluss des GnRH-II-Agonisten D-Lysin in verschiedenen Konzentrationen auf die relative Zellzahl von 17ß-Östradiol stimulierten Zellen der Zelllinie HCC70

Abbildung 13: Einfluss des GnRH-II-Antagonisten N4 in verschiedenen

Konzentrationen auf die relative Zellzahl von 17ß-Östradiol stimulierten Zellen der Zelllinie HCC70

Abbildung 14: Einfluss des GnRH-I-Antagonisten Cetrorelix in verschiedenen

Konzentrationen auf die relative Zellzahl von 17ß-Östradiol stimulierten Zellen der Zelllinie HCC1806...

Abbildung 15: Wirkung von Cetrorelix auf die GPR30-Expression in HCC70-Zellen nach $24 \mathrm{~h}$

Abbildung 16: Wirkung von Cetrorelix auf die GPR30-Expression in HCC70-Zellen nach $48 \mathrm{~h}$

Abbildung 17: Wirkung von Cetrorelix auf die GPR30-Expression in HCC70-Zellen nach $96 \mathrm{~h}$

Abbildung 18: Darstellung der Wirkung von Cetrorelix $10^{-7} \mathrm{M}$ auf die GPR30Proteinexpression in Abhängigkeit von der Inkubationszeit bei der Zelllinie HCC70 
Abbildung 19: Darstellung der Wirkung von Cetrorelix $10^{-6} \mathrm{M}$ auf die GPR30Proteinexpression in Abhängigkeit von der Inkubationszeit bei der Zelllinie HCC70

Abbildung 20: Darstellung der Wirkung von Cetrorelix $10^{-5} \mathrm{M}$ auf die GPR30-

Proteinexpression in Abhängigkeit von der Inkubationszeit bei der Zelllinie HCC70 60

Abbildung 21: Wirkung von Cetrorelix auf die GPR30-Expression in HCC1806-Zellen nach $24 \mathrm{~h}$ 61

Abbildung 22: Wirkung von Cetrorelix auf die GPR30-Expression in HCC1806-Zellen nach $48 \mathrm{~h}$

Abbildung 23: Wirkung von Cetrorelix auf die GPR30-Expression in HCC1806-Zellen nach $96 \mathrm{~h}$

Abbildung 24: Darstellung der Wirkung von Cetrorelix $10^{-5} \mathrm{M}$ auf die GPR30Proteinexpression in Abhängigkeit von der Inkubationszeit bei der Zelllinie HCC1806 64 


\section{Tabellenverzeichnis}

Tabelle 1: Übersicht über die Aminosäuresequenzen von GnRH-I und -II sowie deren

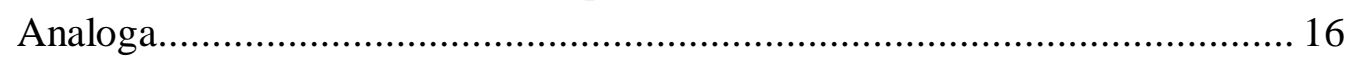

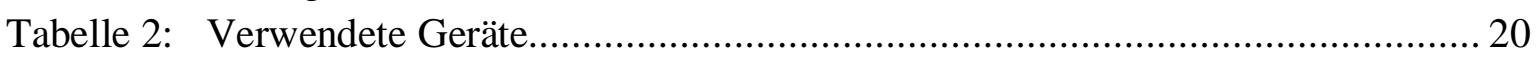

Tabelle 3: Verwendete Verbrauchsmaterialien............................................................ 21

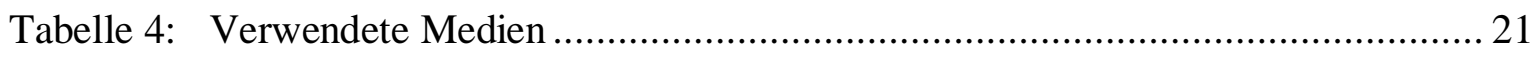

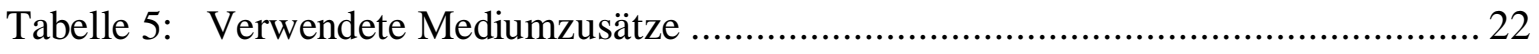

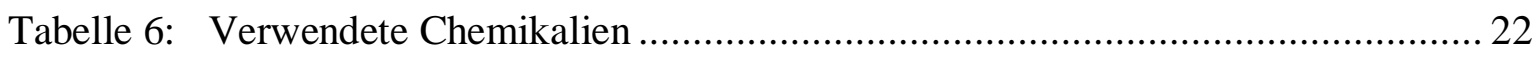

Tabelle 7: Verwendete Puffer und Lösungen ........................................................... 23

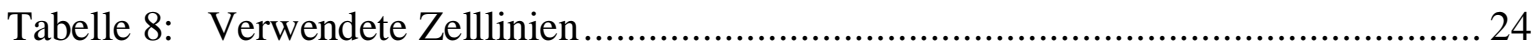

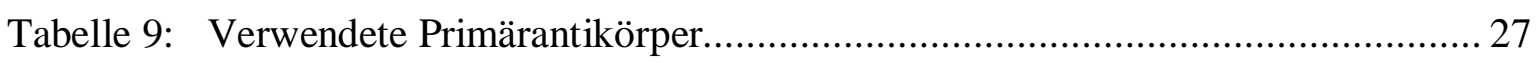

Tabelle 10: Verwendeter Sekundärantikörper ............................................................ 27

Tabelle 11: Verwendete Softwareprogramme …....................................................... 27

Tabelle 12: Beispiel zur Berechnung einer gewünschten Zellzahl ................................. 30

Tabelle 13: Tabellarische Darstellung der Probenauftragung auf eine 96-Well-Platte....... 33

Tabelle 14: Herstellung eines 5\%igen Sammelgels ...................................................... 35

Tabelle 15: Herstellung eines 10\%igen Trenngels................................................. 35

Tabelle 16: Tabellarische Übersicht über die signifikanten Reduktionen der

Proliferation der Zelllinien HCC70 und HCC1806 ....................................... 53

Tabelle 17: Gesamtübersicht der Ergebnisse zur Senkung der GPR30-

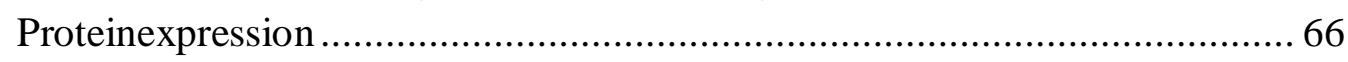




\section{Abkürzungsverzeichnis}

\begin{tabular}{|c|c|}
\hline (D-)Ala & (D-)Alanin \\
\hline ANOVA & analysis of variance \\
\hline APS & Ammoniumpersulfat \\
\hline Arg & Arginin \\
\hline ATCC & American Type Culture Collection \\
\hline AS & Aminosäure \\
\hline BRCA1 & Breast Cancer 1 \\
\hline cDNA & complementary DNA \\
\hline cAMP & cyclisches Adenosinmonophosphat \\
\hline Cetro & Cetrorelix \\
\hline (D-)Cit & (D-)Citrullin \\
\hline CRE & cAMP response element \\
\hline CREB & cAMP response element-binding protein \\
\hline (D-)Cpa & (D-)Chlorphenylanalyl \\
\hline cSRC & Akronym: cellular $\underline{\text { sarcoma }}$ \\
\hline DL & D-Lysin' ${ }^{6}$ II GnRH (D-Lysin) \\
\hline DAG & Diacylglycerol \\
\hline DGVS & $\begin{array}{l}\text { Deutsche Gesellschaft für Gastroenterologie, Verdauungs- und } \\
\text { Stoffwechselkrankheiten }\end{array}$ \\
\hline DMEM & Dulbecco's minimal essenial medium \\
\hline DMSO & Dimethylsulfoxid \\
\hline DNA & Desoxyribonukleinsäure \\
\hline dNTP & Desoxyribonukleosid-Triphosphat \\
\hline DTT & Dithiothreitol \\
\hline EDTA & Ethylendiamintetraessigsäure \\
\hline EGF & epidermal growth factor \\
\hline EGFR & epidermal growth factor receptor \\
\hline EMA & European Medicines Agency \\
\hline
\end{tabular}


$\mathrm{EtBr}$

$\mathrm{ER} \alpha$

ERK1/2

FCS

FOLFOX

FSH

GAPDH

Gly

$\mathrm{GnRH}$

GPR 30

Her2/neu

HEPES

His

HRP

IP3

Ko

Leu

(D-)Lys

L-Gln

Glu

Gly

Gly-NH2

LGC

LH

MAP Kinase

MEM

mRNA

MW
Ethidiumbromid

Östrogenrezeptor $\alpha($ Estrogenreceptor $\alpha)$

Extracellular signal-regulated kinasen 1/2

Fetales Kälberserum (fetales calf serum)

Chemotherapie aus: Folinsäure, 5-Fluorouracil, Oxaliplatin

Follikel-stimulierendes Hormon

Glycerinaldehyd-3-phosphat-Dehydrogenase

Glycin

Gonadotropin-Releasing Hormon

G-Protein gekoppelter Östrogenrezeptor

Human epidermal growth factor receptor 2 (human EGFreceptor 2)

N-(2-hydroxyethyl)-1-Piperazino Ethansulfonsäure

Histidin

Horseradish Peroxidase

Inositol-1,4,5- trisphosphat

Kontrolle

Leucin

(D-)Lysin

L-Glutamin

Glutaminsäure

Glycin

Glycinamid

Laboratory of the Government Chemist

Luteotropin

Mitogen aktivierte Kinase

minimal essential medium

messenger-RNA

Mittelwert 
n

N4

(D-) Nal

NEAS

n.s.

(D-) Pal

PBS

pGlu

(D-)Phe

PR

Pro

$\mathrm{P} / \mathrm{S}$

PTP

PVDF

RNA

RNAse

Ser

SDS

SEM

SERM

siRNA

Src

TBE

TBS

TBST

TEMED

TNBC
Anzahl der durchgeführten Versuche

GnRH-II-Antagonist: DNal- DCpa-DPal-Ser-His-DPal-Trp-LeuPro-DAla

(D-)Naphtyl-Alanin

Nicht essentielle Aminosäuren

nicht significant

(D-) 3-Pyridylalanyl

Phosphate buffered saline

Pyroglutaminsäure

(D-)Phenylalanin

Progesteronrezeptor

Prolin

Penicillin/Streptomycin

Protein Tyrosin Phosphatase

Polyvinyldienfluorid

Ribonukleinsäure (ribonucleic acid)

Ribonuklease

Serin

Natriumdodecylsulfat (sodium dodecyl sulfate)

Standardfehler des Mittelwertes (standard error oft the mean)

Selektive Östrogenrezeptor-Modulatoren (selective estrogen re-

ceptor modulators)

Small interfering $R N A$

Tyrosinkinase Sarcoma

Tris-Borat-EDTA-Puffer

Tris-buffered saline

Tween-TBS-Puffer

Tetramethylethylendiamin

Triple-negative-breast cancer 
(D-) Trp

Tripto

Tris

Tyr

UV
(D-)Tryptophan

Triptorelin

Tris(hydroxymethyl)aminomethan

Tyrosin

Ultraviolett 


\section{Einleitung}

In der heterogenen Gruppe der Mammakarzinome gibt es die therapierelevante Unterscheidung in rezeptorpositive und rezeptornegative Karzinome. Vor der Therapie wird mit immunhistochemischen Nachweismethoden die Expression von drei verschiedenen Rezeptoren untersucht: Östrogenrezeptor $\alpha$, Progesteronrezeptor und Her2-Rezeptor (Chen und Russo 2009).

75-80\% aller Brustkrebsarten exprimieren sowohl den Östrogenrezeptor $\alpha($ ER $\alpha)$ als auch den Progesteronrezeptor (PR) und werden deshalb hormonrezeptorpositiv genannt (Dawson et al. 2009; Konecny et al. 2003). Bei 15-20\% der Mammakarzinome findet sich eine Überexpression des Her2-Rezeptors (Kim et al. 2006). In dieser Gruppe bilden etwa $50 \%$ zusätzlich einen Östrogen- oder Progesteronrezeptor aus (Dawson et al. 2009; Föst et al. 2011).

Ein Mammakarzinom wird triple negativ genannt, wenn ER $\alpha$ und PR nicht exprimiert wird und es keine Her2-Überexpression aufweist. 10-15\% der Mammakarzinome sind triple negativ (Petrelli et al. 2009).

Diese Gruppe der triple negativen Karzinome ist, im Vergleich zu rezeptorpositiven Tumoren wesentlich aggressiver (Carey et al. 2007; Dent et al. 2007; Haffty et al. 2006; Rakha et al. 2007) und besitzt eine höhere Mortalitätsrate (Carey et al. 2007; Dowsett et al. 2010). BRCA-1(breast cancer 1)-assoziierte Mammakarzinome sind in der überwiegenden Zahl der Fälle (75-80\%) triple negativ (Foulkes et al. 2003; Sorlie et al. 2003). Triple negative Mammakarzinome treten häufiger bei jüngeren Patientinnen auf, sowie bei Frauen aus dem afroamerikanischen Raum (Bauer et al. 2007; Morris et al. 2007).

Für Östrogen- und Progesteronrezeptor positive Karzinome oder HER2-überexprimierende Karzinome gibt es bereits spezifische Therapien. Östrogenrezeptor $\alpha$ positive Tumore werden, je nach Menopausenstatus, mit Antiöstrogenen (z. B. Tamoxifen) oder Aromataseinhibitoren (z. B. Anastrozol, Letrozol) therapiert. Für HER-2 positive Tumore steht als spezifische Therapie der monoklonalen Antikörper Trastuzumab (Herzeptin ${ }^{\circledR}$ ) zur Verfügung. Bis jetzt gibt es jedoch noch keine verfügbare adäquate zielgerichtete Therapie für triple negative Brustkrebstumore (TNBC) (Podo et al. 2010). Bei diesen triple negativen Karzinomen ist weder eine antihormonelle Therapie noch eine Behandlung mit dem 
Antikörper gegen den HER-2-Rezeptor (Trastuzumab) wirksam. Zurzeit wird in der aktuell gültigen Leitlinie empfohlen, diese Patientinnen neoadjuvant mit einer primären Kombinationschemotherapie zu behandeln.

Eine spezifische, zielgerichtete Therapie gibt es bisher noch nicht. Neue Therapieoptionen werden daher benötigt. Ein neuer Ansatzpunkt für eine zielgerichtete Therapie könnte der membranständige Östrogenrezeptor G-Protein gekoppelte Rezeptor 30 (GPR30, G-Proteingekoppelter Östrogenrezeptor 1 (GPER1)) sein.

\section{1 Östrogenabhängige Steigerung der Zellproliferation}

Unter dem Einfluss von Östrogenen kommt es in hormonrezeptorpositiven Karzinomzellen, aber auch in TNBC-Zellen zu einer Proliferationssteigerung. Dieser Effekt wird über zwei verschiedene Wirkmechanismen erreicht. Dabei unterscheidet man den genomischen und den nicht genomischen Signalweg. Die schnelle Östrogenwirkung verläuft über den nicht genomischen Signalweg, der genomische Signalweg zeigt einen langsameren Effekt, da die nukleären Strukturen aktiviert werden müssen.

\subsubsection{Der genomische Signalweg über den Östrogenrezeptor $\alpha$ und $\beta$ (ER $\alpha$, ERß)}

Bei den hormonrezeptorpositiven Mammakarzinomzellen wird dieser Effekt über den klassischen genomischen Weg, über Transkription, durch Bindung von 17ß-Östradiol an den intrazellulären (nukleären) Östrogenrezeptor $\alpha$ oder $\beta$ vermittelt. Durch Dimerisierung des Östrogen-Rezeptor-Komplexes und Bindung an Hormone Response Elements (HRE) im Zellkern erfolgt die Aktivierung der Transkription der Zielgene (Deutzmann 2012, S. 553).

Über diesen Rezeptor verläuft auch die Proliferationshemmung durch Antiöstrogene. Direkt antagonistisch am Östrogenrezeptor $\alpha$ wirkt z. B. Fulvestrant. Selektive Östrogenrezeptormodulatoren (z. B. Tamoxifen) wirken im Brustgewebe antagonistisch auf den ER $\alpha$. Aromatasehemmer werden ebenfalls zur den Antiöstrogenen gezählt, wirken jedoch nicht über den Rezeptor, sondern verhindern die Umwandlung von Androgenen in Östrogene und vermindern somit die Produktion des, am ER $\alpha$ proliferationssteigernd wirkenden, Substrates.

Viele Jahre wurde angenommen, dass sich ein Östrogenrezeptor auf der Plasmamembran befindet. Es wurde herausgefunden, dass der GPR30-Rezeptor für die meisten schnellen 
Signaleffekte des 17ß-Östradiol verantwortlich ist (Filardo et al. 2000; Revankar et al. 2005). Bevor der GPR30-Rezeptor als dritter Östrogenrezeptor entdeckt wurde, vermuteten einige Autoren dass der schnelle Östrogeneffekt über einen anderen membrangebundenen ER $\alpha$ verläuft (Razandi et al. 2002).

\subsubsection{Der nicht genomische Signalweg über den G-Protein-gekoppelten Re- zeptor 30}

Bei TNBC- Zellen, die keinen ER $\alpha$ besitzen wird die proliferationssteigernde Wirkung der Östrogene über einen nicht genomischen Signalweg übermittelt. Dieser nicht genomische schnelle Signalweg wird über einen membranständigen G-Protein gekoppelten Rezeptor, den GPR30-Rezeptor (7 Transmembran Rezeptor) übermittelt (Filardo et al. 2000; Girgert et al. 2012; Revankar et al. 2005). Durch die Bindung von 17ß-Östradiol an den GPR30Rezeptor kommt es zu einer Dissoziation des heterotrimären G-Proteins (Deutzmann 2012, S. 535-545). Die ß $\gamma$-Untereinheit aktiviert die Tyrosinkinase Src (sarcoma) (Girgert et al. 2012; Luttrell et al. 1999). Anschließend erfolgt die Freisetzung von EGF aus der extrazellulären Matrix und Autophosphorilierung des EGF-Rezeptors. Die Folge ist eine Aktivierung der Ras-MAP Kinase und Steigerung von ERK1/2 (extracellular-signal regulated kinasen 1/2) (Filardo et al. 2000; Girgert et al. 2012; Maggiolini et al. 2004). Die $\alpha$ Untereinheit aktiviert die Adenylatcyclase, dadurch kommt es zur vermehrten Bildung von cAMP (Deutzmann 2012, S. 538). Es kommt zur cfos Expressionssteigerung, Erhöhung der Mitoserate und zur Zellproliferation (Filardo et al. 2002; Girgert et al. 2012).

\subsection{Der GPR30 in triple negativen Mammakarzinomzellen}

Der GPR30 wird häufig in TNBC-Zellen exprimiert (Girgert et al. 2012; 2014; 2017; Steiman et al. 2013). Durch Bindung von 17ß-Östradiol an den GPR30 kommt es zur Proliferationssteigerung in TNBC (Girgert et al. 2012). Das Vorhandensein dieses Rezeptors steigert die Proliferation der Karzinomzellen und korreliert mit einer erhöhten Rezidivrate (Steiman et al. 2013). 


\subsection{Der GPR30 als Therapieansatzpunkt}

Aufgrund der oben geschilderten Zusammenhänge wird der GPR30 als Ansatzpunkt für eine zielgerichtete Therapie des triple negativen Mammakarzinoms gesehen. In mehreren Studien wurde bereits versucht den GPR30 und damit die Zellproliferation zu hemmen.

\subsubsection{Die direkte Inhibierung des GPR30}

Eine Möglichkeit ist die direkte Inhibierung des GPR30 durch siRNA und Estriol.

Das kurze Ribonukleinsäuremolekül siRNA (short interfering RNA) besteht aus 17-25 Nukleotiden und spielt eine große Rolle in der Regulation der Genexpression. Eine siRNA entsteht aus, durch RNasen klein geschnittenen Vorläufermolekülen. Durch spezifische Basenpaarungen binden sich die Oligonukleotide an die mRNA und führen dadurch zum Abbau der mRNA (sog. RNA-Interferenz). SiRNAs werden in der Grundlagenforschung eingesetzt, um gezielt Genexpressionen zu hemmen (Netzker 2012, S. 436).

Girgert et al. (2012) zeigten in ihren Untersuchungen, dass nach direkter Inhibierung des GPR30 durch eine spezifische siRNA die nicht genomischen Effekte des 17ß-Östradiol, nicht mehr nachgewiesen werden konnten. Daraus zog man den Schluss, dass die Proliferationssteigerung von triple negativen Mammakarzinomzellen durch Bindung von 17ßÖstradiol an den GPR30 ausgelöst wird.

Estriol (syn.: Östratriol) zählt zur Gruppe der natürlich vorkommenden Östrogene. Die wichtigsten Östrogene sind Östradiol, Östron und Östratriol. Östradiol entsteht durch Aromatasewirkung aus Testosteron und ist das wirksamste Östrogen. Durch Bindung einer zusätzlichen Hydroxylgruppe wird Östratriol gebildet. Es besitzt 1/10 der Östradiolaktvität (Deutzmann 2012, S. 602).

Bereits 2010 beschrieben Lappano et al. die antagonistische Wirkung von Estriol auf den GPR30. 2014 veröffentlichten Girgert et al. eine weitere Studie, welche die Hemmung der GPR30 Signalkaskade durch Estriol $\left(\mathrm{E}_{3}\right)$ zeigt. Laut Girgert et al. (2014) sind dazu jedoch unphysiologisch hohe Dosen nötig. Deshalb wurde nach einem anderen Weg gesucht, den GPR30 und somit auch die Proliferation in triple negativen Zellen zu hemmen.

\subsubsection{Die indirekte Inhibierung des GPR30 durch direkte Hemmung des EGF-Rezeptors}

Eine andere Möglichkeit ist die indirekte Inhibierung des GPR30 durch direkte Hemmung des EGF- Rezeptors mittels Cetuximab und Gefitinib. 
Aufgrund der relativ unbefriedigenden Ergebnisse und dem Wissen, dass eine Korrelation zwischen dem GPR30 und dem EGF-Rezeptor besteht, wurde versucht, über den EGFRezeptor eine indirekte GPR30 Hemmung zu erzielen.

Der EGF-Rezeptor 1 (Epidermal Growth Factor Receptor 1, syn.: EGFR 1, Her-1, ErbB-1) ist Rezeptor für den EGF (Epidermal Growth Factor). Neben dem EGFR 1 existieren auBerdem noch der EGFR 2 (syn.: Her-2, ErbB 2), der Her3 (syn.: ErbB 3) und der Her 4 (syn.: ErbB 4). Sie gehören zur Familie der Rezeptortyrosinkinasen (Stern 2000).

Diese Transmembranrezeptoren besitzen an der intrazellulären Seite eine TyrosinkinaseDomäne, die durch extrazelluläre Ligandenbindung und Autophosphorylierung des Rezeptors aktiviert wird. Die Kinase phosphoryliert Tyrosinreste der zytosolischen Domäne des Rezeptors. Diese Phosphotyrosinreste dienen als Andockstelle (docking-sites) für Signaltransduktionsmoleküle mit $\mathrm{SH}_{2}$ Domänen, wie zum Beispiel die Phospholipase $\mathrm{C} \gamma$ (PLC $\gamma$ ), die PI 3 Kinase (Phosphatidylinositl-4,5-bisphosphat 3-kinase) oder die MAP-Kinase ( $m i$ togen activated proteinkinase). Diese stimulieren das Zellwachstum (v.a. PLC $\gamma$ und MAPKinase) und verhindern die Apoptose (v.a. PI-3) (Deutzmann 2012, S. 549, S. 645f.).

\subsubsection{Der EGF-Rezeptor in triple negativen Mammakarzinomzellen}

Im Gegensatz zum EGF-Rezeptor 2 (Her2), der in TNBC nicht auftritt, wird der EGFRezeptor 1 in circa 30-52\% der TNBC exprimiert. Die EGF-Rezeptor 1 Expression korreliert mit einer schlechteren Prognose (Nielsen et al. 2004; Reis-Filho und Tutt 2008).

Wie bereits unter der Beschreibung des nicht genomischen Signalweges beschrieben führt eine GPR30 Stimulation zur EGF Freisetzung und Autophosphorylierung des EGFRezeptors 1.

Vivacqua et al. wiesen 2009 einen Zusammenhang der GPR30-Expression mit dem Vorliegen des aktivierten EGFR-1 sowohl in östrogenpositiven Mammakarzinomzellen als auch in Endometriumkarzinomzellen nach. Dieser Zusammenhang wurde von Albantino et al. (2008) für östrogennegative Mammakarzinomzellen nachgewiesen. Girgert et al konnten dies 2017 für triple negative Mammakarzinomzellen bestätigen.

Durch diese nachgewiesene Korrelation zwischen dem GPR30- und dem EGF-Rezeptor ergibt sich die Möglichkeit, durch Inhibition des EGF 1-Rezeptors auch den GPR30 und damit die Zellproliferation zu hemmen. 


\subsubsection{Die Hemmung des EGF-Rezeptors durch Cetuximab (Erbitux ${ }^{\circledR}$ )}

Eine direkte Hemmung des EGF Rezeptors und damit eine indirekte Hemmung des GPR30 ist durch den monoklonalen Antikörper Cetuximab, der gegen den EGF-Rezeptor gerichtet ist, möglich.

Eine Zulassung für Cetuximab besteht für die Therapie von Patienten mit Plattenepithelkarzinomen des Kopf- und Halsbereiches. Die Therapie erfolgt im fortgeschrittenen Tumorstadium unter parallel laufender Radiotherapie. Bei einer Rezidivsituation oder Fernmetastasierung wird Cetuximab mit einer platinhaltigen Chemotherapie kombiniert (EMA 2020, Erbitux). Weiterhin ist Cetuximab in der Therapie des Kolorektalen Karzinomes zugelassen, unter anderem im Rahmen der Erstlinientherapie in Kombination mit einer Chemotherapie, sofern ein nicht mutiertes Ras-Gen (RAS-Wildtyp) und eine EGFRezeptorexpression im Tumorgewebe vorliegt (Leitlinie Kolorektales Karzinom 2019). Unter der Therapie mit Cetuximab können folgende Nebenwirkungen auftreten: Hautreaktionen, Magnesiummangel, Fatigue, Anstieg Leberenzymwerte, infusionsbedingte Reaktionen, Mukositis, Appetitlosigkeit, Übelkeit, Erbrechen, Diarrhö (EMA 2020, Erbitux)

Die Wirkung von Cetuximab auf triple negative Mammakarzinomzellen wurde in klinischen Phase II Studien untersucht. 2012 führten Carey et al. eine klinische Studie an 102 Patientinnen mit metastasiertem triple negativem Mammakarzinom durch. Untersucht wurde die Ansprechrate von Cetuximab als Monotherapie versus Cetuximab in Kombination mit Carboplatin. Die Ansprechrate unter der Monotherapie lag bei 6\%, die Dauer bis zum Krankheitsprogress bei 1,4 Monaten. In der Kombinationstherapie lagen sowohl die Ansprechrate, mit 16\% sowie die Dauer bis zum Progress mit 2,1 Monaten etwas höher (Carey et al. 2012). Eine ähnliche Studie zeigte die Steigerung der Ansprechrate von Cisplatin von 10\% auf 20\% bei der Kombination mit Cetuximab (Baselga et al. 2013).

\subsubsection{Die Hemmung des EGF-Rezeptors durch Gefitinib}

Auch durch den Tyrosinkinase-Inhibitor Gefitinib kann der EGF-Rezeptor direkt gehemmt werden. Die Hemmung erfolgt durch eine spezifische Bindung an die Tyrosin-kinaseDomäne des EGF-Rezeptors (Wakeling et al. 2002); (EMA 2019, Iressa). Eine Therapiezulassung besteht für das nicht-kleinzellige Bronchialkarzinom, bei Patienten mit EGFRMutation sowohl im lokal fortgeschrittenen, als auch im metastasierten Zustand. Unter der Therapie mit Gefitinib können folgende Nebenwirkungen auftreten: Appetitlosigkeit, 
Übelkeit, Erbrechen, Stomatitis, Diarrhoe, Hautausschläge (z. B. pustulöses Exanthem) und Anstieg der Leberenzyme (EMA 2019, Iressa).

Die Wirkung von Gefitinib auf triple negative Mammakarzinome wurde bereits in mehreren Studien untersucht. 2017 zeigten Girgert et al., dass Gefitinib sowohl die GPR30 Expression als auch die, durch 17ß-Östtradiol induzierte Proliferation von TNBC hemmt. 2001 konnten Anderson et al. bei EGF-Rezeptor 1 exprimierenden TNBC, sowohl eine Hemmung der Zellproliferation, als auch eine Inhibition der Rezeptor- Autophosphorylierung, eine Unterbindung der Signaltransduktion durch PLC $\gamma$ und MAP Kinase, sowie eine Inhibition des Tumorwachstums in vivo nachweisen. In einer 2009 durchgeführten klinischen Phase II Studie bei TNBC Patientinnen wiesen die Autoren einen Einfluss auf den klinische Benefit, im Sinne einer stable disease für 24 Wochen bei zwei von 25 Patientinnen nach. Ein Einfluss auf den Tumor konnte nicht nachgewiesen werden (Green et al. 2009). Diverse andere klinische Studien, die eine Wirkung von Gefitinib auf Mammakarzinome untersuchten zeigten kein signifikantes Ansprechen des Tumors auf Gefitinib (Baselga et al. 2005; Bernsdorf et al. 2011; von Minckwitz et al. 2005).

Sowohl der GPR30 als auch der EGFR-1 sind in vitro gute Ansatzpunkte für eine target (syn.: zielgerichtete) Therapie bei triple negativen Mammakarzinomen. Die bisher durchgeführten klinischen Studien ergaben noch keine erfolgsversprechende Therapieoption. Es wird nach weiteren Möglichkeiten gesucht, sowohl den EGF-Rezeptor 1 als auch den GPR30 Rezeptor zu hemmen. Eine Option könnte der Umweg über die Hemmung des GnRH-Rezeptors sein. Der GnRH-Rezeptor wirkt modulierend auf den EGF-Rezeptor und steht somit indirekt mit dem GPR30 in Verbindung.

\subsection{Gonadotropin-Releasing-Hormon (GnRH) und der GnRH-Rezeptor}

Forschungen zeigen, dass gewisse Karzinomarten GnRH (Gonadotropin-ReleasingHormon) und den GnRH-Rezeptor exprimieren. So findet man GnRH und den GnRHRezeptor in nahezu 80\% der menschlichen Ovarial- und Endometriumkarzinome, sowie in 50\% der Brusttumore (Emons et al. 1997; 2003; Gründker et al. 2002b; Volker et al. 2002).

74\% der triple negativem Mammakarzinomzellen sind GnRH-Rezeptor positiv (Föst et al. 2011). In einer anderen Studie konnten Buchholz et al. (2009) in allen getesteten triple negativen Mammakarzinomzelllinien eine GnRH-Rezeptor Expression nachweisen. 
GnRH-I-Rezeptoren wurden von Schubert (2008) in den TNBC-Zelllinien MDA-MB-453, MDA-MB-435S und HCC70 und von Buchholz et al. (2009) und Föst (2011) in HCC1806 nachgewiesen.

Die Gonadotropin-Releasing Hormone I und II sowie deren Rezeptoren könnten somit als mögliche Ansatzpunkte einer target Therapie für die Behandlung von triple negativen Mammakarzinomen dienen.

\subsubsection{Das Gonadotropin-Releasing Hormon I (GnRH I) in der Hypophyse (syn.: LHRH)}

GnRH ist ein Dekapeptid, das im Hypothalamus synthetisiert wird. Die Struktur und Funktion wurden erstmals 1971 beschrieben (Amoss et al. 1971; Schally et al. 1971). GnRH wird in einem zirkadianem Rhythmus (Sekretion ist nachts am höchsten) und in einer pulsatilen Form (Ausschüttung im Abstand von Minuten bis wenige Stunden) ausgeschüttet (Knobil 1990). Nach dem Transport zum Hypophysenvorderlappen erfolgt dort die Bindung an membranständige Rezeptoren der gonadotropen Zellen (GnRH-I-Rezeptoren). Dadurch wird die Produktion und Freisetzung von FSH und LH induziert (Naor 1990; Neill 2002; Stojilkovic et al. 1994). Je nach Häufigkeit der Pulsfrequenz wird entweder mehr LH oder mehr FSH ausgeschüttet (Deutzmann 2012, S. 576-578). Diese gelangen über das Blut in die Ovarien bzw. in die Hoden und führen dort zur Follikelreifung bzw. zur Unterstützung der Spermatogenese sowie zur Steroidhormonsynthese (Deutzmann 2012, S. 576-578, S. 601).

Der Hypothalamus-Hypophysen-Zielorgan Regelkreislauf wird über einen negativen Feedback Mechanismus reguliert (Deutzmann 2012, S. 580).

\subsubsection{Der hypophysäre GnRH-I-Rezeptor}

Der humane GnRH-I-Rezeptor ist ein G-Protein gekoppelter Rezeptor (GPCR, G-protein coupled receptor) und gehört zur Familie der sog. 7- Transmembran-Rezeptoren (7-TRM). Kloniert und sequenziert wurde er erstmals 1992 (Kakar et al. 1992). Der glykosylierte Amino-Terminus (syn.: N-Terminus) liegt extrazellulär. Der zytoplasmatische CarboxyTerminus (syn.: C-Terminus) ist intrazellulär an der siebten Transmembrandomäne lokalisiert und ist in der Membran verankert (Neill 2002; Sealfon et al. 1997). 


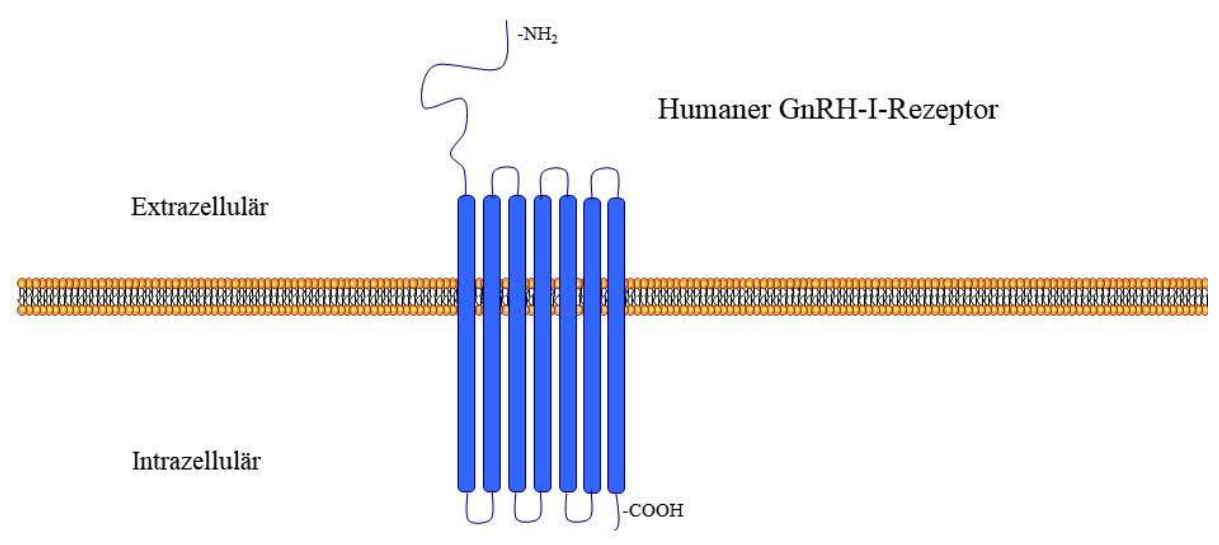

Abbildung 1: Struktureller Aufbau des membranständigen humanen hypophysären GnRH-I-
Rezeptors
Modifiziert nach Gründker und Emons 2017. Mit freundlicher Genehmigung von C. Gründker und G. Emons

\subsubsection{Die GnRH I induzierte Signaltransduktion in der Hypophyse}

Durch spezifische Bindung des GnRH an seinen Rezeptor kommt es zu einer Konformationsänderung und einer anschließenden Aktivierung der heterotrimären G-Protein Untereinheit $\alpha_{\mathrm{q} / 11}$, welche zu einer kalziumabhängigen Signaltransduktion führt (Cheng und Leung 2000; Naor 1990). Die Aktivierung der membranständigen Phospholipase C (PLC) führt zur Hydrolyse des Membranlipids Phosphatidylinositol -4,5-bisphosphat ( $\left.\mathrm{PIP}_{2}\right)$. Dadurch entstehen die beiden second messenger Diacylglycerin (DAG) und Inositol-1,4,5trisphosphat (IP 3 ) (Kraus et al. 2001; McArdle et al. 2002; Ruf et al. 2003) (Deutzmann 2012, S. 541ff.). $\mathrm{IP}_{3}$ diffundiert von der Plasmamembran ab und aktiviert Rezeptoren am Endoplasmatischen Retikulum (ER). Dadurch kommt es zum Ausstrom von Calcium aus dem ER ins Zytosol (Deutzmann 2012, S. 544) (Berridge 1993; Keizer et al. 1995). DAG bleibt in der Membran zurück und aktiviert $\mathrm{Ca}^{2+}$ abhängig die Proteinkinase $\mathrm{C}$ (PKC), welche im Verlauf, über eine Aktivierung von mitogenaktivierten Proteinkinasen (MAPK) (Harris et al. 2002; Zhang und Roberson 2006) zur Gondotropinsynthese (LH und FSH) und Sekretion führt (Bonfil et al. 2004; Harris et al. 2002; Levi et al. 1998; Roberson et al. 1999).

\subsubsection{Die GnRH I induzierte Signaltransduktion in gynäkologischen Tumoren} Die, durch GnRH Analoga induzierte Signaltransduktion über den GnRH Rezeptor in gynäkologischen Tumoren unterscheidet sich vom Signalübertragungsmechanismus in der Hypophyse. 
Durch die Aktivierung des GnRH Rezeptors kommt es zur indirekten Hemmung des EGFund somit auch des GPR30-Rezeptors.

Neben der Expression in gonadotropen Zellen der Hypophyse und in reproduktiven Organen, wie dem Myometrium (Chegini et al. 1996) oder den Ovarien (Minaretzis et al. 1995) konnte das Gonadotropin-Releasing Hormon und sein Rezeptor auch in gynäkologischen Tumoren nachgewiesen werden. Nahezu 50\% der Mamma- (Baumann et al. 1993; Blankenstein et al. 1985; Eidne et al. 1987; Mangia et al. 2002; Miller et al. 1985), 70\% der Ovarial- (Emons et al. 1989; Irmer et al. 1995; Ohno et al. 1993; Yano et al. 1994 a,b) und 80\% der Endometriumkarzinome (Emons et al. 1993b; Irmer et al. 1994; Pahwa et al. 1991; Srkalovic et al. 1990) exprimieren GnRH und den GnRH-Rezeptor (Emons et al. 1997; Gründker et al. 2002b; Volker et al. 2002). Sowohl Buchholz et al. (2009), als auch Föst et al. (2011) konnten zeigen, dass der GnRH Rezeptor auch auf TNBC-Zellen exprimiert wird.

Es zeigt sich eine Übereinstimmung der Sequenz des GnRH I-Rezeptors in der Hypophyse mit der Sequenz des GnRH I- Rezeptors in gynäkologischen Tumoren (Gründker et al. 2001; Kakar et al. 1994) jedoch erfolgt die Signaltransduktion über eine andere Signalkaskade (Gründker et al. 2002b).

Im Gegensatz zur Hypophyse verläuft die GnRH I-Rezeptor vermittelte Signaltransduktion in gynäkologischen Tumoren über die $\alpha_{\mathrm{i}}$ Untereinheit des gebundenen GProteinkomplexes. Diese bewirkt eine Aktivierung einer Phosphotyrosinphosphatase (PTP) (Dondi et al. 1994; Gründker et al. 2001), welche die Autophosphorylierung des EGFRezeptors hemmt (Emons et al. 1997; Gründker et al. 2001). Es kommt zu einer Downregulation, sowohl der EGF induzierten Aktivierung der Mitogen-activated-protein-kinase MAPK (ERK 1/2) (Dondi et al. 1994), als auch des Transkriptionsfaktors cfos, über den PI3K/Akt Signalweg (Gründker et al. 2000) und zu einer Hemmung der EGF induzierten Proliferation (Miller et al. 1985). 


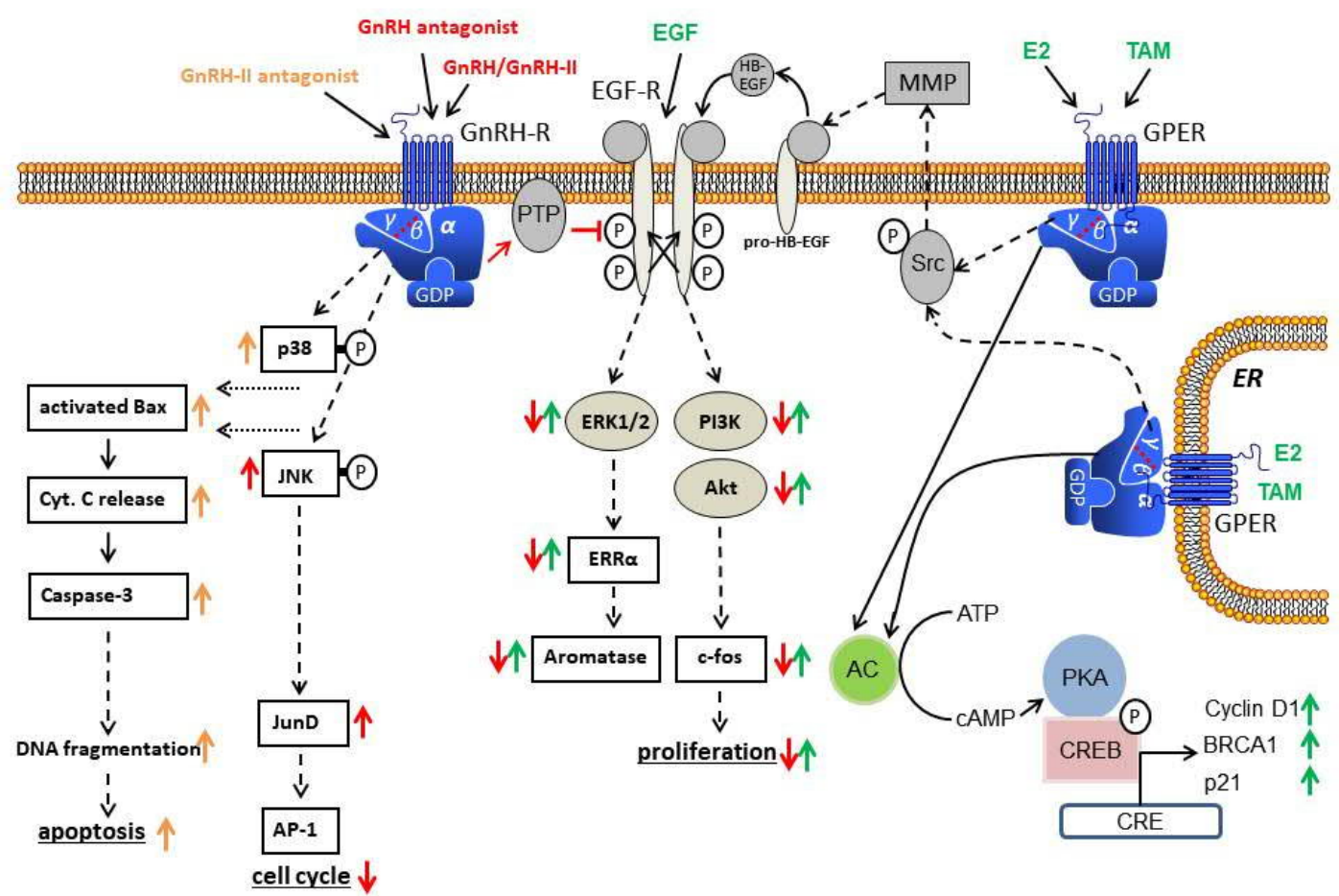

Abbildung 2: Schema der GnRH Signaltransduktionsmechanismen in gynäkologischen Tumoren

Gründker und Emons 2017. Mit freundlicher Genehmigung von C. Gründker und G. Emons

\subsubsection{Das Gonadotropin-Releasing-Hormon II (syn.: GnRH II, chicken GnRH II)}

Neben dem GnRH I gibt es eine weitere Isoform, das GnRH II. Diese unterscheidet sich in drei Aminosäuren an den Positionen fünf, sieben und acht, zu der Sequenz des GnRH I (Chen et al. 1998; White et al. 1998). Es wird auch als chicken GnRH bezeichnet, da es bereits 1984 im Hypothalamus des Huhns entdeckt wurde (Miyamoto et al. 1984). 1998 wurde es erstmals beim Menschen beschrieben (White et al. 1998).

\subsubsection{Der GnRH-II-Rezeptor}

Ein GnRH-II-Rezeptor konnte beim Rhesusaffen (Neill et al. 2001) und Weißbüscheläffchen (Millar et al. 2001) bereits nachgewiesen werden. Es handelt sich dabei um einen 5-Transmembran-Rezeptor (Neill 2002). Das C-terminale Ende reicht ins Zytoplasma (Millar et al. 2001; Neill 2002). Ein humaner GnRH-II-Rezeptor konnte bis jetzt noch nicht sequenziert werden (Gründker et al. 2002a; Millar 2003; Neill et al. 2001). Beim Menschen konnte in der Placenta und in gynäkologischen Tumoren ein GnRH-II-Rezeptor ähnliches Protein nachgewiesen werden, dessen Molekulargewicht von 43kDa auf einen 5- 
Transmembrarezeptor schließen lässt (Eicke et al. 2005). GnRH II wirkt, wie GnRH I an Endometrium- und Ovarialtumorzellen zeit- und dosisabhängig proliferationshemmend (Gründker et al. 2002a). Bei Versuchen, bei denen der GnRH-I-Rezeptor ausgeschaltet wurde, konnte durch GnRH II weiterhin eine proliferationshemmende Wirkung erzielt werden (Gründker et al. 2004). Dadurch wird die These, dass neben GnRH-I-Rezeptoren auch GnRH-II-Rezeptorsystemen in gynäkologischen Tumoren vorkommen untermauert (Gründker et al. 2004). Eicke et al. (2006) fanden heraus, dass die Signaltransduktion des GnRH-II-Rezeptors dem, des GnRH-I-Rezeptors entspricht. GnRH II bewirkt ebenfalls eine Hemmung der EGF- induzierten Wachstumsfaktorsignalkaskade (Eicke et al. 2006).

\subsection{Die GnRH-Analoga}

GnRH-Analoga sind modifizierte Gonadotropin- Releasing- Hormon- Substanzen, die durch Aminosäuresubstitution (AS-Substitution) an verschiedenen Positionen des Dekapeptids synthetisch hergestellt werden. Durch die AS-Substitution (meist erfolgt ein Austausch durch eine D-Aminosäure) an verschiedenen Stellen kommt es zur Änderung der Tertiärstruktur, zu einer Veränderung der Stabilität und Bindungsaffinität an den Rezeptor (Karten und Rivier 1986; Millar et al. 2004; Sealfon et al. 1997) sowie zu einem verzögerten Abbau durch Enzyme (durch D-Aminosäuren ausgelöst) (Koch et al. 1977; Sealfon et al. 1997).

Je nach Anzahl und Positionen der Substituenten erhält man einen Agonisten oder einen Antagonisten.

Der Begriff Agonist beschreibt die Wirkung eines Stoffes, der durch Bindung an einen spezifischen Rezeptor die gleiche Reaktion auslöst, wie das ursprüngliche Substrat. GnRHAgonisten führen, nach einer initialen Steigerung (flare up) der Gonadotropinfreisetzung zur Reduktion von GnRH (Emons und Schally 1994; Limonta et al. 2001).

Ein Antagonist bindet ebenfalls an den Substratrezeptor, löst aber keine entsprechende Aktivierung des Rezeptors aus. Durch die konkurrierende Verdrängung wird die Wirkung des Ursprungssubstrates gehemmt (keine G-Protein Aktivierung, keine Signaltransduktion). Bei der Gabe von GnRH-Antagonisten kommt es, durch kompetitive Hemmung des Rezeptors zur sofortigen Hemmung der GnRH Freisetzung (Murase et al. 2005). 
Bei den GnRH-Analoga lässt sich die Unterscheidung in Agonist und Antagonist nur in der Hypophyse anwenden. Eine Übertragung dieser unterschiedlichen Wirkungsweise ist auf gynäkologische Tumore nicht möglich (Emons et al. 1996a). In gynäkologischen Tumoren wirken die Antagonisten wie Agonisten (Emons et al. 1997; Gründker et al. 2002b).

Das GnRH und GnRH-Agonisten hemmen dosis-/zeitabhängig die Proliferation in Mamma-, Ovarial- und Endometriumkarzinomen (Emons et al. 1997; 2003; Gründker et al. 2002b). In den meisten getesteten Zelllinien führt auch der GnRH-Antagonist zu einer Inhibierung der Zellproliferation (Emons et al. 2003; Gründker et al. 2002b). Es kommt sowohl durch Agonisten, als auch durch Antagonisten zu einer Aktivierung des GnRHRezeptors und somit, über die PTP vermittelte Wirkungskaskade, zur Zellproliferationshemmung.

In der vorliegenden Studie wurden folgende GnRH-Analoga verwendet:

\subsubsection{GnRH-I-Agonist Triptorelin}

Der GnRH-Agonist Triptorelin ist ein synthetisch hergestelltes Dekapeptid. In der Aminosäuresequenz des GnRH wird an Position 6 die Aminosäure Glycin durch D-Tryptophan substituiert.

Durch diese Modifizierung ist der GnRH-I-Agonist Triptorelin stärker wirksam als das natürliche Gonadotropin-Releasing-Hormon (GnRH). In der Hypophyse hat es eine längere Halbwertszeit als GnRH sowie eine stärkere Bindungsaffinität zum Rezeptor (Kenakin 1995; Sealfon et al. 1997)

GnRH-I-Agonisten wie Triptorelin stimulieren bei kurzfristiger Gabe die Sekretion von LH und FSH aus der Hypophyse. Bei langfristiger Behandlung kommt es zu einem Absinken der LH-, FSH-, Testosteron-, Östrogen- und Progesteronspiegel. Therapeutisch wird Triptorelin z. B. beim fortgeschrittenen Prostatakarzinom, bei Pubertas präcox und in der Reproduktionsmedizin eingesetzt.

Die antagonisierende Wirkung von Triptorelin auf die EGF induzierte Signaltransduktion wurde bereits in Mamma-, Endometrium- und Ovarialkarzinomzellen untersucht (Emons et al. 1996a; Gründker et al. 2000). 


\subsubsection{GnRH-I-Antagonist Cetrorelix}

Der GnRH-Antagonist Cetrorelix wurde erstmals 1990 an der Tulane Universität, New Orleans, USA synthetisch hergestellt (Bokser et al. 1990; Reissmann et al. 2000). Im Gegensatz zu Triptorelin, das sich nur durch eine Aminosäure an Position 6 vom natürlichen GnRH unterscheidet, wird die Primärstruktur des GnRH beim Cetrorelix zusätzlich an den Positionen 1,2,3 und 10 verändert. Auch hier wird durch den Ersatz durch D-Aminosäuren die Stabilität, sowie die Bindungsaffinität zum Rezeptor (Karten und Rivier 1986) erhöht.

Anders als die GnRH-Agonisten wird durch den GnRH-Antagonisten in der Hypophyse initial keine Erhöhung der LH- und FSH-Sekretion induziert. Durch kompetitive Hemmung kommt es zu einer schnellen Senkung der LH, FSH Sekretion.

Eine Zulassung für Cetrorelix besteht für die Verzögerung einer Ovulation im Rahmen einer in vitro Fertilisationsbehandlung (EMA 2019, Cetrotide).

Gründker et al wiesen die inhibitorische Wirkung von Cetrorelix sowohl auf Mammakarzinomzellen, als auch auf Endometrium- und Ovarialkarzinomzellen nach (Gründker et al. 2000).

\subsubsection{GnRH-II-Agonist D-Lysin' 6 GnRH II}

Der GnRH-II-Agonist, D-Lysin ${ }^{6}$ GnRH II (auch als D-Lysin bezeichnet), unterscheidet sich zum natürlichen GnRH-II durch den Austausch der Aminosäure Glycin an Position 6 durch D-Lysin.

In der Studie von Eike et al. (2006) wird beschrieben, dass der GnRH-II-Agonist über den gleichen Signalweg wie GnRH-I-Analoga wirkt, nämlich über die Aktivierung der PTP und sowohl bei Endometrium- als auch bei Ovarialkarzinomen die EGF-induzierte Signaltransduktion hemmt.

\subsubsection{GnRH-II-Antagonist DNal-DCpa-DPal-Ser-His-DPal-Trp-Leu-Pro-DAla}

Laborintern wurde als Abkürzung für diesen GnRH-II-Antagonisten "N4" verwendet. Diese Kurzform findet sich auch im Text wieder.

Analog zum GnRH-I-Antagonisten wird bei der Herstellung eines GnRH-II-Antagonisten an insgesamt 5 Positionen die ursprüngliche Aminosäuresequenz durch D-Aminosäuren ersetzt. 
Untersuchungen von Fister et al. $(2007 ; 2009)$ zeigten die Induktion der Apoptose von Endometrium-, Ovar-, und Mammakarzinomzellen durch GnRH-II-Antagonisten. 
Tabelle 1: Übersicht über die Aminosäuresequenzen von GnRH-I und -II sowie deren Analoga

\begin{tabular}{|l|l|l|l|l|l|l|l|l|l|l|}
\hline $\begin{array}{l}\text { Aminosäure } \\
\text { an Position }\end{array}$ & 1 & 2 & 3 & 4 & 5 & 6 & 7 & 8 & 9 & 10 \\
\hline GnRH-I & pGlu & His & Trp & Ser & Tyr & Gly & Leu & Arg & Pro & $\begin{array}{l}\text { Gly- } \\
\text { NH2 }\end{array}$ \\
\hline GnRH-II & pGlu & His & Trp & Ser & His & Gly & Trp & Tyr & Pro & $\begin{array}{l}\text { Gly- } \\
\text { NH2 }\end{array}$ \\
\hline Triptorelin & pGlu & His & Trp & Ser & Tyr & $\begin{array}{l}\text { D- } \\
\text { Trp }\end{array}$ & Leu & Arg & Pro & $\begin{array}{l}\text { Gly- } \\
\text { NH2 }\end{array}$ \\
\hline Cetrorelix & D-Nal & $\begin{array}{l}\text { D- } \\
\text { Phe }\end{array}$ & $\begin{array}{l}\text { D- } \\
\text { Pal }\end{array}$ & Ser & Tyr & $\begin{array}{l}\text { D- } \\
\text { Cit }\end{array}$ & Leu & Arg & Pro & $\begin{array}{l}\text { D- } \\
\text { Ala }\end{array}$ \\
\hline $\begin{array}{l}\text { D-Lysin } \\
\text { GnRH II }\end{array}$ & pGlu & His & Trp & Ser & His & $\begin{array}{l}\text { D- } \\
\text { Lys }\end{array}$ & Trp & Tyr & Pro & $\begin{array}{l}\text { Gly- } \\
\text { NH2 }\end{array}$ \\
\hline N4 & D-Nal & $\begin{array}{l}\text { D- } \\
\text { Cpa }\end{array}$ & $\begin{array}{l}\text { D- } \\
\text { Pal }\end{array}$ & Ser & His & $\begin{array}{l}\text { D- } \\
\text { Pal }\end{array}$ & Trp & Leu & Pro & $\begin{array}{l}\text { D- } \\
\text { Ala }\end{array}$ \\
\hline
\end{tabular}


Schematische Darstellung einer triple negativen Tumorzelle, der wichtigsten Rezeptoren, Darstellung des proliferativen Signaltransduktionsweges sowie Darstellung der Angriffspunkte antiproliferativ wirkender Substanzen

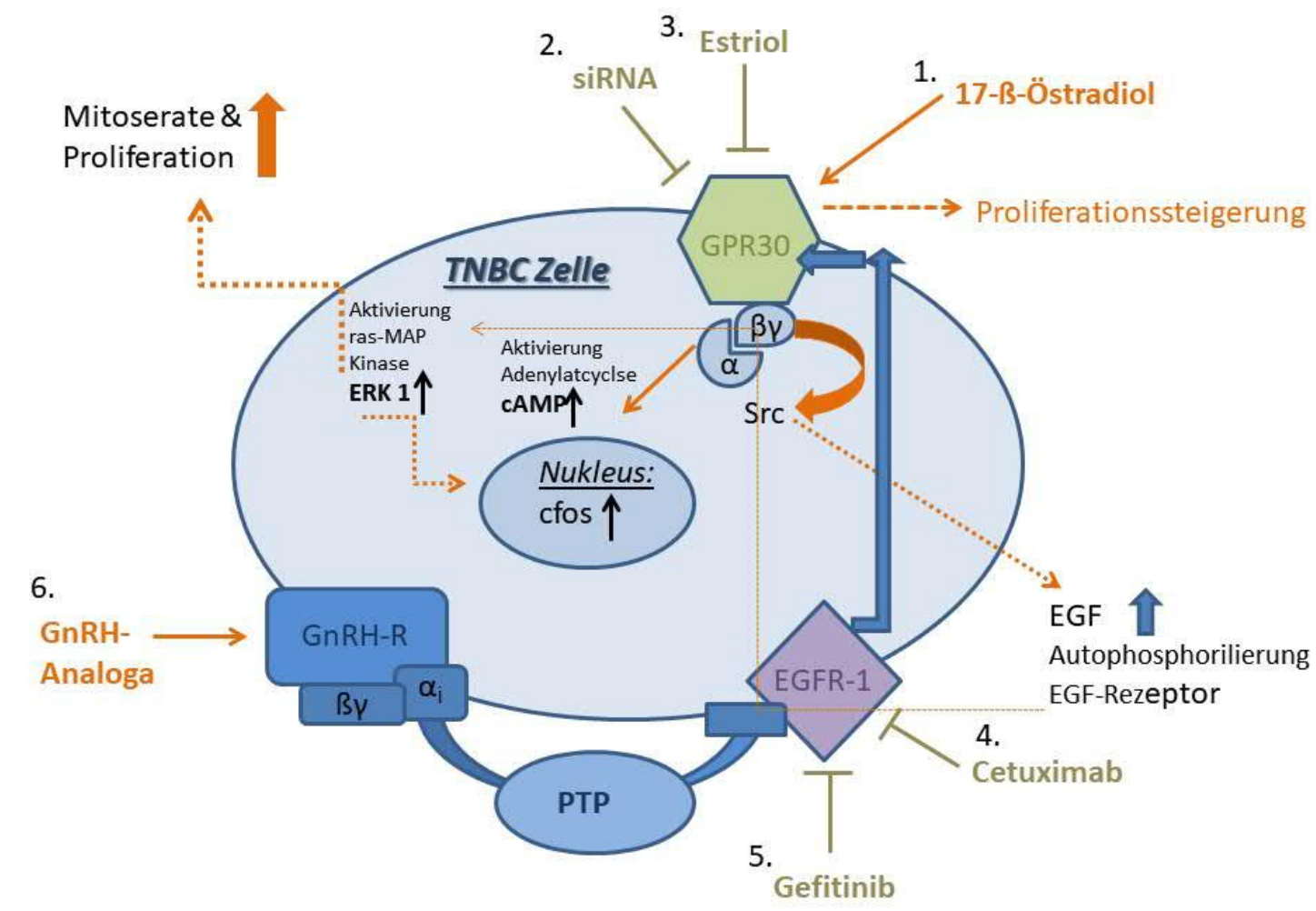

Abbildung 3: Übersichtsgrafik einer triple negativen Tumorzelle

Eigene Darstellung

Schematisch dargestellt ist eine triple negative Tumorzelle inklusive der wichtigsten Rezeptoren (GPR30-, EGF-1-, GnRH-Rezeptor). Die orange dargestellten Pfeile zeigen den proliferativen Signaltransduktionsweg bei initialer Stimulation durch 17ß-Östradiol. In grau dargestellt sind die bereits bekannten Hemmstoffe der einzelnen Rezeptoren.

Ihre Wirkung wird im Folgenden beschrieben:

(1) 17ß-Östradiol $\left(\mathrm{E}_{2}\right)$ bindet an den GPR30 Rezeptor führt zur Dissoziation. Die $\beta \gamma$ Untereinheit aktiviert Src. EGF wird aus der extazellulären Matrix freigesetzt und führt zur Autophosphorilierung des EGF Rezeptors. Außerdem kommt es durch Aktivierung der $\alpha$ Untereinheit zur einer Synthese der Second Messengers cAMP und ERK-1(gehören zur Familie der MAP-Kinasen) Erhöhung zur vermehrten cfos Produktion (Lappano et al. 
2010) und zur Steigerung der Mitoserate. Die Proliferation der Zelle wird gesteigert. (Filardo et al. 2000; Girgert et al. 2012; Luttrell et al. 1999; Maggiolini et al. 2004; Revankar et al. 2005). (2) siRNA hemmt direkt den GPR30 Rezeptor und führt so zur Proliferationshemmung (Girgert et al. 2012). (3) Estriol hemmt direkt den GPR30 Rezeptor und führt so zur Proliferationshemmung (Girgert et al. 2014). (4) Cetuximab ist ein Antikörper gegen den EGF-1 Rezeptor. Durch die direkte Korrelation des EGF-1 Rezeptors mit dem GPR30 Rezeptor führt die Hemmung des EGF-Rezeptor zu einer Reduktion der GPR30 Reduktion (Carey et al. 2007). (5) Gefitinib bindet an die hydrophobe ATP Bindungsstelle des Tyrosinkinasebereiches am EGF- Rezeptor und inhibiert diesen dadurch. Durch die direkte Korrelation des EGF-1 Rezeptors mit dem GPR30 Rezeptor führt die Hemmung des EGF-Rezeptor zu einer Reduktion der GPR30 Reduktion (Girgert et al. 2017). (6) Durch die Bindung der GnRH-Analoga an den GnRH-Rezeptor wird eine Phosphotyrosinphosphatase durch die $\alpha_{1}$ Untereinheit des G-Protein gekoppelten Rezeptors aktiviert, welche wiederum den EGF-1 Rezeptor indirekt hemmt. 


\subsection{Zielsetzung}

Ziel dieser Arbeit ist es, den GPR30 als neues Target für die Therapie des ER $\alpha$-negativen (triple negativen) Mammakarzinoms zu evaluieren. Dafür gibt es verschiedene Optionen. Ein Weg verläuft über die Blockierung des GnRH-Rezeptors durch GnRH-Analoga.

Bei den vorliegenden Untersuchungen soll geklärt werden, ob GnRH-Analoga durch die indirekte Inhibition des EGF-Rezeptors die Expression des membranständigen Östrogenrezeptor GPR30 hemmen, die Tumorzellproliferation der triple negativen Mammakarzinomzellen senken können und damit als zielgerichtete Therapie für triple negative Mammakarzinome geeignet sind.

Dazu wurden die Proliferationssteigerung der TNBC-Zellen durch 17ß-Östradiol, die Proliferationsminderung durch GnRH-Analoga und die GPR30-Expressionsminderung durch GnRH-Analoga untersucht. 


\section{Material und Methoden}

\subsection{Material}

\subsubsection{Geräte}

Tabelle 2: Verwendete Geräte

\begin{tabular}{|l|l|}
\hline Gerät & Hersteller \\
\hline Analysenwaage & Sartorius \\
\hline Autoklav LGAK0019 & Schütt GmbH \\
\hline Biofuge pico & Heraeus Holding \\
\hline C-Digit ${ }^{\odot}$ Blot Scanner & LI-COR \\
\hline IKA Schüttler MTS4 & IKA Werke GmbH \\
\hline Kühlschrank & Liebherr \\
\hline Mikroskop & Olympus \\
\hline Mikrowaage, elektrisch & Sartorius \\
\hline Mini-Protean-Tetra Cell System & Bio Rad \\
\hline Multipette plus & Eppendorf \\
\hline Pipetus electronic & HirschmannLaborgeräte \\
\hline Schüttler Titramax1000 & Heidolph \\
\hline Sterilwerkbank HLB2448GS & Heraeus Lamin Air \\
\hline Synergy ${ }^{\text {TM }}$ Multi-Detections-Microplate-Reader & Bio Tek \\
\hline Thermocycler T3000 & Biometra \\
\hline Thermomixer compact & Eppendorf \\
\hline Ultrazentrifuge(Laborfuge400R) & Heraeus Instruments \\
\hline Vortex Gene2 & Scientific Industries \\
\hline Wasserbad & GFL \\
\hline Zell Inkubator HERA cell & Heraeus \\
\hline
\end{tabular}




\subsubsection{Verbrauchsmaterialien}

Tabelle 3: Verwendete Verbrauchsmaterialien

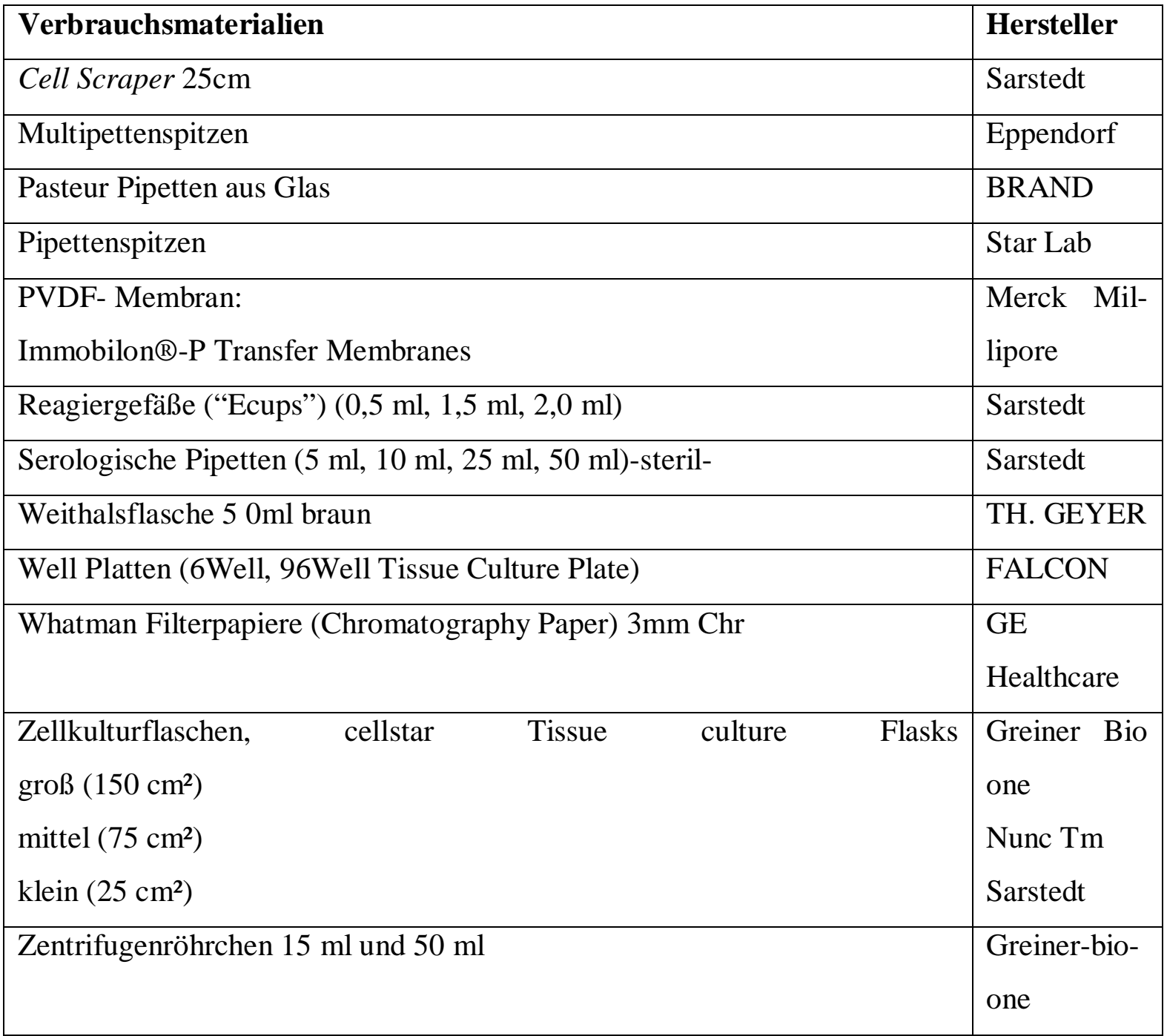

\subsubsection{Kultur- und Einfriermedien}

Tabelle 4: Verwendete Medien

\begin{tabular}{|c|c|}
\hline Verwendete Medien (Hersteller) & Zusammensetzung \\
\hline Nähr-/Kulturmedium (nur zur Aufzucht) & \\
\hline MEM Earle's w Phenolrot (Biochrom GmbH) & $\begin{array}{l}10 \%(\mathrm{v} / \mathrm{v}) \mathrm{FCS}, 1 \%(\mathrm{v} / \mathrm{v}) \mathrm{P} / \mathrm{S}, 0,1 \% \text { Insu- } \\
\text { lin, } 0,1 \% \text { Transferrin }\end{array}$ \\
\hline $\begin{array}{l}\text { Versuchsmedium (Zellkultivierung für Pro- } \\
\text { teingewinnung GPR30 Versuche) }\end{array}$ & $\begin{array}{l}1 \%(\mathrm{v} / \mathrm{v}) \text { gestripptes FCS, } 1 \%(\mathrm{v} / \mathrm{v}) \mathrm{P} / \mathrm{S} \text {, } \\
0,1 \% \text { Insulin, } 0,1 \% \text { Transferrin }\end{array}$ \\
\hline MEM Earle's w Phenolrot (Biochrom GmbH) & \\
\hline
\end{tabular}




\begin{tabular}{|l|l|}
\hline Verwendete Medien (Hersteller) & Zusammensetzung \\
\hline Experimentalmedium: Hormonfreies Medium & $1 \%$ FCS-Hormonfrei, 1\% NEAS, 1\% \\
für Versuche: Proliferationsassays (Alamar & HEPES, \\
blue) und FCS-Konzentrationsreihe & $\begin{array}{l}\text { 1\%P/S, 1\%L-Gln, 0,1\% Insulin, 0,1\% } \\
\text { DMEM Phenolrot-frei (gibco) }\end{array}$ \\
\hline Einfriermedium & Transferrin \\
& MEM Earle's Kulturmedium $+5 \%$ \\
\hline
\end{tabular}

\subsubsection{Mediumzusätze}

Tabelle 5: Verwendete Mediumzusätze

\begin{tabular}{|l|l|}
\hline Verwendete Mediumzusätze & Hersteller \\
\hline $\begin{array}{l}\text { 1\% FCS gestrippt: fetal bovine serum EU approved activated charcoal } \\
\text { absorbed sterile filtered }\end{array}$ & PAN Bio Tech \\
\hline $10 \%$ FCS: fetal bovine serum superior & Biochrom \\
\hline HEPES Solution 1M & Sigma-Aldrich \\
\hline Insulin: Insuman Rapid 40IE/nl & Sanofi \\
\hline L-Gln: L-Alanyl L-Glutamine $200 \mathrm{mM}(1 \% \mathrm{Glu})$ & $\begin{array}{l}\text { Biochrom } \\
\text { (Merck) }\end{array}$ \\
\hline NEAS & $\begin{array}{l}\text { Biochrom } \\
\text { (Merck) }\end{array}$ \\
\hline Penicillin10.000 U/ml /Streptomycin $10.000 \mu \mathrm{g} / \mathrm{ml}$ & Gibco \\
\hline Transferrin-human & Sigma-Aldrich \\
\hline
\end{tabular}

\subsubsection{Chemikalien}

Tabelle 6: Verwendete Chemikalien

\begin{tabular}{|l|l|}
\hline Verwendete Chemikalien & Hersteller \\
\hline Alamar Blue & Biosource GmbH \\
\hline Ampuwa & Fressenius \\
\hline Dimethylsulfoxide (DMSO) & Sigma \\
\hline EDTA & Millipore (Merck) \\
\hline
\end{tabular}




\begin{tabular}{|l|l|}
\hline Verwendete Chemikalien & Hersteller \\
\hline $\begin{array}{l}\text { Molekularmassenmarker (WB): } \\
\text { peq GOLD Protein Marker V, 11-250 kDa, } \\
\text { 9bands }\end{array}$ & peQlab Biotechnologie GmbH \\
\hline $\begin{array}{l}\text { Protein Assay Dye Reagent Concentrate } \\
\text { (zur Proteinbestimmung) }\end{array}$ & Bio-Rad Laboratories GmbH \\
\hline $\begin{array}{l}\text { Rinderserumalbumin Albumin Fraktion V, } \\
\text { Minimum 98\% } \\
\text { (Proteinstandards) }\end{array}$ & Carl Roth GmbH \\
\hline $\begin{array}{l}\text { Super Signal West Femto } \\
\text { Super Signal West Femto Stable Peroxide } \\
\text { Buffer + Super Signal West Femto Luminol } \\
\text { Enhancer Solution }\end{array}$ & \\
\hline TEMED & Thermo Scientific \\
\hline Trypanblau-Lösung & Serva \\
\hline
\end{tabular}

\subsubsection{Puffer und Lösungen}

Für das Ansetzen von Puffern sowie anderern Lösungen wurde $\mathrm{H}_{2} \mathrm{O}$ aus einer Reinstwasseranlage der Firma Sartorius verwendet.

Tabelle 7: Verwendete Puffer und Lösungen

\begin{tabular}{|l|l|}
\hline Verwendete Puffer und Lösungen & Zusammensetzung/ Hersteller \\
\hline 1x Elektrophoresepuffer (mit SDS) & $\begin{array}{l}100 \mathrm{ml} 5 \mathrm{x} \text { Elektrophoresepuffer + 5 ml 10\% SDS + 400 } \\
\text { ml bidest }\end{array}$ \\
\hline 5x Elektrophoresepuffer (ohne SDS) & $15,1 \mathrm{~g}$ Tris + 72 g Glycin + 1000 ml bidest \\
\hline Ammoniumpersulfat 10\% (APS) & $10 \mathrm{~g}$ APS auf $100 \mathrm{ml}$ PBS \\
\hline Antibody Stripping Buffer & Interchim \\
\hline Blocking-Solution & Solution TBST + 5\% (w/v) Magermilchpulver \\
\hline $\begin{array}{l}\text { Acrylamid Fertiglösung (Lsg A 50\% } \\
\text { acrylamide mix) }\end{array}$ & Pro Sieve TM \\
\hline Lsg B (1,5M Tris pH 8,8) & $90,9 \mathrm{~g}$ Tris Pufferan + 400 ml bidest \\
\hline Lsg C (10\% SDS) & $10 \mathrm{~g}$ SDS + 90 ml bidest \\
\hline Lsg D (1,0M Tris pH 6,8) & $30,3 \mathrm{~g}$ Tris Pufferan + 400 ml bidest \\
\hline LDS sample buffer (4x) NuPAGE & Life Technologies Darmstadt \\
\hline
\end{tabular}




\begin{tabular}{|c|c|}
\hline Verwendete Puffer und Lösungen & Zusammensetzung/ Hersteller \\
\hline Sample Reducing Agent NuPAGE ${ }^{\circledR}$ & Life Technologies Darmstadt \\
\hline Laemmli- Puffer & $\begin{array}{l}5 \mathrm{ml} \text { LDS sample buffer }+5 \mathrm{ml} \text { Amuwa }+1 \mathrm{ml} \\
\text { Sample Reducing Agent }\end{array}$ \\
\hline PBS EDTA & DPBS $(100 \mathrm{ml})+200 \mathrm{mg}$ Tetrasulfonium (EDTA) \\
\hline DPBS (phosphate buffered saline) & Pan Biotec \\
\hline $\begin{array}{l}\text { SDS-Lösung 10\% (= Lösung C) } \\
\text { (Sodiumdodecysulfate) }\end{array}$ & Carl Roth GmbH \\
\hline TBS (10x) & $\begin{array}{l}80 \mathrm{~g} \mathrm{NaCl}+2 \mathrm{~g} \mathrm{KCl}+30 \mathrm{~g} \text { Tris }+1000 \mathrm{ml} \text { bidest, } \\
\mathrm{pH} 7,5\end{array}$ \\
\hline TBST & $100 \mathrm{ml}$ 10xTBS + $10 \mathrm{ml}(\mathrm{v} / \mathrm{v})$ Tween $2010 \%$ \\
\hline Transferpuffer $(\mathrm{pH} 8,3)$ & $48 \mathrm{mM}$ Tris, $39 \mathrm{mM}$ Glycin, 20\% (v/v) Methanol \\
\hline Trypsin-EDTA & $\begin{array}{l}\text { 0,05\% Trypsin/0,02\% EDTA in PBS } \\
\text { (Biochrom sowie c.c.pro GmbH) }\end{array}$ \\
\hline Zell Lysis Puffer & $\begin{array}{l}10 \mathrm{ml} \text { Cell Lytic M Cell Lysis Reagent }+0,1 \% \\
\text { Phosphatase Inhibitor }+0,1 \% \text { Protease Inhibitor } \\
\text { (Sigma-Aldrich) }\end{array}$ \\
\hline
\end{tabular}

\subsubsection{Zelllinien}

Die folgenden Zelllinien wurden von der American Type Culture Collection (ATCC) bezogen.

Tabelle 8: Verwendete Zelllinien

\begin{tabular}{|l|lr|l|l|}
\hline Zelllinie & Herkunft & Histologie & Referenz \\
\hline HCC1806 & $\begin{array}{l}\text { Homo sapiens, } \\
\text { 60jährige Frau, far- } \\
\text { big }\end{array}$ & $\begin{array}{l}\text { Primär epitheliales Mamma Kar- } \\
\text { zinom }\end{array}$ & $\begin{array}{l}\text { ATCC - } \\
\text { CRL 2335 }\end{array}$ \\
\hline HCC70 & $\begin{array}{l}\text { Homo sapiens, } \\
49 \text { jährige Frau, far- } \\
\text { big }\end{array}$ & Primär duktales Mamma Karzinom & $\begin{array}{l}\text { ATTCC- } \\
\text { CRL 2335 }\end{array}$ \\
\hline $\begin{array}{l}\text { MDA-MB } \\
\text { 435S }\end{array}$ & $\begin{array}{l}\text { Homo sapiens, } \\
\text { weiblich }\end{array}$ & Malignes Melanom (*) & $\begin{array}{l}\text { ATCC HTB- } \\
129\end{array}$ \\
\hline
\end{tabular}




\begin{tabular}{|l|l|l|l|}
\hline Zelllinie & Herkunft & Histologie & Referenz \\
\hline MDA-MB & Homo sapiens, & Perikarderguss, durch Metastase & ATCC- \\
453 & weiblich & $\begin{array}{l}\text { eines primär glandulären Mamma } \\
\text { Karzinom }\end{array}$ & HTB-131 \\
& & & \\
\hline
\end{tabular}

* zur Zeit der Planung und Durchführung der Experimente dieser Arbeit wurde die Histologie dieser Zelllinie als Pleuraerguss, durch Metastase eines primär ducatalen Mammakarzinom beschrieben und gewertet. 


\subsubsection{GnRH-Analoga}

Triptorelin, GnRH-I-Agonist,

[D-Trp $\left.{ }^{6}\right] \mathrm{GnRH}, \mathrm{pGlu}$-His-Trp-Ser-Tyr-D-Trp-Leu-Arg-Pro-Gly-NH $\mathrm{N}_{2}$

(Ferring Pharmaceuticals, Copenhagen/Denmark)

\section{Cetrorelix GnRH-I-Antagonist,}

$\left[\mathrm{Ac}-\mathrm{D}-\mathrm{Nal}(2)^{1}, \mathrm{D}-\mathrm{Phe}(4 \mathrm{Cl})^{2}, \mathrm{D}-\mathrm{Pal}(3)^{3}, \mathrm{D}-\mathrm{Cit}^{6}, \mathrm{DAla}^{10}\right]$

(ASTA Medica AG [Aeterna-Zentaris], Frankfurt a.M. /Deutschland)

\section{GnRH-II-Antagonist (N4),}

$\left[\mathrm{Ac}-\mathrm{D} 2 \mathrm{Nal}^{1}{ }^{1}, \mathrm{D}-4 \mathrm{Cpa}^{2}, \mathrm{D}-3 \mathrm{Pal}^{3,6}, \mathrm{Leu}^{8}, \mathrm{D}-\mathrm{Ala}^{10}\right]$

(Peptide Specialty Laboratories GmbH, Heidelberg/Deutschland)

\section{D-Lysin ${ }^{6} \mathrm{GnRH}$ II, GnRH-II-Agonist,}

[pGlu-His-Trp-Ser-His-D-Lys-Trp-Try-Pro-Gly- $\mathrm{NH}_{2}$ ]

(Peptide Specialty Laboratories GmbH, Heidelberg/Deutschland)

\subsubsection{7ß-Östradiol}

17ß-Estradiol (Sigma Aldrich) wurden in Ethanol gelöst (Stammlösung $10^{-3} \mathrm{M}$ ). Die weiteren Verdünnungen erfolgten in Experimetalmedium. 


\subsubsection{Antikörper}

Tabelle 9: Verwendete Primärantikörper

\begin{tabular}{|c|c|c|}
\hline Antikörper (Firma) & Herkunft & Verdünnung \\
\hline $\begin{array}{l}\text { Anti-GPR30 (PA5-28647) } \\
\text { (Thermo Scientific) }\end{array}$ & $\begin{array}{l}\text { aus Kaninchen, IgG, po- } \\
\text { lyklonal, } \\
\text { (Molekülmasse: } 42 \mathrm{kDA} \text { ) } \\
\text { (abgelesen bei } 57 \mathrm{kDA} \text { ) }\end{array}$ & $1: 2.000$ \\
\hline $\begin{array}{l}\text { Anti- GAPDH } \\
\text { (GAPDH(D16H11)) } \\
\text { (CellSignalling Technology) }\end{array}$ & $\begin{array}{l}\text { aus Kaninchen, IgG, mo- } \\
\text { noklonal } \\
\text { (Molekülmasse: } 37 \mathrm{kDa} \text { ) }\end{array}$ & $1: 2.000$ \\
\hline
\end{tabular}

(werden alle mit Natriumazid [M=65,01 $\mathrm{g} / \mathrm{mol}]$ versetzt)

Tabelle 10: Verwendeter Sekundärantikörper

\begin{tabular}{|l|l|l|}
\hline Antikörper (Firma) & Herkunft & Verdünnung \\
\hline $\begin{array}{l}\text { Anti-Kaninchen IgG, an } \\
\text { HRP gekoppelt (ECL TM) }\end{array}$ & aus Esel & $\begin{array}{l}\text { Für Anti-GPR30 1:20.000 } \\
(2 \mu 1 \mathrm{AK}+40 \mu 1 \mathrm{TBST}) \\
\end{array}$ \\
& $\begin{array}{l}\text { Für Anti-GAPDH } 1: 40.000 \\
(1 \mu 1+40 \mu 1 \mathrm{TBST})\end{array}$ \\
\hline
\end{tabular}

\subsubsection{Softwareprogramme}

Tabelle 11: Verwendete Softwareprogramme

\begin{tabular}{|l|l|}
\hline Graph Pad Prism ${ }^{\circledR}$ Version 6.0 & Graph Pad Software Inc. \\
\hline IMAGE Studio Digits Vers 4.0 & LI-COR \\
\hline Microsoft ${ }^{\circledR}$ Office 2007/2010 & Microsoft Cooperation \\
\hline Gen5 (Synergy HT ${ }^{\circledR}$ ) & Bio-Tek \\
\hline EndNote X5 & \\
\hline
\end{tabular}




\subsection{Methoden}

Die in der vorliegenden Arbeit angegebenen Konzentrationen beziehen sich allzeit auf die Endkonzentration in den Wells.

Die verwendeten Zelllinien wurden von der American Type Culture Collection (ATCC, Manassas, VA) bezogen. Die Zellen wurden aliquotiert, eingefroren und in flüssigem Stickstoff gelagert. Bei Bedarf wurde eine Zellsuspension aufgetaut, kultiviert und für weitere Versuche verwendet oder wieder eingefroren.

\subsubsection{Auftauen der Zellsuspension}

Vor Gebrauch erfolgte das Auftauen der Zellsuspension und anschließende Zentrifugation bei $400 \mathrm{~g}$ für 5 Minuten. Nach Absaugen und Verwerfen des Einfriermediums wurde das Zellpellet in MEM-Earl-Kulturmedium resuspendiert und in Zellkulturflaschen überführt. Je nach Zelllinie konnten die Zellen nach 3-4 Tagen Kultivierung, bei HCC1806, MDAMB-435S und MDA-MB-453 und nach 7-8 Tagen Kultivierung, bei HCC70 für Versuche verwendet werden.

\subsubsection{Zellkultivierung}

Die Kultivierung der Zellen erfolgte in Zellkulturflaschen der Firma Nunc in einer wasserdampfgesättigten Atmosphäre mit $5 \% \mathrm{CO}_{2}$ - Anteil bei $37^{\circ}$ Celsius. Als Nährmedium in den Zellkulturflaschen $\left(75 \mathrm{~cm}^{2}\right)$ diente $10 \mathrm{ml}$ MEM-Earl-Kulturmedium mit Phenolrot, welches alle drei bis vier Tage erneuert wurde. Bei Erreichen einer Zelldichte von etwa 90\% wurden die Zellen weiterverwendet. Dazu wurde das verbrauchte Medium mit einer Pasteurpipette abgesaugt und die Zellen für 5 Minuten mit $10 \mathrm{ml}$ DPBS gewaschen. Nach Entfernen des DPBS wurden die Zellen wurden bei $37^{\circ} \mathrm{C}$ für etwa $10-15$ Minuten mit $3 \mathrm{ml}$ Trypsin/EDTA inkubiert, um die adhärenten Zellen vom Flaschenboden chemisch abzulösen. Die Reaktion wurde mit $7 \mathrm{ml}$ des MEM-Earl-Kulturmedium abgestoppt. Die Zellen wurden mit einem Cell Scrapper vom Flaschenboden mechanisch abgelöst und im Anschluss für 5 Minuten bei $400 \mathrm{~g}$ bei Raumtemperatur zentrifugiert. Nach Absaugen des Überstandes wurde das Zellpellet in frischem Medium resuspendiert und nach Bedarf passagiert, kryokonserviert oder für die Versuche eingesetzt. 


\subsubsection{Passagieren und Rekultivierung}

Für die Passagierung wurde das Zellpellet in $1 \mathrm{ml}$ MEM-Earl-Kulturmedium mit Phenolrot resuspendiert und ein Teil dieser Lösung in einer neuen Zellkulturflasche mit Kulturmedium auf insgesamt $10 \mathrm{ml}$ Volumen aufgefüllt.

\subsubsection{Kryokonservierung}

Für die Kryokonservierung wurde das Zellpellet in $1 \mathrm{ml}$ MEM-Earl-Kulturmedium resuspendiert und $1 \mathrm{ml}$ Einfriermedium hinzugefügt. Um eine Kristallbildung und somit eine Zerstörung der Zellen zu verhindern, wird die Lösung für circa $24 \mathrm{~h}$ bei $-80^{\circ} \mathrm{C}$, isoliert durch Styropor und Alufolie, langsam eingefroren und im Anschluss in flüssigem Stickstoff konserviert.

\subsubsection{Zellzahlbestimmung und -berechnung}

Die Zellzahlbestimmung wurde mittels einer Neubauer-Zählkammer unter dem Lichtmikroskop durchgeführt. Dazu wurden $10 \mu 1$ der Zellsuspension in die Zählkammer gegeben, die in neun Quadrate eingeteilt ist. In der Zählung wurden nur die vitalen Zellen berücksichtigt. Die Unterscheidung zwischen vitalen und avitalen Zellen erfolgte mittels einer Tryptanblau-Färbung, bei der sich avitale Zellen durch eine Blaufärbung des Zytosols deutlich von vitalen Zellen unterscheiden ließen. Verdünnung der Zellsuspension mit der Tryptanblau-Lösung im Verhältnis 1:2. Die vier Eckquadranten wurden ausgezählt. Aus der Zellzahl der vier Eckquadranten wurde der Mittelwert berechnet. Durch die Multiplikation mit dem Faktor 10.000 erhielt man die Zellzahl pro Milliliter.

Durch die Division der errechneten Zellzahl pro Milliliter durch die gewünschte Zellzahl pro Milliliter ergab sich der Verdünnungsfaktor. Die Zellzahl pro $\mu 1$ der Zellsuspension ergab sich aus der Division des Endvolumens in $\mu 1$ durch den errechneten Verdünnungsfaktor. Um eine Zellzahl von 2000/100 $\mu \mathrm{l}$ zu erhalten wurde die oben errechnete Menge der Zellsuspension mit der Differenz aus Endvolumen und errechnete Menge der Zellsuspension vermischt und somit jeweils $100 \mu \mathrm{l}$ (2000 Zellen) pro Well ausplattiert. 
Tabelle 12: Beispiel zur Berechnung einer gewünschten Zellzahl

\begin{tabular}{|c|c|}
\hline$(554: 4) \times 10.000=1.385 .000 / \mathrm{ml}$ & $\begin{array}{l}\text { Bildung des Mittelwertes der gezählten } \\
\text { Zellzahl in Neubauer Zählkammer und Mul- } \\
\text { tiplikation mit dem Faktor } 10.000 \\
\text { Das Ergebnis ist die Zellzahl pro Milliliter }\end{array}$ \\
\hline $1.385 .000 / \mathrm{ml}: 20.000 / \mathrm{ml}=69,25$ & $\begin{array}{l}\text { Division der Zellzahl pro Milliliter durch } \\
\text { die gewünschte Zellzahl pro Milliliter } \\
\text { Das Ergebnis ist der Verdünnungsfaktor }\end{array}$ \\
\hline $\begin{array}{l}20.000 \mu \mathrm{l}(\mathrm{A})-288 \mu \mathrm{l}(\mathrm{B})=19.712 \mu \mathrm{l} \mathrm{Me}- \\
\operatorname{dium}(\mathrm{C}) \\
19.712 \mu 1 \mathrm{Medium}(\mathrm{C})+288 \mu \mathrm{l}(\mathrm{B}) \text { Zellsu- } \\
\text { spension }=20.000 \mu \mathrm{l} \text { Endlösung (A) mit } \\
2.000 \text { Zellen } / 100 \mu \mathrm{l}\end{array}$ & $\begin{array}{l}\text { Division des gewünschten Endvolumen (in } \\
\mu l)(A) \text { durch den Verdünnungsfaktor ergibt } \\
\text { die Einsatzmenge/ die benötigte/das zu ver- } \\
\text { wendende Volumen (in } \mu \text { l) der ursprüngli- } \\
\text { chen Zellsuspension (B). } \\
\text { Die Differenz aus dem Gesamtvolumen (A) } \\
\text { und der benötigten Menge der Zellsuspensi- } \\
\text { on (B) ergibt die Menge an zu verwenden- } \\
\text { den Medium in } \mu 1 \text { (C). } \\
\text { Bei der Verwendung dieses Zell- } \\
\text { Mediumgemisches (C + B) erhält man die } \\
\text { gewünschte Zelldichte von } 20.000 / m l \text { bzw. } \\
\text { 2.000 Zellen/100 } \mu 1 \text {. }\end{array}$ \\
\hline
\end{tabular}

\subsubsection{Proliferationsassay}

Um die direkte Stimulation des EGF-Rezeptors durch EGF aus dem Kulturmedium auszuschließen, wurden diese Versuche in serumfreiem Medium (DMEM von gibco) durchgeführt.

Je nach Zelllinie wurden 2000 (bei HCC1806) und 3000 (bei HCC70, MDA-MB-435S und MDA-MB-453) Zellen in $100 \mu \mathrm{l} /$ Well in einer 96-Well-Platte ausgesät. Dazu wurde das Zellpellet nach der Zentrifugation in DMEM Phenolrot-freiem Experimentalmedium resuspendiert und die Zellzahl nach 2.2.5 bestimmt. Die Ausplattierung der gewünschten Zellzahl erfolgte in $100 \mu 1$ Phenolrot-freiem 5\%-igem DMEM Experimentalmedium. 
Zur Ermittlung der optimalen Wirkkonzentration von 17ß-Östradiol, wurden die Zellen, 24 Stunden nach Aussäen, mit $50 \mu 1$ 17 -Östradiol (E2) behandelt.

Die $\mathrm{E}_{2}$-Endkonzentrationen in den Wells betrugen $2 \times 10^{-11} \mathrm{M}, 2 \times 10^{-10} \mathrm{M}, 10^{-9} \mathrm{M}, 2 \times 10^{-9} \mathrm{M}$, $10^{-8} \mathrm{M}, 2 \times 10^{-8} \mathrm{M}, 2 \times 10^{-7} \mathrm{M}, 2 \times 10^{-6} \mathrm{M}$. Die Inkubation erfolgte bei $37^{\circ} \mathrm{C}$ und $5 \% \mathrm{CO}_{2}$ für 5 Tage.

Zur Optimierung der proliferationssteigernden 17ß-Östradiolwirkung, untersuchten wir das Wachstum von Zellen, die mit $10^{-8} \mathrm{M}$ 17ß-Östradiol stimuliert wurden, in Abhängigkeit von der FCS Konzentration im Medium. Es wurde Medium mit gestripptem FCS, d.h. mit Aktivkohle gereinigtes FCS in den Konzentrationen 1\%, 0,5\%, 0,2\%, 0,1\% verwendet.

Die Reduktion der Zellproliferation, der zunächst mit 17ß-Östradiol stimulierten Zellen, durch Einwirkung von GnRH-Analoga, wurde in einem weiteren Versuchsaufbau untersucht. Dazu wurden die Zellen mit $50 \mu \mathrm{E}_{2} 10^{-8} \mathrm{M}$ sowie mit $50 \mu 1$ der verschiedenen GnRH-Analoga in den Konzentrationen $10^{-9} \mathrm{M}, 10^{-8} \mathrm{M}, 10^{-7} \mathrm{M}, 10^{-6} \mathrm{M}, 10^{-5} \mathrm{M}$ behandelt. Die Inkubation erfolgte bei $37^{\circ} \mathrm{C}$ und $5 \% \mathrm{CO}_{2}$ für fünf Tage.

Nach Inkubation der Zellen wurde die relative Zellzahl bei allen Versuchen durch einen kolorimetrischen Assay unter Verwendung von AlamarBlue ${ }^{\circledR}$ bestimmt. Die Absorption des Farbstoffes wurde bei $570 \mathrm{~nm}$ vs. $630 \mathrm{~nm}$, nach einer vier stündigen Inkubationszeit von AlamarBlue ${ }^{\circledR}$ bestimmt.

Mithilfe des Synergy ${ }^{\mathrm{TM}}$ HT Multi-Detektions-Reader wurde der Farbumschlag detektiert und die relative Zellzahl mithilfe der Software GEN5 ausgewertet.

\subsubsection{Proteinbiochemische Methoden}

\subsubsection{Proteingewinnung von GPR30}

Die Expression des GPR30 Proteins in den, mit Cetrorelix behandelten triple negativen Mammakarzinomzelllinien (HCC1806, HCC70) wurde qualitativ und semiquantitativ mit Hilfe der Western Blot Methode untersucht. Zellen ohne Cetrorelix-Behandlung dienten dabei als Kontrolle.

\subsection{Zellkultivierung}

Das Zellpellet (Herstellung wie in 2.2.2 beschrieben) wurde in MEM Earle's w Phenolrotem Medium resuspendiert und die Zellzahl wie in 2.2 .5 beschrieben bestimmt. Je $4 \mathrm{ml}$ Zelllösung (Zelldichte: 1 Million Zellen pro Milliliter) wurden in $25 \mathrm{~cm}^{2}$ Zellkulturfla- 
schen ausgesät. Nach einer Kultivierungszeit von 24 h wurde das überstehende Medium abgesaugt und pro Flasche $2 \mathrm{ml}$ frisches MEM Earle's phenolrotes Medium mit 1\% HF FCS hinzugefügt.

\subsection{Behandlung mit Cetrorelix}

Die Inkubation mit Cetrorelix erfolgte in unterschiedlichen Konzentrationen und für unterschiedliche Zeitintervalle ( $24 \mathrm{~h}, 48 \mathrm{~h}, 96 \mathrm{~h}$ ) bei $37^{\circ} \mathrm{C}$ und $5 \% \mathrm{CO}_{2}$.

Herstellung Cetrorelix Verdünnungsreihe:

$100 \mu 15 \times 10^{-4}$ M Cetrorelix (Stammlösung) $+400 \mu 1$ DPBS $=500 \mu 11 \times 10^{-4}$ M Cetrorelix.

Davon wurden $200 \mu \mathrm{l}$ in eine mit $2 \mathrm{ml}$ Medium befüllten Zellkulturflasche gegeben. Cetrorelixendkonzentration in dieser Flasche $10^{-5} \mathrm{M}$.

$50 \mu \mathrm{l}$ der $1 \times 10^{-4} \mathrm{M}$ Cetrorelixlösung wurden mit $450 \mu \mathrm{l}$ DPBS vermischt $=500 \mu \mathrm{l}$ $1 \times 10^{-5}$ M Cetrorelix. Davon wurden $200 \mu \mathrm{l}$ in eine mit $2 \mathrm{ml}$ Medium befüllten Zellkulturflasche gegeben. Cetrorelixendkonzentration in dieser Flasche $10^{-6} \mathrm{M}$.

$50 \mu \mathrm{l}$ der $1 \times 10^{-5} \mathrm{M}$ Cetrorelixlösung wurden mit $450 \mu \mathrm{l}$ DPBS vermischt $=500 \mu \mathrm{l}$ $1 \times 10^{-6}$ M Cetrorelix. Davon werde $200 \mu \mathrm{l}$ in eine mit $2 \mathrm{ml}$ Medium befüllten Zellkulturflasche gegeben. Cetrorelixendkonzentration in dieser Flasche $10^{-7} \mathrm{M}$.

Die Endkonzentration von Cetrorelix in den Kulturflaschen beträgt $10^{-7} \mathrm{M}, 10^{-6} \mathrm{M}$ und $10^{-5} \mathrm{M}$. Als Kontrolle diente eine Zellkulturflasche ohne Cetrorelix. Um das Volumen identisch zu halten, wurden hier $200 \mu$ DPBS hinzugefügt. Anschließende Inkubation bei $37^{\circ} \mathrm{C}$ und $5 \% \mathrm{CO}_{2}$ für $24 \mathrm{~h}, 48 \mathrm{~h}$ und $96 \mathrm{~h}$.

\subsection{Proteinisolation}

Nach den jeweiligen Inkubationszeiten wurden die Zellen mit $2 \mathrm{ml}$ PBS-EDTA für $5 \mathrm{~min}$ inkubiert und anschließend mit dem Cell Scraper vom Flaschenboden abgelöst und in $3 \mathrm{ml}$ DPBS resuspendiert. Um die Proteine aus den Zellen zu lösen, wurden die Zellpellets, nach Zentrifugation über 5 min bei $400 \mathrm{~g}$ und Absaugen des Überstandes in $30 \mu 1$ Zell-LysisPuffer resuspendiert (A) und in neue Eppendorf-Cups überführt.

\subsection{Proteinbestimmung}

Nach Zentrifugation der Suspension (A) bei 16.000 g für 5 min wurde der Überstand $(30 \mu l)$ in neue E-cups überführt und auf Eis gestellt (B). Die weitere Verarbeitung wurde 
auf Eis durchgeführt. Je $5 \mu 1$ der Protein- Lösung (aus B) wurde in neue Eppendorf- Cups pipettiert und mit $45 \mu 1$ Aqua bidest 1:10 verdünnt. Je $10 \mu 1$ der verdünnten Lösung wurde pro Well auf einer unsterilen 96-Well-Platte aufgetragen.

Zur späteren Western Blot Bestimmung wurden die restlichen $25 \mu 1$ des Überstands (B) mit $25 \mu$ l zweifach konzentriertem Lämmli-Probenpuffer verdünnt und bis zur weiteren Verwendung bei $-80^{\circ} \mathrm{C}$ eingefroren.

Zur quantitativen Proteinbestimmung wurden Proteinstandards verwendet. Es wurden je $10 \mu 1$ des jeweiligen Standards auf derselben Well-Platte aufgetragen. Als Proteinstandards diente Rinderserumalbumin Fraktion V (Carl Roth) mit einem Konzentrationsspektrum von $0,1 \mu \mathrm{g} / \mu \mathrm{l}, 0,25 \mu \mathrm{g} / \mu \mathrm{l}, 0,5 \mu \mathrm{g} / \mu \mathrm{l}, 0,75 \mu \mathrm{g} / \mu \mathrm{l}$ und $1 \mu \mathrm{g} / \mu \mathrm{l}$.

Tabelle 13: Tabellarische Darstellung der Probenauftragung auf eine 96-Well-Platte

\begin{tabular}{|l|l|l|l|}
\hline Leer & $\begin{array}{l}0,75 \mu \mathrm{g} / \mu \mathrm{l} \text { Proteinstan- } \\
\text { dard }\end{array}$ & Ko $(10 \mu \mathrm{l})$ & Probe 4 $(10 \mu \mathrm{l})$ \\
\hline Leer & $\begin{array}{l}0,75 \mu \mathrm{g} / \mu \mathrm{l} \text { Proteinstan- } \\
\text { dard }\end{array}$ & Ko $(10 \mu \mathrm{l})$ & Probe 4 $(10 \mu \mathrm{l})$ \\
\hline $0,1 \mu \mathrm{g} / \mu \mathrm{l}$ Proteinstandard & $1 \mu \mathrm{g} / \mu \mathrm{l}$ Proteinstandard & Probe $1(10 \mu \mathrm{l})$ & \\
\hline $0,1 \mu \mathrm{g} / \mu \mathrm{l}$ Proteinstandard & $1 \mu \mathrm{g} / \mu \mathrm{l}$ Proteinstandard & Probe $1(10 \mu \mathrm{l})$ & \\
\hline $\begin{array}{l}0,25 \mu \mathrm{g} / \mu \mathrm{l} \text { Proteinstan- } \\
\text { dard }\end{array}$ & & Probe $2(10 \mu \mathrm{l})$ & \\
\hline $\begin{array}{l}0,25 \mu \mathrm{g} / \mu \mathrm{l} \text { Proteinstan- } \\
\text { dard }\end{array}$ & & Probe $2(10 \mu \mathrm{l})$ & \\
\hline $0,5 \mu \mathrm{g} / \mu \mathrm{l}$ Proteinstandard & & Probe 3 $(10 \mu \mathrm{l})$ & \\
\hline $0,5 \mu \mathrm{g} / \mu \mathrm{l}$ Proteinstandard & & Probe 3 $(10 \mu \mathrm{l})$ & \\
\hline
\end{tabular}

Zur kolorimetrischen Proteinmengenbestimmung wurde eine 1:5 verdünnte Bio Rad Protein Assay Lösung in einer Menge von $200 \mu$ lauf die Wells gegeben. Die Auswertung erfolgte über den Mikrodetection Microplate Reader Synergy HT (Bio-Tek).

Um eine definierte Proteinmenge von $40 \mu \mathrm{g}$ zu erhalten, wurde mittels Proteinstandards die Proteinmenge der Proben ermittelt und das benötigte Volumen in $\mu l$ berechnet. Diese Menge Probelösung (aus B) wurde zur SDS- Polyacrylamid-Gelelektrophorese auf das Gel aufgetragen. 


\subsection{Denaturierung der Proteine}

Vor der Verwendung der Proteine mussten diese aufbereitet werden. Hierfür wurden die Proben ( $25 \mu$ l Lysate), wie unter 2.2.7.1.4 beschrieben, zu gleichen Teilen mit LaemmliPuffer $(25 \mu \mathrm{l})$ versetzt, im Weitern dann für $5 \mathrm{~min}$. bei $95{ }^{\circ} \mathrm{C}$ im Thermomixer denaturiert, dann bei 16.000g für 1 min zentrifugiert und anschließend auf Eis gestellt.

\subsubsection{SDS-Polyacrylamid-Gelelektrophorese}

SDS-Page ( Sodiumdodecyls $\underline{\text { ulfate }}$ Polyacrylamide gel electrophoresis) nach Laemmli ist eine Methode zur Trennung von Proteinen nach ihrer Molekülmasse in einem elektrischen Feld. Als Matrix dient ein Gel auf Polyacrylamid Basis. Dieser Matrix wird SDS (Sodiumdodecylsulfat) hinzugefügt.

Das anionische Tensid SDS bindet an die Aminosäureketten der, durch Hitze denaturierten Proteine und überdeckt mit ihrer negativen Ladung die Eigenladung der Proteine.

Die Proteine der Zell-Lysate werden in einem Sammelgel konzentriert und im Trenngel nach ihrer Größe sortiert.

Die Auftrennung der Proteine erfolgt nach der Kettenlänge, die zur Molekülmasse proportional ist. Längere Proteine werden im Gel stärker zurückgehalten als kurze. Je kleiner ein Protein ist, desto schneller wandert es im Gel.

Herstellung des Sammelgels (mit $5 \%$ Polyacrylamid) erfolgte mit den in Tabelle 14 aufgeführten Substanzen, die Herstellung des Trenngels (mit $10 \%$ Polyacrylamid) mit den in Tabelle 15 aufgelisteten Substanzen. Für die SDS Page wurde das Mini-Protean Tetra System von Bio-Rad nach Herstellerangaben aufgebaut und verwendet. Die Apparatur wurde mit 500 ml SDS- Elektrophorese- Puffer aufgefüllt. Die erste Geltasche des Sammelgels wurde mit $10 \mu 1$ Molekularmassenmarker (peq GOLD Protein Marker V, Peqlab) befüllt, die folgenden mit $40 \mu \mathrm{g}$ der zu untersuchenden Proteinproben. Die Elektrophorese erfolgte zunächst bei $80 \mathrm{~V}$ für $30 \mathrm{~min}$, anschließend bei $100 \mathrm{~V}$ für $60 \mathrm{~min}$ in SDSElektrophoresepuffer.

Nach Auftrennung der Proteine wurden diese im nachfolgenden Western-Blot Verfahren auf eine PVDF-Membran übertragen. 
Tabelle 14: Herstellung eines 5\%igen Sammelgels

\begin{tabular}{|l|l|}
\hline Material & Menge \\
\hline ProSieve $^{\circledR}$ 50Gel Acrylamid Lösung & $750 \mu \mathrm{l}$ \\
\hline Lsg D ( Tris pH 6,8) & $1,9 \mathrm{ml}$ \\
\hline Lsg C (10\% SDS) & $75 \mu \mathrm{l}$ \\
\hline $\mathrm{H}_{2} \mathrm{O}$ & $5,0 \mathrm{ml}$ \\
\hline TEMED & $22 \mu \mathrm{l}$ \\
\hline $10 \%$ APS & $37 \mu \mathrm{l}$ \\
\hline
\end{tabular}

Tabelle 15: Herstellung eines 10\%igen Trenngels

\begin{tabular}{|l|l|}
\hline Material & Menge \\
\hline ProSieve $^{\circledR}$ 50Gel Acrylamid Lösung & $2,3 \mathrm{ml}$ \\
\hline Lsg B (Tris pH 8,8) & $2,8 \mathrm{ml}$ \\
\hline Lsg C (10\% SDS) & $110 \mu \mathrm{l}$ \\
\hline $\mathrm{H}_{2} \mathrm{O}$ & $5,7 \mathrm{ml}$ \\
\hline TEMED & $20 \mu \mathrm{l}$ \\
\hline $10 \%$ APS & $37 \mu \mathrm{l}$ \\
\hline
\end{tabular}




\subsubsection{Western Blot}

Beim Western-Blot Verfahren werden die aufgetrennten Proteine durch Anlegen eines elektrischen Feldes vom Polyacrylamid- Gel auf eine PVDF-Membran (Immobilon®-P Membrane, Millipore, USA) übertragen (blotting). Anschließend können die Proteine durch spezifische Antikörper nachgewiesen werden.

Das Mini-Protean Tetra System von Bio-Rad wurde nach Herstellerangaben aufgebaut. Die PVDF-Membran wurde zunächst mit Methanol aktiviert und mit $\mathrm{ddH}_{2} \mathrm{O}$ und TBST gewaschen. Nach Entfernung des Sammelgels wurde die Trenngelplatte zunächst luftblasenfrei auf die Membran aufgebracht. Auf beiden Seiten wurden je drei mit Transferpuffer getränkte Filterpapiere gelegt. Dieses Konstrukt wurde zwischen zwei Schaumstoffschichten gelegt und in die Blotting-Apparatur überführt. Dabei musste die PVDF-Membran der Anode zugewandt sein. Die Blottingkammer wurde mit Transferpuffer gefüllt und anschließend eine Spannung von $100 \mathrm{~V}$ für $1 \mathrm{~h}$ angelegt.

\subsubsection{Detektion und Visualisierung}

Nach dem Blotting wurde die PVDF Membran mit der Blocking-Solution $1 \mathrm{~h}$ lang inkubiert. Das darin enthaltene Milchpulver-Protein blockiert freie unspezifische Bindungsstellen auf der Membran. Dadurch wird eine Anlagerung der Antikörper an unspezifische Bindungsstellen verhindert. Anschließend wurde die Membran viermal für je 15 min mit TBST gewaschen. Die Inkubation mit dem vorverdünnten GPR30 Primärantikörper (Verdünnung 1:2000, siehe 2.1.10) erfolgte über Nacht bei $4^{\circ} \mathrm{C}$. Nach Abschütten des Primärantikörpers wurde die Membran viermal für jeweils 15 min mit TBST gewaschen. Im Anschluss folgte die Inkubation mit dem Peroxidase-gekoppelten Sekundärantikörper (Verdünnung 1:20.000, siehe 2.1.10) für $1 \mathrm{~h}$ bei Raumtemperatur. Nach viermal Waschen für je 15 min mit TBST wurde die Membran für 15 min in TBS gelegt. Durch das Waschen mit TBS wird das Tween herausgelöst, um eine Störung der Peroxidase des Lumineszenz zu verhindern. Durch eine fünfminütige Inkubation der Membran mit dem LumineszenzReagenz Super Signal West Femto (400 $\mu 1$ Super Signal West Femto Stable Peroxide Buffer $+400 \mu 1$ Super Signal West Femto Luminol Enhancer Solution) wurde der Sekundärantikörper markiert. Die Detektion des Zielproteins wurde mittels des C-DiGit Blot Scanner von LI-COR, für die Dauer von 12 min durchgeführt und mit der korrespondierenden Software ausgewertet. 
Um die Gleichmäßigkeit der aufgetragenen Proteine zu überprüfen wurde als Ladekontrolle ein GAPDH Antikörper (Anti-Glyceraldehyd-3-Phosphat Dehydrogenase) verwendet. Nach dem unter 2.2.7.5 beschriebenen Strippen der Membran wurde der Anti-GAPDHAntikörper als Primärantikörper (Verdünnung 1:2.000, siehe 2.1.10) aufgetragen und durch den Sekundärantikörper (Verdünnung 1:40.000, siehe 2.1.10) und das Chemilumineszenz detektiert. Die konstanten Bandbreiten demonstrierten die gleichmäßige Verteilung der aufgetragenen Proteinmengen.

\subsubsection{Strippen der PVDF-Membran}

Um eine erneute Verwendung der PVDF Membran mit verschiedenen Primärantikörpern zu ermöglichen, müssen die Membranen von den zuvor gebundenen Antikörpern befreit werden.

Die Entfernung von primären und sekundären Antikörpern von einer Western Blot Membran bezeichnet man als Strippen. Anschließend kann ein weiteres Protein im selben Blot detektiert werden.

Nach der GPR30 Detektion wurde die Membran mit 20 ml eines Antibody Stripping Puffer für 5 min inkubiert. Nach einem zweiminütigen Waschen mit $\mathrm{ddH}_{2} \mathrm{O}$ folgte noch ein fünfminütiger Waschvorgang mit TBST. Anschließend wurde die Membran für 1 Stunde mit blocking-Solution behandelt. Nach Abwaschen der blocking-Solution mit TBST wurde der Primärantikörper (GAPDH- AK) aufgetragen und bei $4^{\circ} \mathrm{C}$ über Nacht inkubiert. 


\section{Versuchsergebnisse}

\subsection{Beeinflussung der Proliferationsraten von vier TNBC-Zellpopulationen durch verschiedene Konzentrationen von 17ß-Östradiol $\left(\mathbf{E}_{2}\right)$}

Der Einfluss von 17ß-Östradiol auf die Proliferationsrate der Zelllinien MDA-MB-435S, MDA-MB-453, HCC70 und HCC1806 wurde mittels Proliferationsassays getestet. Die Zellen wurden jeweils für sieben Tage mit verschiedenen Konzentrationen 17 $\beta$-Östradiol von $2 \times 10^{-11} \mathrm{M}$ über $2 \times 10^{-10} \mathrm{M}, 10^{-9} \mathrm{M}, 2 \times 10^{-9} \mathrm{M}, 10^{-8} \mathrm{M}, 2 \times 10^{-8} \mathrm{M}, 2 \times 10^{-7} \mathrm{M}$ bis $2 \times 10^{-6} \mathrm{M}$ stimuliert. Die Proliferation wurde anhand der relativen Zellzahl gegenüber der Kontrolle $1,00 \pm 0,0$ gemessen.

\subsubsection{Beeinflussung der Proliferationsraten der MDA-MB-435S- Zellpopulation durch verschiedene Konzentrationen von 17ß-Östradiol $\left(\mathbf{E}_{2}\right)$}

Bei der Zelllinie MDA-MB-435S zeigte sich die größte Steigerung der relativen Proliferation durch die Stimulation mit einer Konzentration von $2 \times 10^{-9} \mathrm{M} \mathrm{E}_{2}$ : auf $1,17 \pm 3,4$ der Kontrolle und mit $10^{-8} \mathrm{M} \mathrm{E}_{2}$ : auf 1,12 $\pm 2,5$. Im One-Way ANOVA-Test wurde keine Signifikanz erreicht. Der unpaired t-Test ergab bei einer Konzentration von $10^{-9} \mathrm{M}$ und auch bei $10^{-8} \mathrm{M}$ eine hohe Signifikanz (***, $\left.\mathrm{p}<0,001\right)$. 


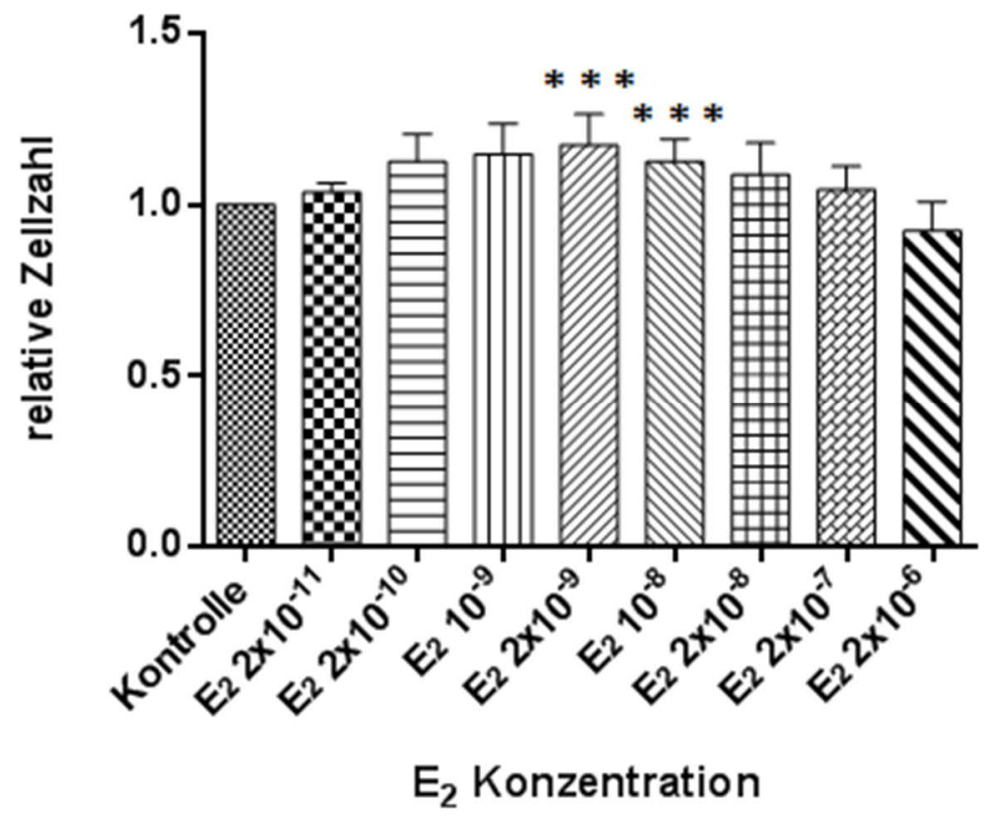

Abbildung 4: Einfluss von $E_{\mathbf{2}}$ auf die Proliferationsrate von MDA-MB-435S-Zellen

Das Verhalten der relativen Zellzahl der Zelllinie MDA-MB-435S bei Stimulierung mit $17 \beta$-Östradiol $\left(\mathrm{E}_{2}\right)$ in den Konzentrationen von $2 \times 10^{-11} \mathrm{M}$ bis $2 \times 10^{-6} \mathrm{M}$ über die Dauer von sieben Tagen. Die Kontrolle zeigt die Proliferation der Zelllinie ohne 17ß-Östradiol. Der signifikante Anstieg der Proliferation durch die Stimulation mit $2 \times 10^{-9} \mathrm{M} \mathrm{E}_{2}$ und $10^{-8} \mathrm{M}$ ist dargestellt. Angegeben sind die MW \pm SEM. Die Daten wurden mittels unpaired t-Test auf signifikante Unterschiede geprüft. (***, p<0,001 vs. Ko), $\mathrm{n}=7$

\subsubsection{Beeinflussung der Proliferationsraten der MDA-MB-453-Zellpopulation durch verschiedene Konzentrationen von 17 $\beta$-Östradiol $\left(E_{2}\right)$}

Bei der Zelllinie MDA-MB-453 kam es bei einer $\mathrm{E}_{2}$-Konzentration von $2 \times 10^{-8} \mathrm{M}$ zur größten Steigerung der Zellproliferation. Der Anstieg lag nicht im signifikanten Bereich.

\subsubsection{Beeinflussung der Proliferationsraten der HCC70-Zellpopulation durch verschiedene Konzentrationen von 17ß-Östradiol $\left(E_{2}\right)$}

Bei der Zelllinie HCC70 wurde eine, im One-Way ANOVA-Test signifikante Steigerung der Proliferation im Vergleich zur Kontrolle 1,00 $\pm 0,0$ durch Stimulation mit 17ßÖstradiol in der Konzentration $10^{-9} \mathrm{M}$ : auf 1,22 $\pm 0,07\left(^{*}, \mathrm{p}<0,05\right)$ und in einer Konzentration von $10^{-8}$ M: auf 1,24 $\pm 0,07(*, p<0,05)$ erreicht (Abb. 5). 


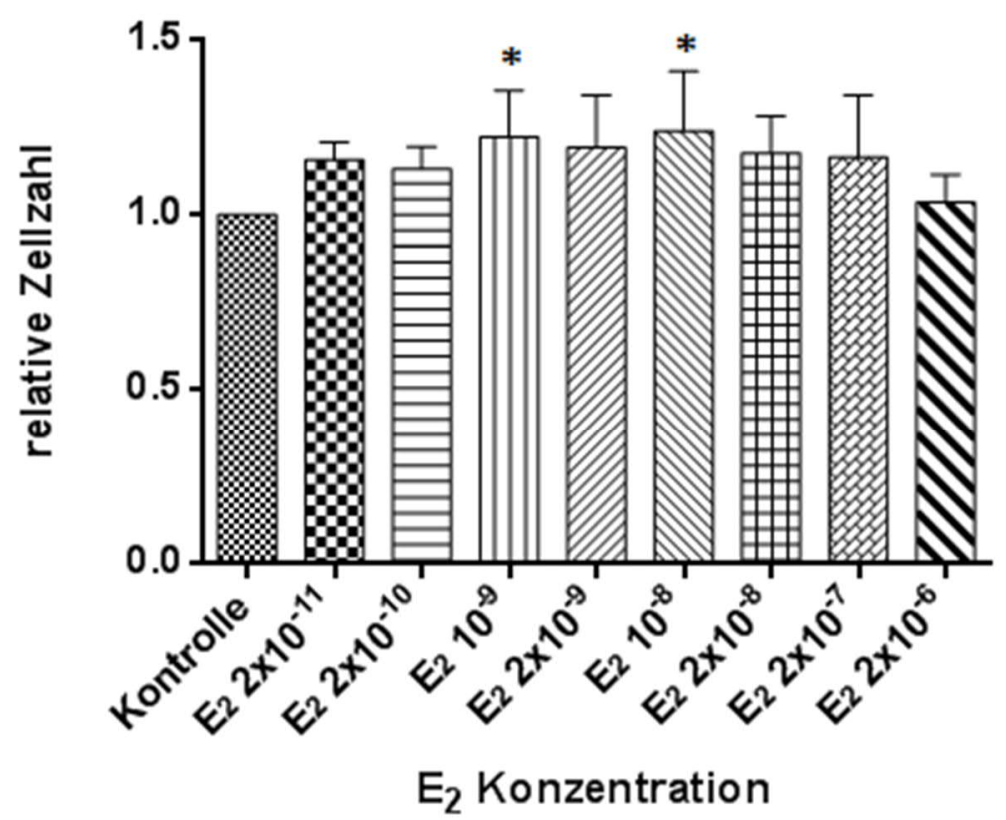

Abbildung 5: Einfluss von $\mathrm{E}_{2}$ auf die Proliferationsrate von HCC70-Zellen

Das Verhalten der relativen Zellzahl der Zelllinie HCC70 durch Stimulation mit 17ß-Östradiol $\left(\mathrm{E}_{2}\right)$ in den Konzentrationen von $2 \times 10^{-11} \mathrm{M}$ bis $2 \times 10^{-6} \mathrm{M}$ über die Dauer von sieben Tagen. Die Kontrolle zeigt die Proliferation der Zelllinie ohne Östradiol. Angegeben sind die MW \pm SEM. Die Daten wurden mittels one way Analysis of Variance (ANOVA) auf signifikante Unterschiede geprüft. (*, p<0,05 vs. Ko), n = 6

\subsubsection{Beeinflussung der Proliferationsraten der HCC1806-Zellpopulation durch verschiedene Konzentrationen von 17 $\beta$-Östradiol $\left(\mathbf{E}_{2}\right)$}

Bei der Zelllinie HCC1806 wurde durch Zugabe von $10^{-9}$ M 17ß-Östradiol eine, im unpaired t-Test signifikante Proliferationssteigerung auf das 1,11 \pm 0,04-fache der Kontrolle $\left.{ }^{*}, \mathrm{p}<0,05\right)$ erreicht. Die Konzentration $2 \times 10^{-9} \mathrm{M} \mathrm{E}_{2}$ steigerte die relative Zellzahl auf das $1,15 \pm 0,02$-fache (n.s). Durch $10^{-8} \mathrm{M} \mathrm{E}_{2}$ konnte ebenfalls eine, im unpaired t-Test signifikante Proliferationssteigerung auf $1,13 \pm 0,04$ (**, $\mathrm{p}<0,01)$ erreicht werden (Abb. 6). Die Proliferationsstimulation der Zelllinie HCC1806 mit 17ß-Östradiol zeigte im ANOVA keine Signifikanz. 


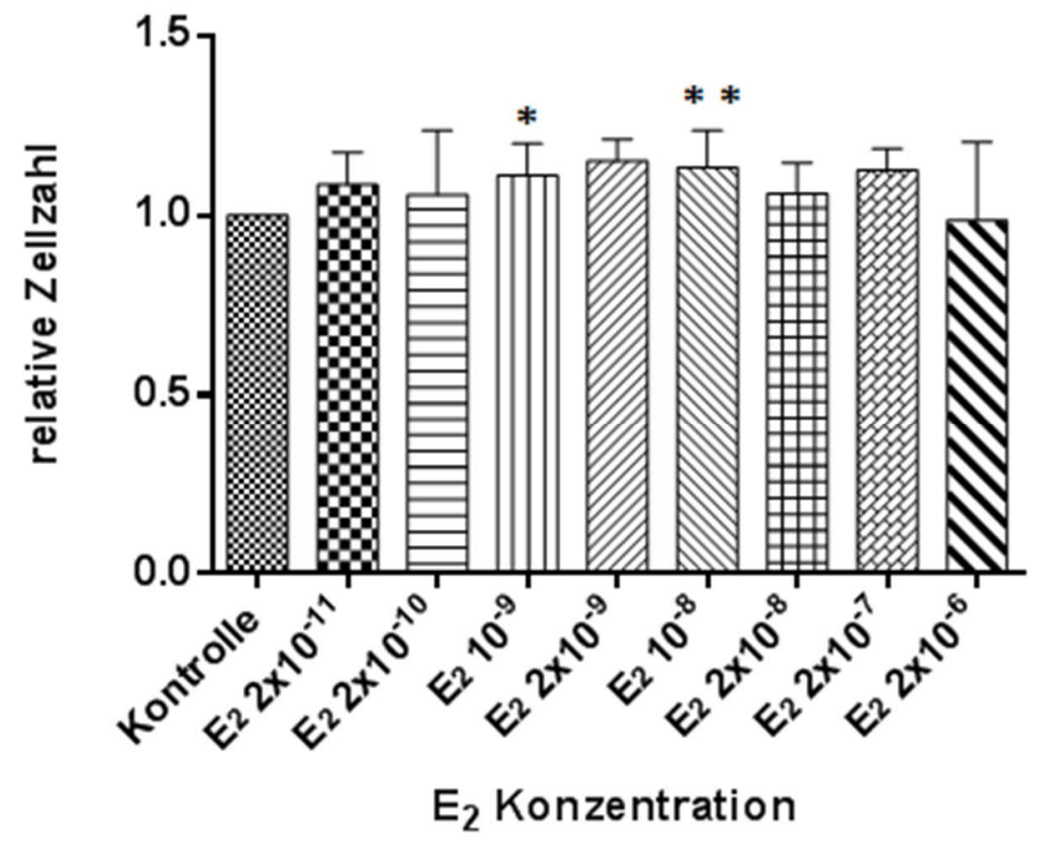

\section{Abbildung 6: Einfluss von $E_{\mathbf{2}}$ auf die Proliferationsrate von HCC1806-Zellen}

Das Verhalten der relativen Zellzahl der Zelllinie HCC1806 durch Behandlung mit 17ß-Östradiol $\left(\mathrm{E}_{2}\right)$ in den Konzentrationen von $2 \times 10^{-11} \mathrm{M}$ bis $2 \times 10^{-6} \mathrm{M}$ über die Dauer von sieben Tagen. Die Kontrolle zeigt die Proliferation der Zelllinie ohne Östradiol. Angegeben sind die MW \pm SEM. Die Daten wurden mittels t-Test (ungepaart) auf signifikante Unterschiede geprüft. (*, p<0,05 vs. Ko; **, p<0,01 vs. Ko), n = 6

\subsubsection{Zusammenfassung}

Die in dieser Arbeit verwendeten triple negativen Mammakarzinomzelllinien wurden mit $17 \beta$-Östradiol zum Wachstum angeregt. Bei drei der vier verwendeten Zelllinien kam es bei einer $\mathrm{E}_{2}$-Konzentration von $10^{-8} \mathrm{M}$ zu einer signifikanten Proliferationssteigerung bis zu 24\% (bei HCC70). Aufgrund dieser Ergebnisse wurde 17ß-Östradiol in den nachfolgenden Versuchen in der Konzentration von $10^{-8} \mathrm{M}$ verwendet. 


\subsection{Vergleich der Wachstumsraten von $\mathbf{E}_{2}$-stimulierten und nicht $\mathbf{E}_{2}$ - stimulierten TNBC-Zellen unter Reduzierung des FCS-Gehaltes}

Das Nährmedium der vorangehenden Untersuchung enthielt eine 1\% Konzentration von FCS. Eine weitere Untersuchung sollte zeigen, ob eine Konzentrationsänderung des FCS im Nährmedium einen Einfluss auf die 17ß-Östradiol-induzierte Proliferationsrate der TNBC-Zellen hat. In der Annahme, dass die im gestrippten FCS (d.h. durch Aktivkohle wurden bereits kleine Proteine wie Steroide zum Teil herausgefiltert) enthaltenen Reststeroide die GPR30-Rezeptoren eventuell blockieren könnten, wurde untersucht, ob und wie sich eine Konzentrationsänderung von FCS im Nährmedium auf die, durch $10^{-8} \mathrm{M}$ $17-\beta$ Östradiol stimulierte Proliferationsrate von TBNC Zellen auswirkt. Dazu wurde, in den Zelllinien HCC1806 und HCC70, ausgehend von der 1\% -igen FCS-Konzentration, die Konzentration von FCS im Nährmedium stufenweise reduziert und die Proliferationsrate bei Zellen mit und ohne zusätzlicher $\mathrm{E}_{2}$-Stimulation verglichen. Bei jeder Reduzierungsstufe von FCS $(1 \%, 0,5 \%, 0,2 \%, 0,1 \%)$ wurde ein Teil der Zellen fünf Tage mit $10^{-8} \mathrm{M}$ $17 \beta$-Östradiol (diese Konzentration zeigte bei den Vorversuchen den stärksten proliferationssteigernden Effekt) stimuliert. Die Zellen der Vergleichsgruppe blieben ohne zusätzliche $E_{2}$-Stimulation im Nährmedium. Verglichen wurden die Proliferationsraten von $\mathrm{E}_{2}$ stimulierten und von nicht stimulierten Zellen in der jeweiligen Reduzierungsstufe von FCS.

Es wurde untersucht, bei welcher FCS Konzentration sich die größte Steigerung der Proliferation durch $\mathrm{E}_{2}$ innerhalb von fünf Tagen erzielen lässt.

Dadurch sollte untersucht werden, ob eine geänderte FCS Konzentration im Nährmedium den proliferationssteigernden Effekt von Östradiol verstärken kann. Der Versuch wurde bei den Zelllinien HCC70 und HCC1806 durchgeführt.

\subsubsection{Vergleich der Wachstumsraten von $\mathbf{E}_{2}$-stimulierten und nicht $\mathbf{E}_{2}$ - stimulierten HCC70-Zellen unter Reduzierung des FCS-Gehaltes}

Die Zelllinie HCC70 zeigte bei einem 1\% -igem FCS Gehalt des Nährmediums eine signifikante Steigerung der Zellproliferation bei Zugabe von $10^{-8} \mathrm{M} \mathrm{E}_{2}$ : auf 1,23 $\pm 0,04$ (**, $\mathrm{p}<0,05)$ im Vergleich zur nicht $\mathrm{E}_{2}$-stimulierten Kontrolle 1,00 \pm 0,04.

Die Proliferationsraten bei 0,5\%-igem und 0,1\%-igem FCS Gehalt blieben bei Zugabe von $10^{-8} \mathrm{M}_{2}$ gleich. Zu einer Senkung der Proliferationsrate nach der Zugabe von $\mathrm{E}_{2}$ kam es bei einem FCS Gehalt von $0,2 \%$. 


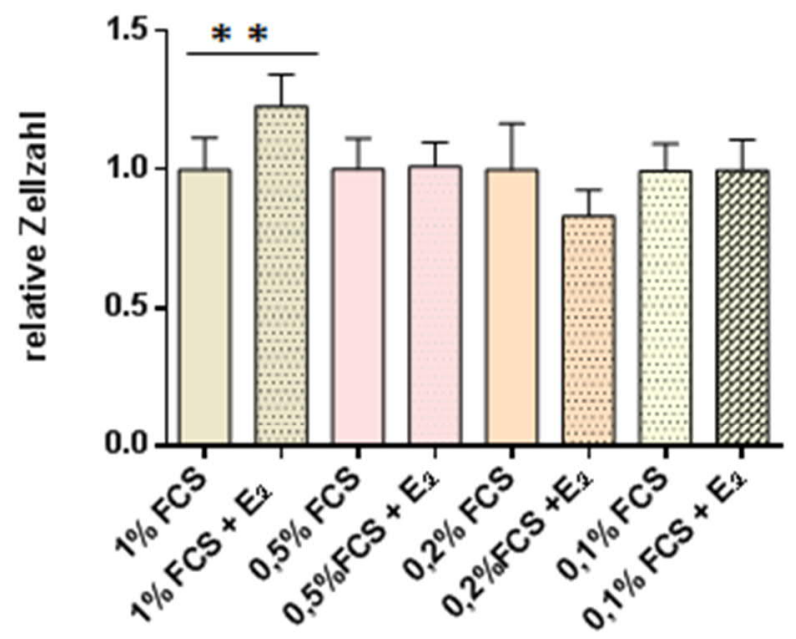

FCS Konzentrationen
mit
$\mathrm{E}_{2} \mathbf{1 0}^{10-8 \mathrm{M}}$

Abbildung 7: Vergleich der Wachstumsraten von $\mathrm{E}_{2}\left(\mathbf{1 0}^{-8} \mathrm{M}\right)$ stimulierten und nicht $\mathrm{E}_{2}$ stimulierten HCC70-Zellen unter Reduzierung des FCS-Gehaltes

Die Konzentration des FCS im Nähmedium lag im Bereich von $1 \%$ bis $0,1 \%$. Angegeben sind MW \pm SEM, die Daten wurden mittels One Way Analysis of Variance (ANOVA) auf signifikante Unterschiede geprüft. $(* *, p<0,01$ vs. $1 \%$ FCS), $\mathrm{n}=8$

\subsubsection{Vergleich der Wachstumsraten von $\mathrm{E}_{2}$-stimulierten und nicht $\mathbf{E}_{2}$ - stimulierten HCC1806-Zellen unter Reduzierung des FCS-Gehaltes}

Die Zellen der Zelllinie HCC1806 zeigten bei einem FCS Gehalt von 1\% eine signifikante Steigerung der Proliferation durch $10^{-8} \mathrm{M} \mathrm{E}_{2}$ von 1,00 $\pm 0,09$ auf $1,44 \pm 0,15\left(^{*}, \mathrm{p}<0,05\right)$.

Bei 0,5\%-igem FCS Gehalt kam es zu einer nicht signifikanten Proliferationssteigerung bei Zugabe von $10^{-8} \mathrm{M} \mathrm{E}_{2}$. Zu einer Senkung der Proliferationsrate nach der Zugabe von $\mathrm{E}_{2}$ kam es bei einem FCS Gehalt von $0,2 \%$ und $0,1 \%$. 


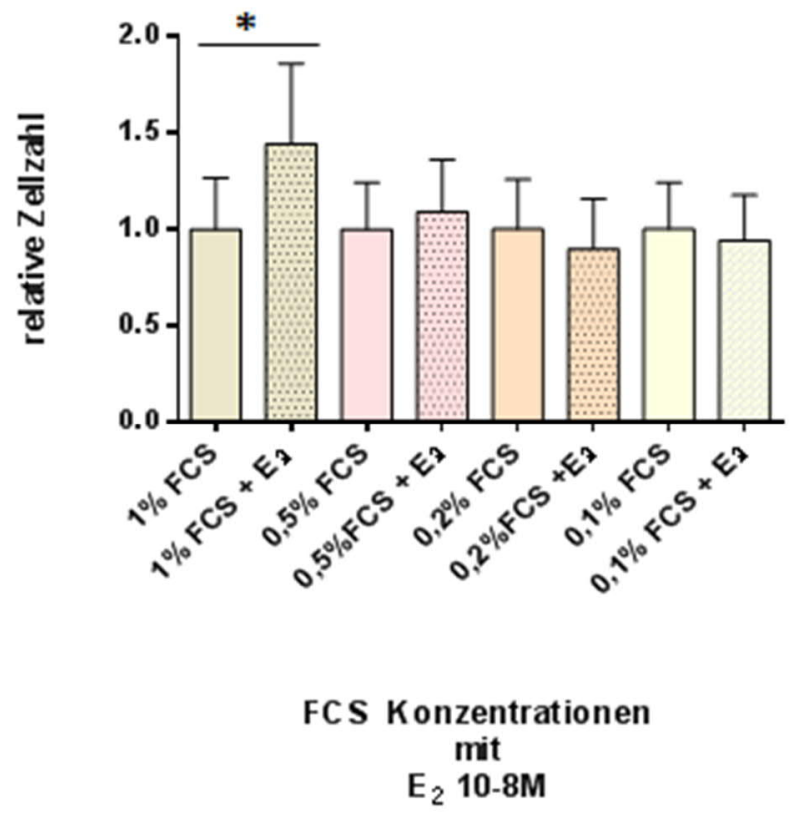

Abbildung 8: Vergleich der Wachstumsraten von $\mathrm{E}_{2}\left(\mathbf{1 0}^{-8} \mathrm{M}\right)$ stimulierten und nicht $\mathrm{E}_{2}$ stimulierten HCC1806-Zellen unter Reduzierung des FCS-Gehaltes

Die Konzentration des FCS im Nähmedium lag im Bereich von $1 \%$ bis 0,1\%. Angegeben sind MW \pm SEM, die Daten wurden mittels One Way Analysis of Variance (ANOVA) auf signifikante Unterschiede geprüft. (*, $\mathrm{p}<0,05$ vs. $1 \%$ FCS), $\mathrm{n}=8$

\subsubsection{Zusammenfassung}

Beim Nährmedium mit 1\%-igen FCS Gehalt zeigte sich eine signifikante Wachstumssteigerung durch Zugabe von $10^{-8} \mathrm{M} \mathrm{E}_{2}$.

Aufgrund dieser Ergebnisse wurden die Hemmversuche mit den GnRH-Analoga weiterhin mit einem Nährmedium mit einer 1\%-igen FCS Konzentration durchgeführt. 


\subsection{Wirkung der GnRH-Analoga Triptorelin, Cetrorelix, D-Lysin ${ }^{6}$ GnRH II und N4 auf die relative Zellzahl der Zelllinien MDA-MB-435S, MDA-MB-453, HCC70, HCC1806}

In der vorliegenden Arbeit sollen die antiproliferativen Effekte von GnRH-I- und GnRHII-Analoga auf hormonrezeptornegative Mammakarzinomzellen in vitro untersucht werden.

Die triple-negativen Zelllinien MDA-MB-435S, MDA-MB-453, HCC70 und HCC1806 wurden für $24 \mathrm{~h}$ mit $17 \beta$-Östradiol $\left(10^{-8} \mathrm{M}\right)$ inkubiert und stimuliert. Anschließend wurden die jeweiligen GnRH-I- und GnRH-II-Agonisten und Antagonisten, Triptorelin (GnRH-IAgonist), Cetrorelix (GnRH-I-Antagonist), D-Lysin ${ }^{6}$ GnRH-II-Agonist (GnRH-II-Agonist) und N4 (GnRH-II-Antagonist) in verschiedenen Konzentrationen $\left(10^{-9} \mathrm{M}, 10^{-8} \mathrm{M}, 10^{-7} \mathrm{M}\right.$, $\left.10^{-6} \mathrm{M}, 10^{-5} \mathrm{M}\right)$ hinzugefügt. Die Auswertung der relativen Zellzahlen erfolgte nach fünf Tagen.

Als Kontrolle dienten nur mit $\mathrm{E}_{2}$-stimulierte Karzinomzellen der jeweiligen Zelllinie.

\subsubsection{Wirkung der GnRH-Analoga auf die relative Zellzahl der Zellinie MDA-MB-435S}

\subsubsection{Triptorelin, Cetrorelix, D-Lysin ${ }^{6}$ GnRH II, N4}

Bei dieser Zelllinie wurde durch keines der vier GnRH-Analoga eine wachstumshemmende Wirkung erzielt. Bei allen vier Substraten kam es zu einer Zellzahlsteigerung. Die erwartete Hemmung der Proliferation blieb aus.

\subsubsection{Wirkung der GnRH-Analoga auf die relative Zellzahl der Zelllinie MDA-MB-453}

\subsubsection{Triptorelin}

Bei der Zugabe von Triptorelin zeigte sich bei allen Konzentrationsstufen ein Anstieg der Zellzahl.

\subsubsection{Cetrorelix}

Bei der Zugabe des GnRH-I-Antagonisten Cetrorelix wurde bei den geringeren Konzentrationen $\left(10^{-9} \mathrm{M}, 10^{-8} \mathrm{M}, 10^{-7} \mathrm{M}, 10^{-6} \mathrm{M}\right)$ ein Anstieg der relativen Zellzahl beobachtet. Bei einer Konzentration von $10^{-5} \mathrm{M}$ zeigte sich eine Senkung der Zellzahl von 1,00 $\pm 0,02$ auf $0,95 \pm 0,09$ (n.s.) (Abb. 9). 


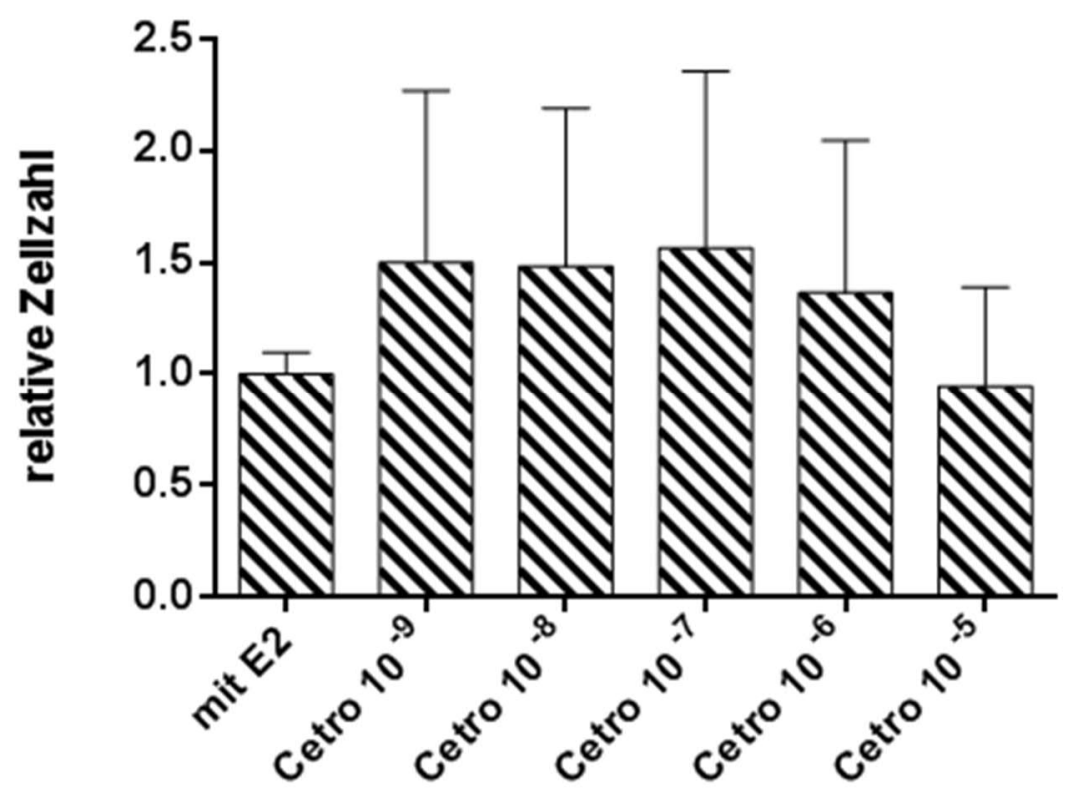

Abbildung 9: Einfluss des GnRH-I-Antagonisten Cetrorelix in verschiedenen Konzentrationen auf die relative Zellzahl von 17ß-Östradiol stimulierten Zellen der Zelllinie MDA-MB453

Wirkung von Cetrorelix auf die relative Zellzahl der Zelllinie MDA-MB-453. Die konzentrationsabhängige Behandlung der triple negativen Zellen wurden über fünf Tage mit einer Konzentration von $10^{-9} \mathrm{M}$ bis $10^{-5} \mathrm{M}$ Cetrorelix durchgeführt. Eine Senkung der relativen Zellzahl ergab sich bei einer Konzentration von $10^{-5} \mathrm{M}$ Cetrorelix. Angegeben sind MW \pm SEM, die Daten wurden mittels One Way Analysis of Variance (ANOVA) auf Signifikanz überprüft, $n=24$

\subsubsection{D-Lysin ${ }^{6}$ GnRH II}

Bei der Zugabe von D-Lysin ${ }^{6}$ GnRH II zeigte sich bei allen Konzentrationsstufen ein Anstieg der relativen Zellzahl. Die erwartete Hemmung der Proliferation blieb aus.

\subsubsection{4 $\mathrm{N}_{4}$}

Bei der Zugabe von N4 zeigte sich bei allen Konzentrationsstufen ein Anstieg der relativen Zellzahl. Die erwartete Hemmung der Proliferation blieb aus.

\subsubsection{Wirkung der GnRH-Analoga auf die relative Zellzahl der Zelllinie HCC70}

\subsubsection{Triptorelin}

Bei der Zelllinie HCC70 wurde durch Zugabe des GnRH-I-Agonisten Triptorelin in allen Konzentrationsstufen eine Reduzierung der Zellproliferation, im Vergleich zur Kontrollgruppe beobachtet (Abb.10). 
Im Vergleich zur Kontrollgruppe $(1,00 \pm 0,06)$ kam es durch Zugabe von Triptorelin in einer Konzentration von $10^{-9} \mathrm{M}$ zu einer signifikanten Reduktion der relativen Zellzahl: auf $0,83 \pm 0,04(* \mathrm{p}<0,05)$. Bei einer Konzentration des Triptorelins von $10^{-8} \mathrm{M}$ zeigte sich eine Reduktion: auf $0,92 \pm 0,02$ (n.s), bei $10^{-7} \mathrm{M}$ : auf $0,84 \pm 0,04\left(^{*}, \mathrm{p}<0,05\right)$, bei $10^{-6} \mathrm{M}$ : auf $0,81 \pm 0,04(*, p<0,05)$ und bei $10^{-5} \mathrm{M}$ : auf $0,90 \pm 0,02$ (n.s) (Abb. 10).

Die stärkste Reduzierung des Zellwachstums (um 19\%) wurde bei Triptorelin in der Konzentration $10^{-6} \mathrm{M}$ beobachtet.

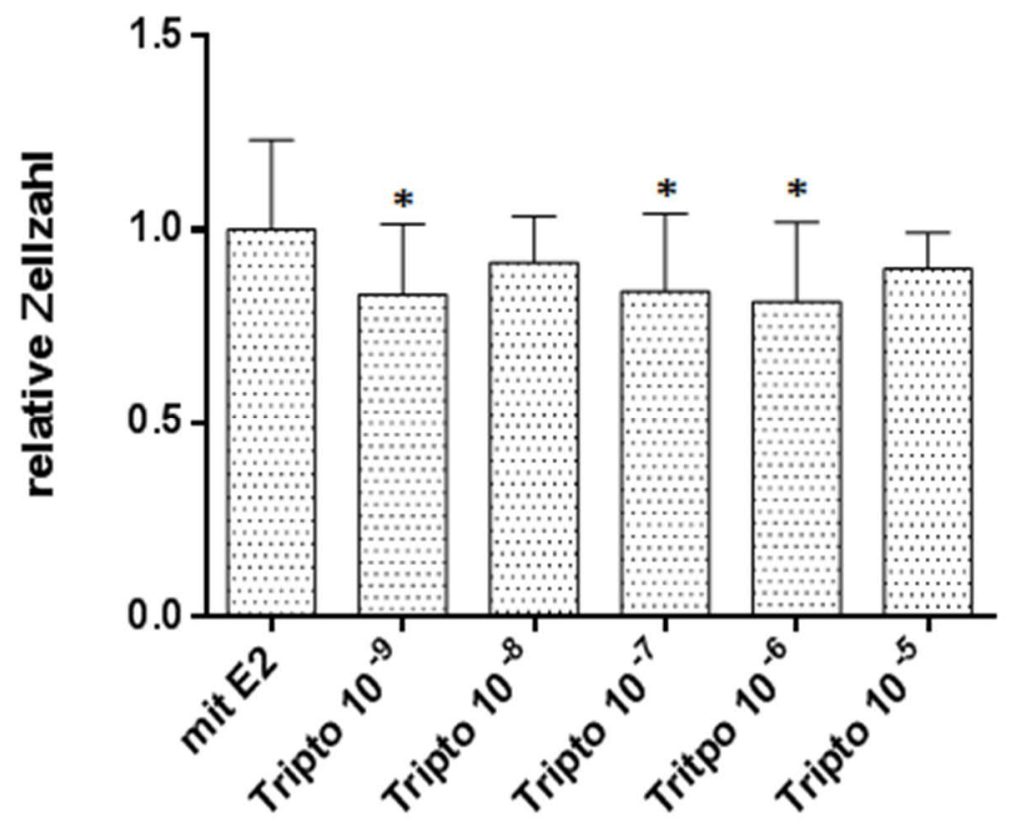

\section{Abbildung 10: Einfluss des GnRH-I-Agonisten Triptorelin in verschiedenen Konzentrationen auf die relative Zellzahl von 17ß-Östradiol stimulierten Zellen der Zelllinie HCC70}

Wirkung von Triptorelin auf die relative Zellzahl der Zelllinie HCC70. Die konzentrationsabhängige Behandlung der triple negativen Zellen wurden über fünf Tage mit einer Konzentration von $10^{-9} \mathrm{M}$ bis $10^{-5} \mathrm{M}$ Triptorelin durchgeführt. Eine signifikante Senkung der relativen Zellzahl ergab sich bei den Konzentrationen $10^{-9} \mathrm{M}, 10^{-7} \mathrm{M}$ und $10^{-6} \mathrm{M}$ Triptorelin. Angegeben sind $\mathrm{MW} \pm \mathrm{SEM}$, die Daten wurden mittels One Way Analysis of Variance (ANOVA) auf Signifikanz überprüft. (*, $\mathrm{p}<0,05$ vs. mit $\mathrm{E}_{2}$ ), $\mathrm{n}=24$

\subsubsection{Cetrorelix}

Bei der Zelllinie HCC70 wurde durch Zugabe des GnRH-I-Antagonist Cetrorelix in allen Konzentrationsstufen eine Hemmung der Zellproliferation, im Vergleich zur Kontrollgruppe beobachtet (Abb.11). Die relative Zellzahl verringerte sich von 1,00 \pm 0,014 (Kontrolle) durch die Zugabe von Cetrorelix $10^{-9} \mathrm{M}$ auf: $0,89 \pm 0,03$, durch Cetrorelix $10^{-8} \mathrm{M}$ : auf 
$0,85 \pm 0,03$, durch Cetrorelix $10^{-7} \mathrm{M}$ : auf 0,84 $\pm 0,03$. Eine signifikante Reduktion ergab sich durch Cetrorelix $10^{-6} \mathrm{M}$ : auf 0,84 $\pm 0,04(*, \mathrm{p}<0,05)$, sowie durch Cetrorelix $10^{-5} \mathrm{M}$ : auf $0,73 \pm 0,04(* * *, p<0,001)$

Die stärkste Reduktion der Zellproliferation um 27\%, zeigte sich bei der Zugabe von Cetrorelix in der Konzentration $10^{-5} \mathrm{M}$.

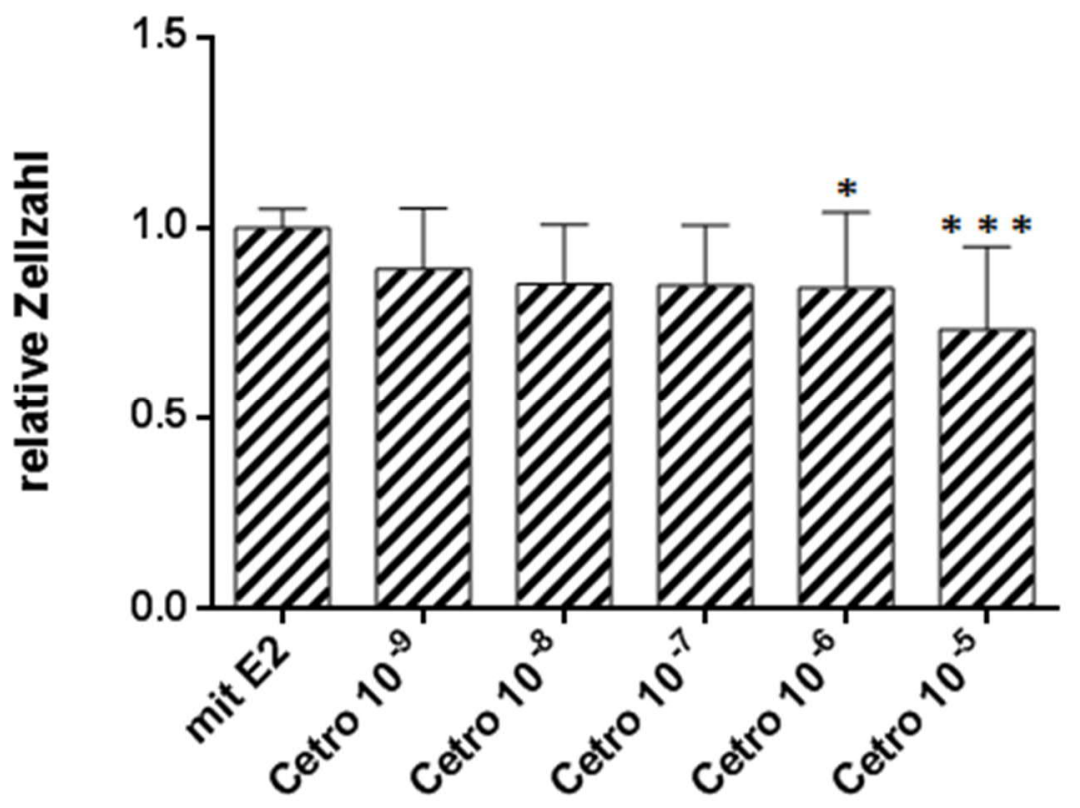

Abbildung 11: Einfluss des GnRH-I-Antagonisten Cetrorelix in verschiedenen Konzentrationen auf die relative Zellzahl von 17ß-Östradiol stimulierten Zellen der Zelllinie HCC70 Wirkung von Cetrorelix auf die relative Zellzahl der Zelllinie HCC70. Die konzentrationsabhängige Behandlung der triple negativen Zellen wurden über fünf Tage mit einer Konzentration von $10^{-9} \mathrm{M}$ bis $10^{-5} \mathrm{M}$ Cetrorelix durchgeführt. Eine signifikante Senkung der relativen Zellzahl ergab sich bei den Konzentrationen $10^{-6} \mathrm{M}$ und $10^{-5} \mathrm{M}$ Cetrorelix. Angegeben sind $\mathrm{MW} \pm \mathrm{SEM}$, die Daten wurden mittels One Way Analysis of Variance (ANOVA) auf Signifikanz überprüft. (*, $\mathrm{p}<0,05$ vs. mit $\mathrm{E}_{2}$; ***, $\mathrm{p}<0,001$ vs. mit $\mathrm{E}_{2}$ ), $\mathrm{n}=24$

\subsubsection{D-Lysin ${ }^{6}$ GnRH II}

Bei der Zelllinie HCC70 wurde durch Zugabe des GnRH-II-Agonist D-Lysin ${ }^{6}$ II GNRH in allen Konzentrationsstufen eine Hemmung der Zellproliferation, im Vergleich zur Kontrollgruppe beobachtet (Abb.12). 
Die Zellzahl wurde von 1,00 \pm 0,014 (Kontrolle), durch Zugabe von D-Lysin in einer Konzentration von $10^{-9} \mathrm{M}$ : auf $0,86 \pm 0,0486$, in einer Konzentration von $10^{-8} \mathrm{M}$ : auf 0,88 $\pm 0,0313$, in einer Konzentration von $10^{-7} \mathrm{M}$ : auf $0,93 \pm 0,0172$, in einer Konzentration von $10^{-6} \mathrm{M}$ : auf $0,87 \pm 0,042$ und in einer Konzentration von $10^{-5} \mathrm{M}$ : auf 0,92 $\pm 0,0328$ gesenkt.

Die Reduzierung der Zellzahl war in keinem Fall signifikant. Die stärkste Zellzahlreduktion wurde bei D-Lysin in einer Konzentration von $10^{-9} \mathrm{M}$ beobachtet.

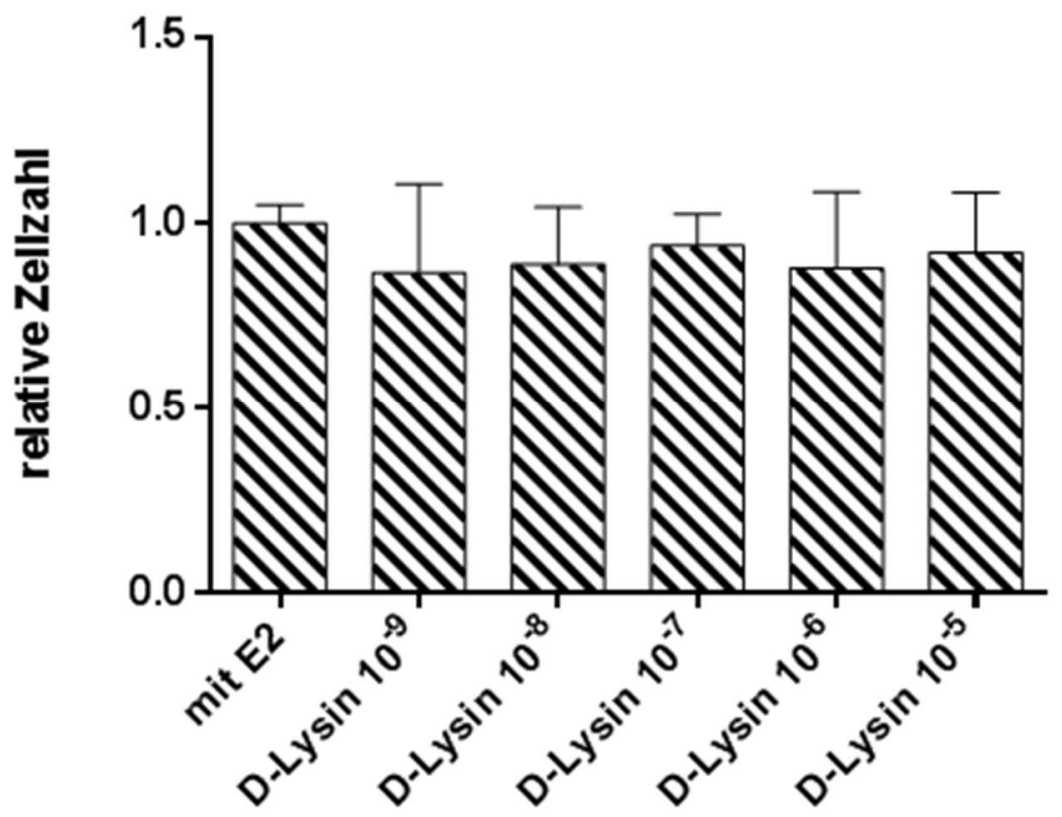

\section{Abbildung 12: Einfluss des GnRH-II-Agonisten D-Lysin in verschiedenen Konzentrationen auf die relative Zellzahl von 17ß-Östradiol stimulierten Zellen der Zelllinie HCC70}

Die Abb. 12 zeigt die Wirkung des GnRH-II-Agonisten D-Lysin ${ }^{6}$ GNRH II auf die relative Zellzahl der HCC70-Zellen bei gleichzeitiger Stimulation mit $10^{-8}$ M 17ß-Östradiol.

Die konzentrationsabhängige Behandlung der triple negativen Zellen wurde über fünf Tage mit einer Konzentration von $10^{-9} \mathrm{M}$ bis $10^{-5} \mathrm{M}$ D-Lysin ${ }^{6} \mathrm{GNRH}-\mathrm{II}$ durchgeführt. Die bei allen Konzentrationsstufen beobachtete Zellzahlreduktion war in keinem Fall signifikant. Angegeben sind MW \pm SEM, die Daten wurden mittels One Way Analysis of Variance (ANOVA) auf Signifikanz überprüft, $n=24$ 


\subsubsection{N4}

Bei der Zelllinie HCC70 wurde durch Zugabe des GnRH-II-Antagonist N4 in allen Konzentrationsstufen eine Hemmung der Zellproliferation, im Vergleich zur Kontrollgruppe beobachtet (Abb.13).

Die relative Zellzahl wurde von 1,00 \pm 0,06 (Kontrolle), durch N4 in einer Konzentration von $10^{-9} \mathrm{M}$ : auf $0,73 \pm 0,07$, in einer Konzentration von $10^{-8} \mathrm{M}$ : auf $0,71 \pm 0,06$, in einer Konzentration von $10^{-7} \mathrm{M}$ : auf $0,69 \pm 0,06\left(^{*}, \mathrm{p}<0,05\right)$, in einer Konzentration von $10^{-6} \mathrm{M}$ : auf $0,78 \pm 0,06$, in einer Konzentration von $10^{-5} \mathrm{M}$ : auf 0,72 $\pm 0,06$ gesenkt.

Eine signifikante Hemmung um $31 \%$ wurde bei N4 in der Konzentration $10^{-7} \mathrm{M}$ beobachtet.

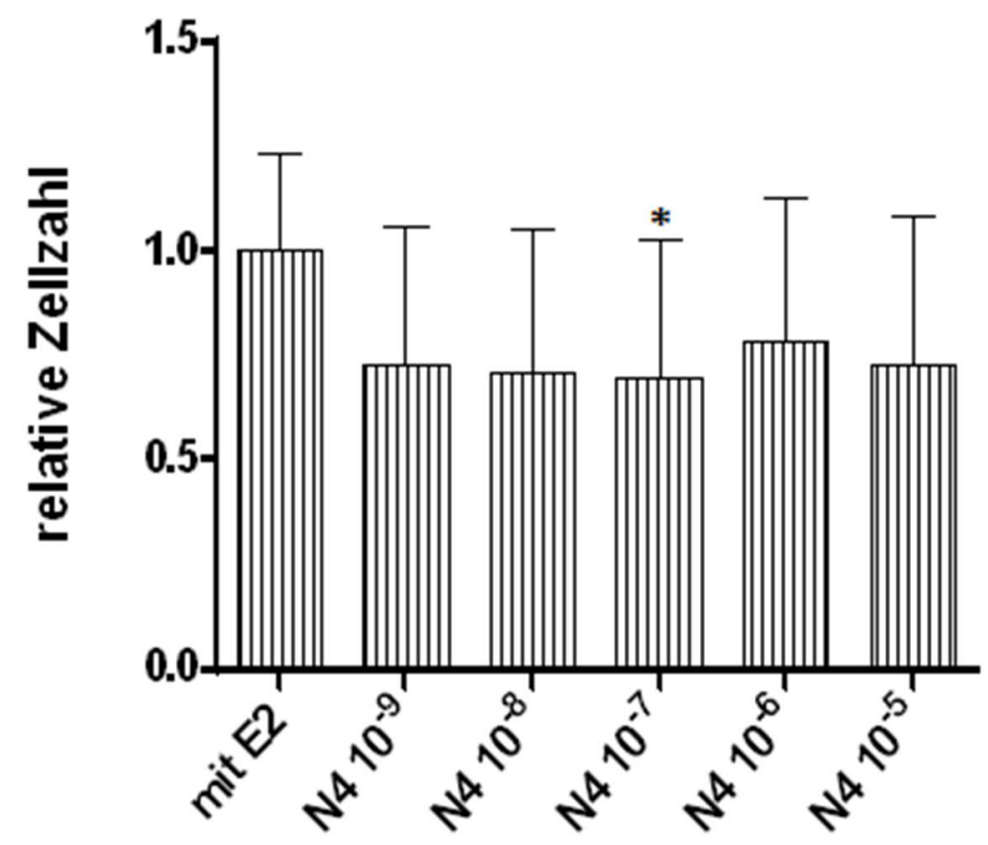

\section{Abbildung 13: Einfluss des GnRH-II-Antagonisten N4 in verschiedenen Konzentrationen auf die relative Zellzahl von 17ß-Östradiol stimulierten Zellen der Zelllinie HCC70}

Die Abb. 13 zeigt die konzentrationsabhängige Wirkung des GnRH-II-Antagonisten N4 auf die relative Zellzahl der HCC70-Zellen in Gegenwart von $10^{-8} \mathrm{M} \mathrm{E}_{2}$.

Die konzentrationsabhängige Behandlung der triple negativen Zellen wurden über fünf Tage mit einer Konzentration von $10^{-9} \mathrm{M}$ bis $10^{-5} \mathrm{M}$ N4 durchgeführt. Eine signifikante Hemmung konnte bei einer N4 Konzentration von $10^{-7} \mathrm{M}$ beobachtet werden. Angegeben sind $\mathrm{MW} \pm \mathrm{SEM}$, die Daten wurden mittels One Way Analysis of Variance (ANOVA) auf Signifikanz überprüft. (*, p<0,05 vs. mit $\left.\mathrm{E}_{2}\right), \mathrm{n}=24$ 


\subsubsection{Wirkung der GnRH-Analoga auf die relative Zellzahl der Zelllinie HCC1806}

\subsubsection{Triptorelin}

Bei der Zelllinie HCC1806 wurde durch den GnRH-I-Agonisten Triptorelin bei keiner der eingesetzten Konzentrationen ein hemmender Effekt auf die Proliferation beobachtet.

\subsubsection{Cetrorelix}

Bei der Zelllinie HCC1806 führte, im Vergleich zur Kontrollgruppe (1,00 \pm 0,043), die Behandlung mit dem GnRH-I-Antagonisten Cetrorelix nur in der Konzentration von $10^{-5} \mathrm{M}$ $\mathrm{zu}$ einer Senkung der relativen Zellzahl auf $(0,65 \pm 0,04)(* *, \mathrm{p}<0,01)($ Abb. 14).

Bei allen anderen Konzentrationsstufen kam es zu einer leichten Steigerung der relativen Zellzahl. Die Zugabe von Cetrorelix in der Konzentration $10^{-5} \mathrm{M}$ ergab eine signifikante Hemmung der Zellproliferation um 35\%.

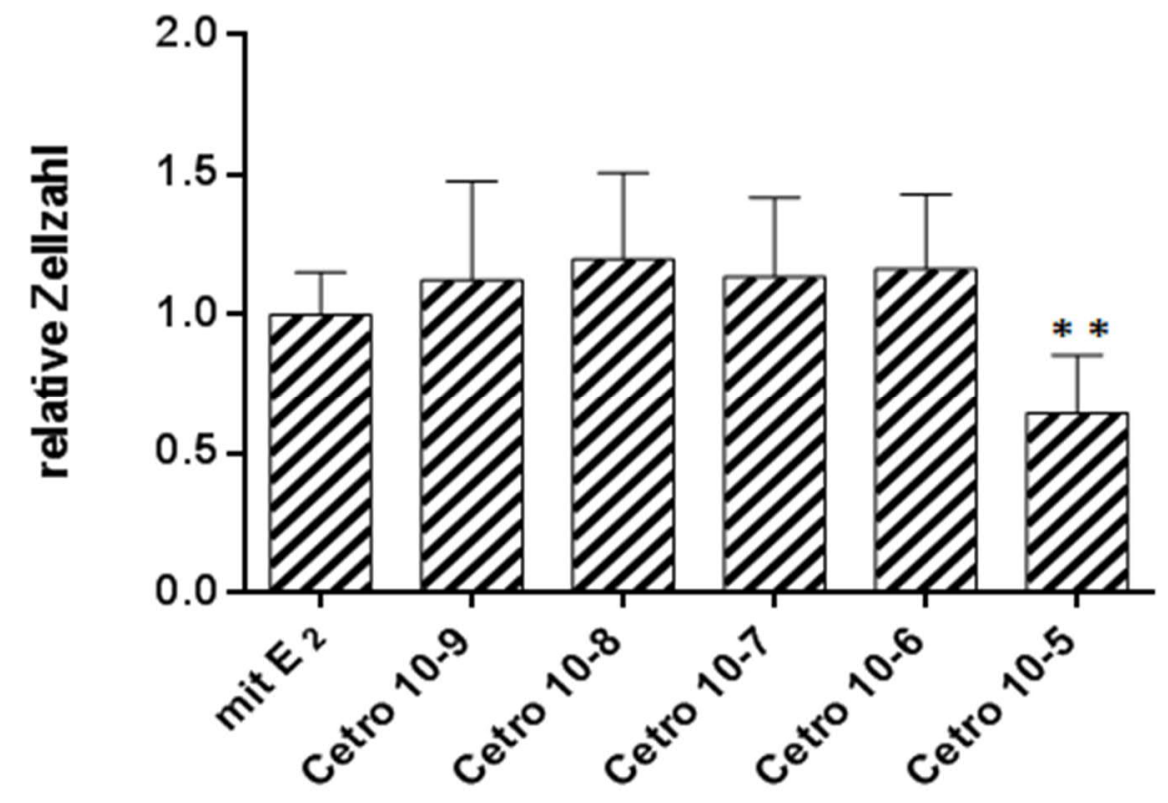

Abbildung 14: Einfluss des GnRH-I-Antagonisten Cetrorelix in verschiedenen Konzentrationen auf die relative Zellzahl von 17ß-Östradiol stimulierten Zellen der Zelllinie HCC1806 Wirkung von Cetrorelix auf die relative Zellzahl der Zelllinie HCC1806. Die konzentrationsabhängige Behandlung der triple negativen Zellen wurde über fünf Tage mit einer Konzentration von $10^{-9} \mathrm{M}$ bis $10^{-5} \mathrm{M}$ Cetrorelix durchgeführt. Eine signifikante Senkung der relativen Zellzahl ergab sich bei der Konzentration $10^{-5}$ M Cetrorelix. Angegeben sind MW \pm SEM, die Daten wurden mittels One Way Analysis of Variance (ANOVA) auf Signifikanz überprüft. (**, $\mathrm{p}<0,01$ vs. mit E2), $\mathrm{n}=16$ 


\subsubsection{D-Lysin ${ }^{6}$ GnRH II}

Bei der Zelllinie HCC1806 wurde durch die Zugabe des GnRH-II-Agonisten D-Lysin in keiner der Konzentrationsstufen eine Reduktion erreicht. Die Proliferationsrate wurde in geringem Maße gesteigert.

\subsubsection{N4}

Durch die Zugabe des GnRH-II-Antagonisten N4 wurde bei der Zelllinie HCC1806 in keiner Konzentration eine Reduktion der relativen Zellzahl erreicht. Die Proliferationsrate wurde in geringem Maße gesteigert.

\subsubsection{Zusammenfassung}

Das primäre Ziel der Versuche war es, herauszufinden, welches GnRH-Analogon bei welcher Zelllinie die größtmögliche Hemmung der durch 17ß-Östradiol ausgelösten Proliferationssteigerung bewirkt.

Unter Auswertung der Proliferationsrate nach fünf Tagen mittels Alarma Blue Assay zeigte sich, dass der GnRH-I-Antagonist Cetrorelix in der höchsten verwendeten Konzentration $\left(10^{-5} \mathrm{M}\right)$ bei drei der vier verwendeten Zelllinien eine Reduktion der relativen Zellzahl bewirkte. Bei den Zelllinien HCC70 und HCC1806 war die Hemmung signifikant. Bei der Zelllinie HCC70 konnte durch alle vier GnRH-Analoga eine Reduktion der Proliferation erreicht werden. Die höchste signifikante Reduktion bei dieser Zelllinie ergab sich jedoch durch Cetrorelix $10^{-5} \mathrm{M}$.

Bei den Zellen der Linie HCC1806 konnte lediglich durch Cetrorelix in der Konzentration $10^{-5} \mathrm{M}$ eine signifikante Senkung der Proliferation erzielt werden. Die Hemmung der Proliferation um 35\% war die maximal erreichbare Hemmung bei dieser Versuchsreihe. 


\subsubsection{Schlussfolgerung}

Bei den Zelllinien MDA-MB-435S und MDA-MB-453 war keine Reduktion der Zellproliferation, durch die verwendeten Substanzen nachweisbar. Diese Zelllinien wurden deshalb in den weiteren Versuchen nicht mehr verwendet. Bei der Zelllinie HCC1806 wurde durch Triptorelin, D-Lysin ${ }^{6}$ GnRH II und N4 keine Reduktion erreicht. Diese GnRHAnaloga wurden in den weiteren Versuchen deshalb nicht mehr verwendet. Da es nur mit dem GnRH-I-Antagonisten Cetrorelix, sowohl bei HCC70 als auch bei HCC1806 zu einer signifikanten Reduzierung der relativen Zellzahl kam, wurden die weiteren Versuche mit diesen beiden Zelllinien sowie dem GnRH-Antagonisten Cetrorelix (in einer Konzentration $10^{-5} \mathrm{M}$ ) durchgeführt.

Tabelle 16: Tabellarische Übersicht über die signifikanten Reduktionen der Proliferation der Zelllinien HCC70 und HCC1806

\begin{tabular}{|l|l|l|l|}
\hline \multicolumn{2}{|l|}{ HCC70 } & HCC1806 \\
\hline Triptorelin $10^{-6} \mathrm{M}$ & $19 \%$ & & \\
\hline $\mathrm{N} 4 \quad 10^{-7} \mathrm{M}$ & $31 \%$ & & \\
\hline Cetrorelix $10^{-5} \mathrm{M}$ & $27 \%$ & Cetrorelix $10^{-5} \mathrm{M}$ & $35 \%$ \\
\hline
\end{tabular}




\subsection{Wirkung des GnRH-I-Antagonisten Cetrorelix auf die GPR30-Expression bei den Zelllinien HCC70 und HCC1806}

Um zu untersuchen, ob es durch die Behandlung mit Cetrorelix zu einer Reduzierung der GPR30 Expression in TNBC-Zellen kommt wurden die Zellen der Zelllinien HCC70 und HCC1806 mit dem GnRH-I-Antagonisten Cetrorelix in den Konzentrationen $10^{-7} \mathrm{M}$, $10^{-6} \mathrm{M}$ und $10^{-5} \mathrm{M}$ für die Dauer von jeweils einem, zwei und vier Tagen inkubiert. Als Kontrolle diente eine nicht behandelte Zellpopulation. Die Expressionsrate des GPR30 wurde mittels Western Blot ermittelt. Als Ladekontrolle diente der Nachweis von GAPDH.

\subsubsection{Wirkung des GnRH-I-Antagonisten Cetrorelix auf die GPR30- Expression bei der Zelllinie HCC70}

\subsubsection{Darstellung der GPR30-Expression in Abhängigkeit von der} Cetrorelix-Konzentration

\subsubsection{1 nach $24 \mathrm{~h}$}

24 Stunden nach Zugabe von Cetrorelix zeigten sich folgende Ergebnisse:

Bei einer Konzentration von Cetrorelix $10^{-7} \mathrm{M}$ zeigte sich eine Erhöhung der GPR30Expression von 1,00 $\pm 0,0$ auf 1,16 $\pm 0,27$.

Bei einer Konzentration von Cetrorelix $10^{-6} \mathrm{M}$ ergab sich ein Rückgang der GPR30Expression von 1,00 $\pm 0,0$ auf 0,60 $\pm 0,37$ (n.s., im unpaired t-Test).

Bei einer Konzentration von Cetrorelix $10^{-5} \mathrm{M}$ kam es zu einer signifikante Senkung der GPR30-Expression von 1,00 $\pm 0,0$ auf 0,51 $\pm 0,09$ (**, $\mathrm{p}<0,01$, im unpaired $\mathrm{t}$-Test). 


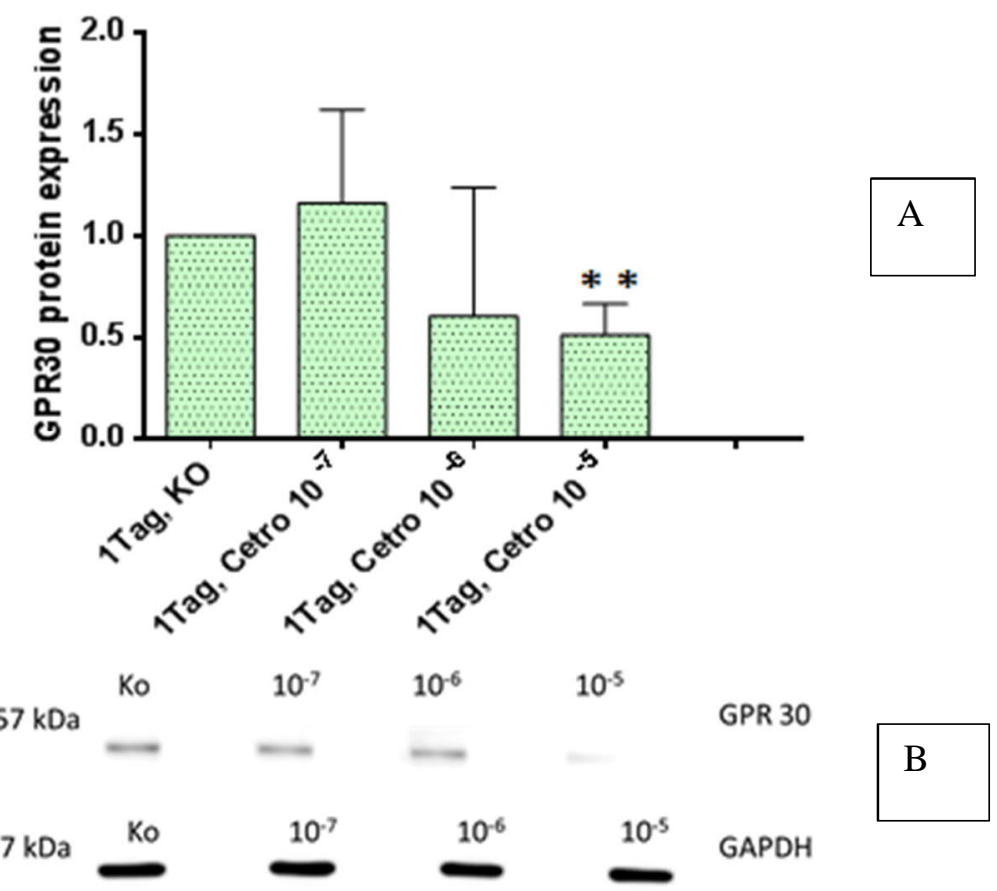

\section{Abbildung 15: Wirkung von Cetrorelix auf die GPR30-Expression in HCC70-Zellen nach $24 \mathrm{~h}$}

A: Darstellung der konzentrationsabhängigen Wirkung von Cetrorelix auf die GPR30Proteinexpression in HCC70-Zellen, nach $24 \mathrm{~h}$.

Bei der Zelllinie HCC70 zeigte sich nach 24 h eine konzentrationsabhängige Wirkung des Cetrorelix auf die Proteinexpression von GPR30, d.h. eine Abnahme der Expression bei steigender Dosis. Eine signifikante Senkung der GPR30-Expression ergab sich durch Cetrorelix in der Konzentration $10^{-5} \mathrm{M}$. Angegeben sind MW \pm SEM, die Daten wurden mittels t-Test (ungepaart) auf signifikante Unterschiede getestet. ${ }^{* *}, p<0,01$ vs. Ko), $\mathrm{n}=3$

B: Repräsentativer Blot für die konzentrationsabhängige Wirkung von Cetrorelix auf die GPR30Expression nach 24 Stunden Cetrorelix-Behandlung unter dem Kontrolllauf von GADPH

\subsubsection{2 nach $48 \mathrm{~h}$}

48 Stunden nach Zugabe von Cetrorelix zeigten sich folgende Ergebnisse:

Bei einer Konzentration von Cetrorelix $10^{-7} \mathrm{M}$ zeigte sich eine Erhöhung der GPR30Expression von $1,00 \pm 0,0$ auf 3,86 $\pm 2,06$.

Bei einer Konzentration von Cetrorelix $10^{-6} \mathrm{M}$ ergab sich eine Erhöhung der GPR30Expression von $1,00 \pm 0,0$ auf $1,31 \pm 0,42$.

Bei einer Konzentration von Cetrorelix $10^{-5} \mathrm{M}$ zeigte sich eine Senkung der GPR30Expression von $1,00 \pm 0,0$ auf $0,563 \pm 0,208$. 


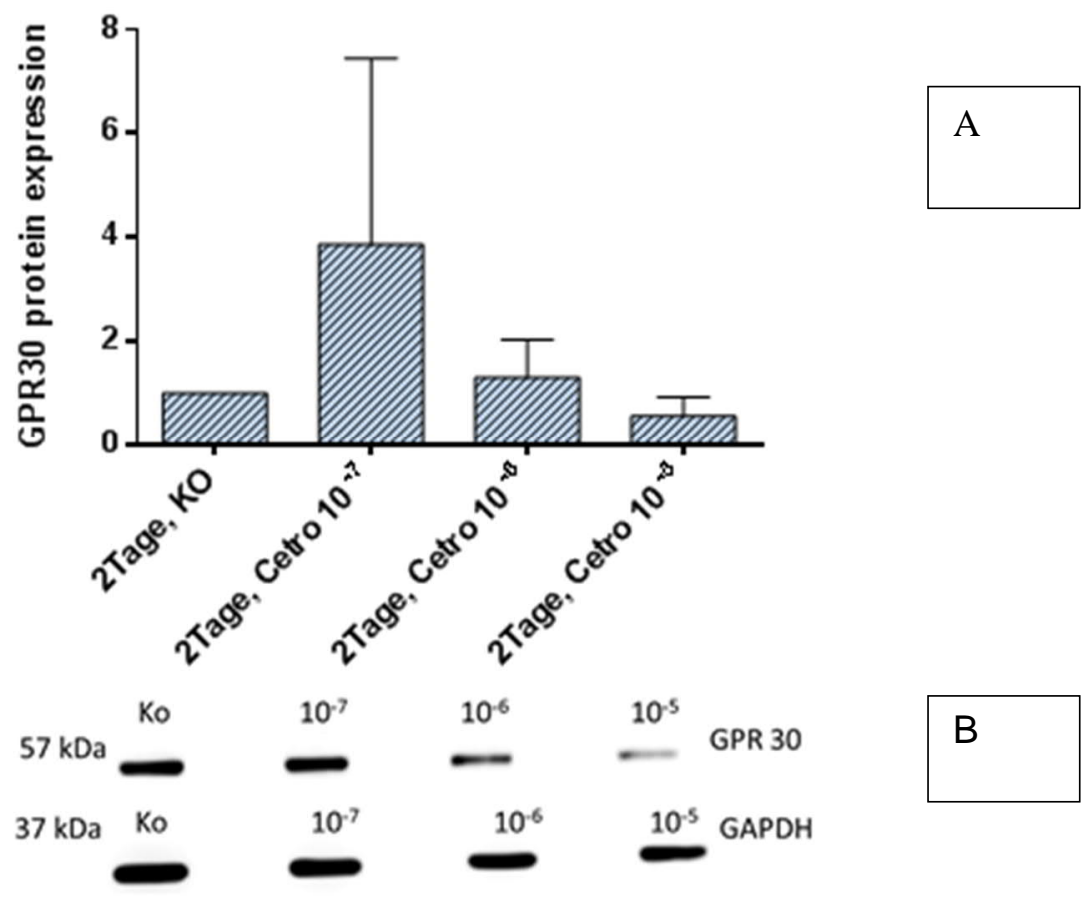

\section{Abbildung 16: Wirkung von Cetrorelix auf die GPR30-Expression in HCC70-Zellen nach 48 h}

A: Darstellung der konzentrationsabhängigen Wirkung von Cetrorelix auf die GPR 30 Proteinexpression in HCC70-Zellen, nach $48 \mathrm{~h}$

Eine Abnahme der GPR30-Expression zeigte sich $48 \mathrm{~h}$ nach Zugabe von Cetrorelix in der Konzentration $10^{-5} \mathrm{M}$. Bei den geringeren Dosierungen kommt es zu einem Anstieg der GPR30-Expression. Angegeben sind MW \pm SEM, die Daten wurden mittels t-Test (ungepaart) auf signifikante Unterschiede getestet. $\mathrm{n}=3$

B: Repräsentativer Blot für die konzentrationsabhängige Wirkung von Cetrorelix auf die GPR30Expression nach 48 h Cetrorelilx-Einwirkzeit unter dem Kontrolllauf von GADPH

\subsubsection{3 nach $96 \mathrm{~h}$}

96 Stunden nach Zugabe von Cetrorelix zeigte sich eine konzentrationsabhängige Wirkung des GnRH-I-Antagonisten Cetrorelix auf die Zellproliferation. Im Vergleich zur Kontrolle 1,00 \pm 0,0 sank die GPR30-Expression durch die Behandlung mit Cetrorelix $10^{-7} \mathrm{M}$ : auf $0,89 \pm 0,07$ (n.s), durch Cetrorelix $10^{-6} \mathrm{M}$ : auf 0,63 $\pm 0,10\left(^{*}, \mathrm{p}<0,05\right.$, im unpaired t-Test) und durch Cetrorelix $10^{-5} \mathrm{M}$ : auf 0,57 $\pm 0,21$ (n.s) 


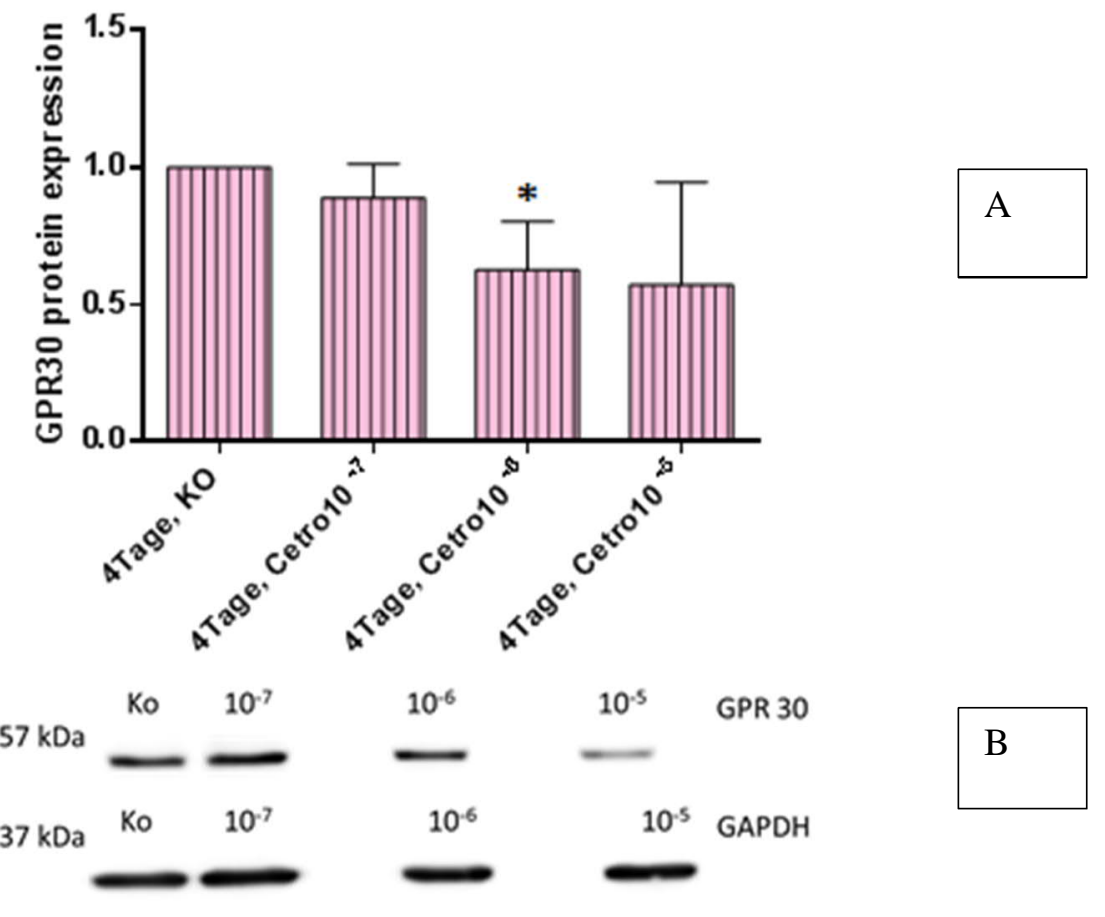

Abbildung 17: Wirkung von Cetrorelix auf die GPR30-Expression in HCC70-Zellen nach $96 \mathrm{~h}$

A: Darstellung der konzentrationsabhängigen Wirkung von Cetrorelix auf die GPR30Proteinexpression in HCC70-Zellen, nach 96 h. Eine eindeutige Konzentrationsabhängigkeit zeigt sich bei einer Einwirkzeit von 96 Stunden. Bei der Konzentration $10^{-6} \mathrm{M}$ zeigt sich eine signifikante Senkung. Angegeben sind MW \pm SEM, die Daten wurden mittels t-Test (ungepaart) auf signifikante Unterschiede getestet. (*, $\mathrm{p}<0,05$ vs. Ko), $\mathrm{n}=3$

B: Repräsentativer Blot für die konzentrationsabhängige Wirkung von Cetrorelix auf die GPR30Expression nach 96 h Cetrorelix-Einwirkzeit unter dem Kontrollauf von GADPH

\subsubsection{Darstellung der GPR30-Expression in Abhängigkeit von der Cetrorelix- Inkubationszeit}

Darstellung der unter 3.4.1.1 genannten Ergebnisse in Abhängigkeit von der CetrorelixEinwirkzeit.

\subsection{Cetrorelix $10^{-7} \mathrm{M}$}

Die Zellen wurden mit $10^{-7} \mathrm{M}$ Cetrorelix für jeweils einen, zwei und vier Tage behandelt. Als Kontrolle dienten Zellen, die für die genannten Zeiträume lediglich in Kulturmedium inkubiert wurden. 
Am Tag 1 und Tag 2 nach Zugabe von Cetrorelix zeigte sich ein Anstieg der GPR30Expression. Am Tag 4 zeigte sich ein Rückgang der GPR30-Expression von 1,00 $\pm 0,0$ (Kontrolle) auf 0,89 $\pm 0,070$ (n.s.) (Abb. 18).

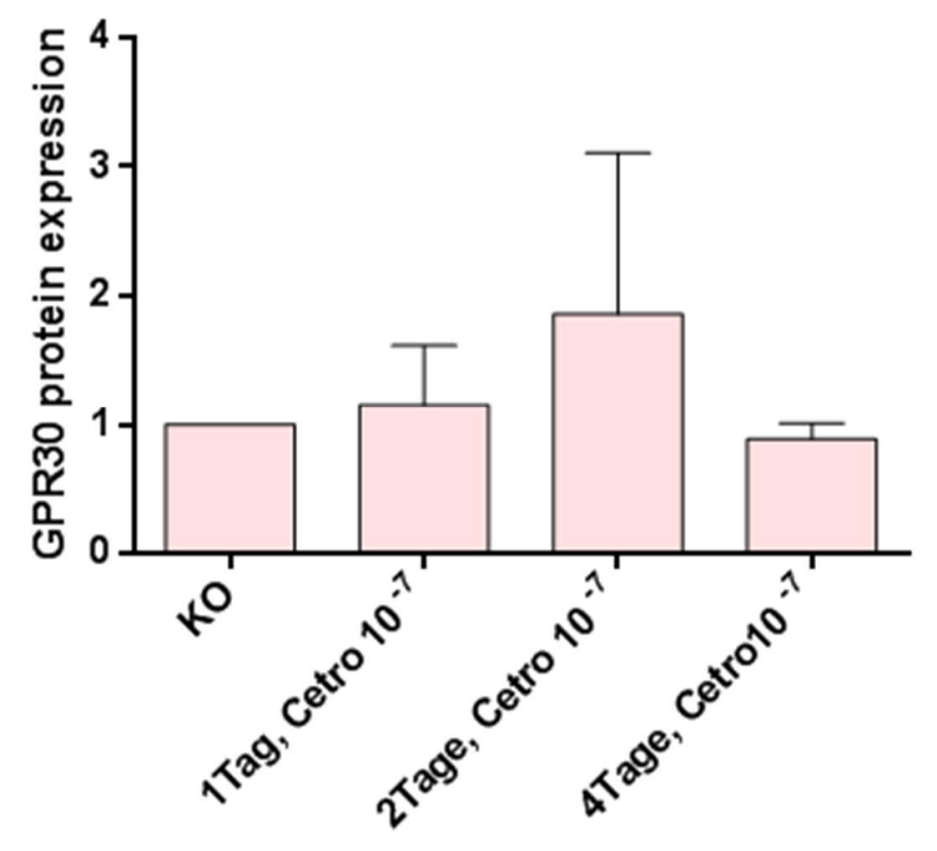

Abbildung 18: Darstellung der Wirkung von Cetrorelix $10^{-7} \mathrm{M}$ auf die GPR30-

\section{Proteinexpression in Abhängigkeit von der Inkubationszeit bei der Zelllinie HCC70}

Reduktion der GPR30-Expression nach einer Einwirkzeit von vier Tagen auf 89\%. Angegeben sind $\mathrm{MW} \pm \mathrm{SEM}$, die Daten wurden mittels One Way Analysis of Variance (ANOVA) auf signifikante Unterschiede geprüft. $n=3$

\subsection{Cetrorelix $10^{-6} \mathrm{M}$}

Bei einer Konzentration von $10^{-6}$ M Cetrorelix kommt es nach $24 \mathrm{~h}$ zu einer Senkung der GPR30-Expression. Nach 48 Stunden zeigt sich eine Erhöhung der Expressionsrate. Beide Ergebnisse sind aufgrund der hohen Standardabweichung nicht signifikant. Nach einer Einwirkzeit von vier Tagen zeigt sich eine, im t-Test signifikante Senkung der GPR30Proteinexpression von $1,00 \pm 0,0$ (Kontrolle) auf $0,626 \pm 0,101(*, p<0,05)$. 


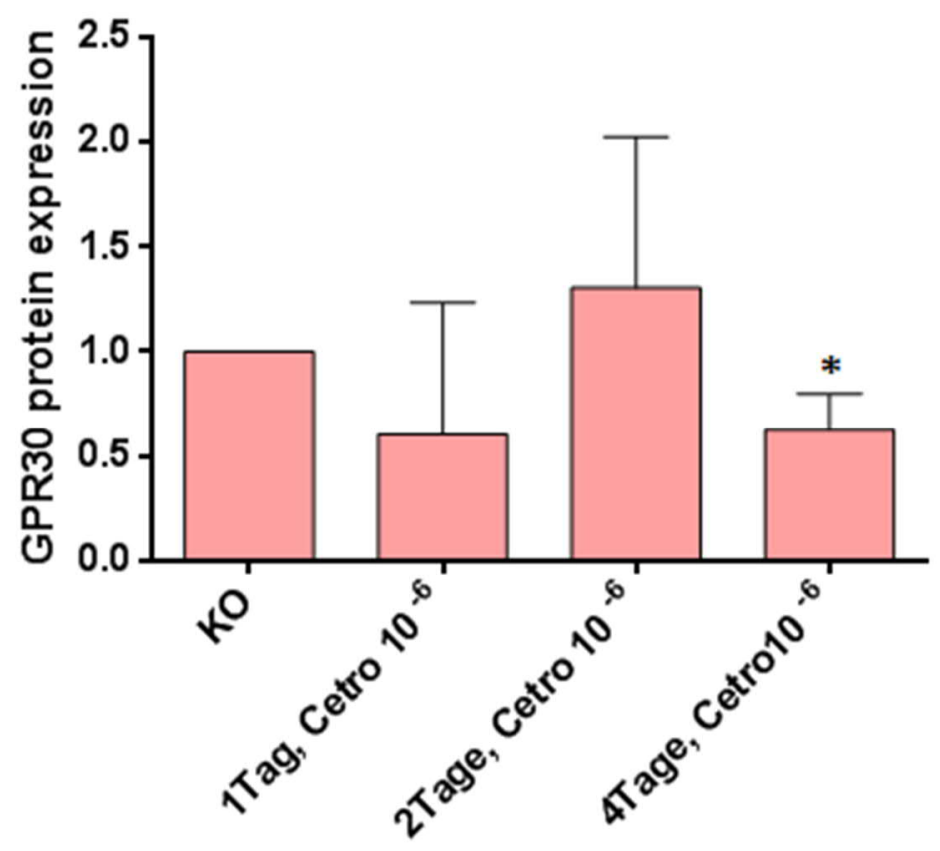

Abbildung 19: Darstellung der Wirkung von Cetrorelix $10^{-6} \mathrm{M}$ auf die GPR30-

Proteinexpression in Abhängigkeit von der Inkubationszeit bei der Zelllinie HCC70

Signifikante Reduktion der GPR30-Expression auf 62,6\% nach vier Tagen Inkubationszeit. Angegeben sind $\mathrm{MW} \pm \mathrm{SEM}$, die Daten wurden mittels t-Test (ungepaart) auf signifikante Unterschiede geprüft. (* $\mathrm{p}<0,05 \mathrm{vs}$. Ko), $\mathrm{n}=3$

\subsection{Cetrorelix $10^{-5} \mathrm{M}$}

Bei der Zugabe von $10^{-5}$ M Cetrorelix wurde, nach 24 h eine signifikante Senkung der GPR30-Expression von 1,00 $\pm 0,0$ (Kontrolle) auf 0,51 $\pm 0,087(* *, p<0,01$, im unpaired tTest) erreicht. $48 \mathrm{~h}$ nach der Zugabe sank die GPR30-Proteinexpression auf 0,563 $\pm 0,208$ (n.s, ANOVA) und nach $96 \mathrm{~h}$ auf 0,573 $\pm 0,214$ (n.s, ANOVA). 


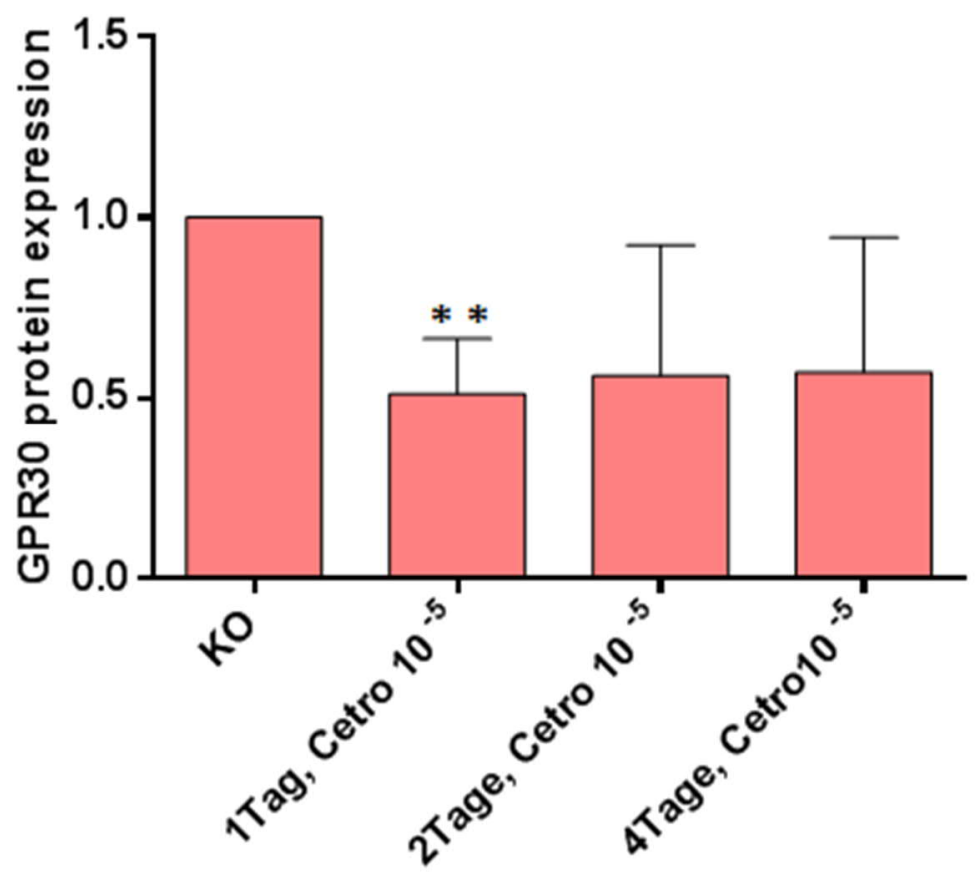

Abbildung 20: Darstellung der Wirkung von Cetrorelix $10^{-5} \mathrm{M}$ auf die GPR30Proteinexpression in Abhängigkeit von der Inkubationszeit bei der Zelllinie HCC70

Signifikante Reduktion der GPR30-Expression nach 24 h Einwirkdauer. Angegeben sind MW \pm SEM, die Daten wurden mittels One Way Analysis of Variance (ANOVA) auf signifikante Unterschiede geprüft. ( $* *$ p $<0,01$ vs. Ko), $\mathrm{n}=3$

\subsubsection{Wirkung des GnRH-I-Antagonisten Cetrorelix auf die GPR30-} Expression bei der Zelllinie HCC1806

\subsubsection{Darstellung der GPR30-Expression in Abhängigkeit von der Cetrorelix-Konzentration}

\subsubsection{1 nach $24 \mathrm{~h}$}

Bei der Zelllinie HCC1806 zeigten sich 24 Stunden nach Zugabe von Cetrorelix folgende Ergebnisse:

Bei einer Konzentration von Cetrorelix $10^{-7} \mathrm{M}$ ergab sich eine signifikante Senkung der GPR30-Expression von $1,00 \pm 0,0$ auf $0,78 \pm 0,06$ (* $\mathrm{p}<0,05$, im unpaired t-Test). Bei einer Konzentration von Cetrorelix $10^{-6} \mathrm{M}$ zeigte sich eine signifikante Hemmung der GPR30-Expression von $1,00 \pm 0,0$ auf $0,55 \pm 0,11\left(^{*} \mathrm{p}<0,05\right.$, im unpaired $\mathrm{t}$-Test). Bei einer Konzentration von Cetrorelix $10^{-5} \mathrm{M}$ kam es zu einem signifikanten Rückgang der GPR30-Expression von 1,00 $\pm 0,0$ auf 0,38 $\pm 0,20$ (* $\mathrm{p}<0,05$, im One- way ANOVA). 


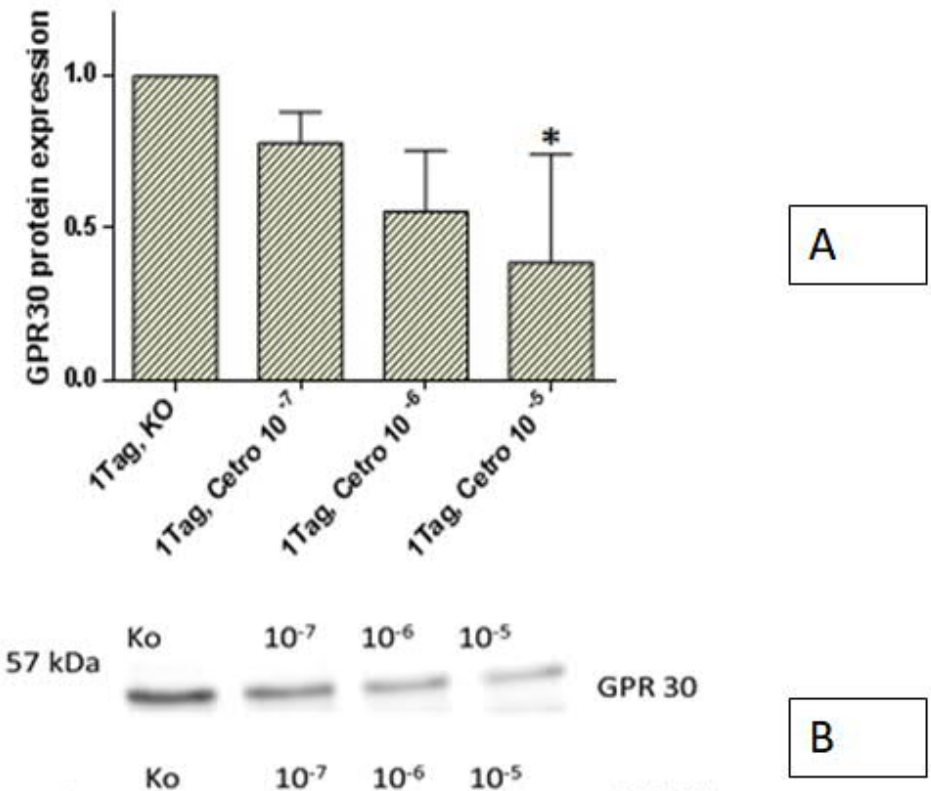

Abbildung 21: Wirkung von Cetrorelix auf die GPR30-Expression in HCC1806-Zellen nach 24 h

A: Darstellung der konzentrationsabhängigen Wirkung von Cetrorelix auf die GPR30Proteinexpression in HCC1806-Zellen, nach $24 \mathrm{~h}$.

Bei der Zelllinie HCC1806 zeigte sich nach einer Einwirkzeit von 24 h eine deutliche Konzentrationsabhängigkeit der GPR30-Expression. Im One- way ANOVA stellte sich eine signifikante Senkung auf 30\% durch $10^{-5} \mathrm{M}$ Cetrorelix $(* \mathrm{p}<0,05)$ dar. Im unpaired t-Test erwiesen sich auch die Reduzierungen durch $10^{-7} \mathrm{M}$ und $10^{-6} \mathrm{M}$ als signifikant $(* \mathrm{p}<0,05)$. Diese Signifikanzen wurden in der Grafik nicht abgebildet. Angegeben sind MW \pm SEM, die Daten wurden mittels One Way Analysis of Variance (Anova) auf signifikante Unterschiede getestet. (*, $\mathrm{p}<0,05$ vs. Ko), $\mathrm{n}=3$

B: Repräsentativer Blot für die konzentrationsabhängige Wirkung von Cetrorelix auf die GPR30Expression nach $24 \mathrm{~h}$ Cetrorelix-Einwirkzeit unter dem Kontrolllauf von GAPDH

\subsubsection{2 nach $48 \mathrm{~h}$}

48 Stunden nach Zugabe von Cetrorelix zeigten sich folgende Ergebnisse:

Bei Cetrorelix $10^{-7} \mathrm{M}$ und Cetrorelix $10^{-6} \mathrm{M}$ kam es zu einer Steigerung der GPR30Expression. Bei Cetrorelix $10^{-5} \mathrm{M}$ ergab sich eine Hemmung der GPR30-Expression von $1,00 \pm 0,0$ auf $0,77 \pm 0,22$ (n.s). 


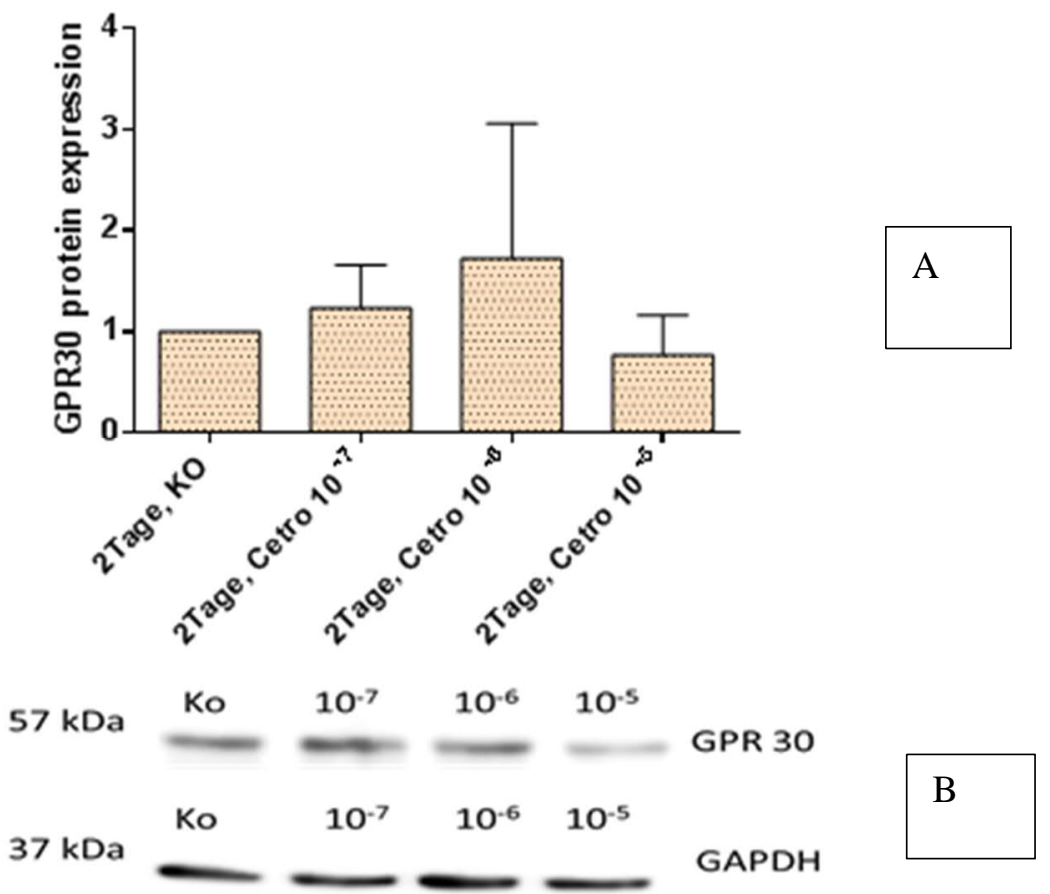

Abbildung 22: Wirkung von Cetrorelix auf die GPR30-Expression in HCC1806-Zellen nach $48 \mathrm{~h}$

A: Darstellung der konzentrationsabhängigen Wirkung von Cetrorelix auf die GPR30Proteinexpression in HCC1806-Zellen, nach 48 h. Bei der Behandlung mit Cetrorelix $10^{-5} \mathrm{M}$ sank die GPR30-Expression gegenüber der Kontrolle auf 77\% (n.s.). Angegeben sind MW \pm SEM, die Daten wurden mittels One Way Analysis of Variance (Anova) auf signifikante Unterschiede getestet. $\mathrm{n}=3$

B: Repräsentativer Blot für die Konzentrationsabhängige Reduktion der GPR30-Expression nach 48 h Cetrorelix-Einwirkzeit unter dem Kontrolllauf von GAPDH

\subsubsection{3 nach $96 \mathrm{~h}$}

96 Stunden nach Zugabe von Cetrorelix zeigten sich folgende Ergebnisse: Bei einer Konzentration von Cetrorelix $10^{-7} \mathrm{M}$ zeigte sich eine signifikante Senkung der GPR30-Expression von $1,00 \pm 0,0$ auf 0,62 $\pm 0,11(* \mathrm{p}<0,05$, im One- way ANOVA). Bei einer Konzentration von Cetrorelix $10^{-6} \mathrm{M}$ ergab sich ein signifikanter Rückgang der GPR30-Expression von 1,00 $\pm 0,0$ auf 0,68 $\pm 0,09$ (* $\mathrm{p}<0,05$, im One- way ANOVA). Bei einer Konzentration von Cetrorelix $10^{-5} \mathrm{M}$ zeigte sich eine hoch signifikante Hemmung der GPR30-Expression von $1,00 \pm 0,0$ auf $0,36 \pm 0,03$ (** $\mathrm{p}<0,0$, im One- way ANOVA). 


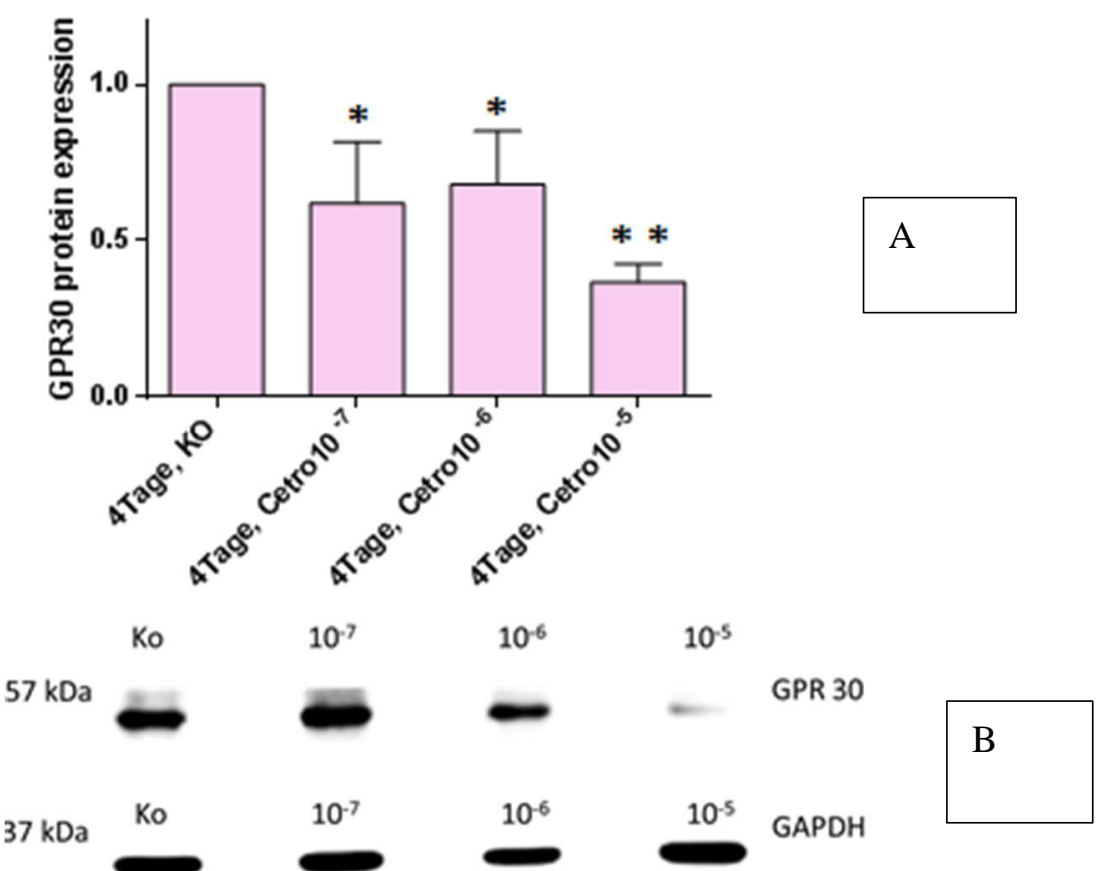

Abbildung 23: Wirkung von Cetrorelix auf die GPR30-Expression in HCC1806-Zellen nach $96 \mathrm{~h}$

A: Darstellung der konzentrationsabhängigen Wirkung von Cetrorelix auf die GPR30Proteinexpression in HCC1806-Zellen, nach 96 h. Bei einer Konzentration von $10^{-7} \mathrm{M}$ sank die GPR30Expression signifikant auf $62 \%(* \mathrm{p}<0,05)$. Cetrorelix in einer Konzentration von $10^{-6} \mathrm{M}$ senkte die Expression signifikant auf $68 \%(* \mathrm{p}<0,05)$. Cetrorelix $10^{-5} \mathrm{M}$ reduzierte die GPR30-Expression hoch signifikant auf $36 \%(* * \mathrm{p}<0,01)$. Angegeben sind MW \pm SEM, die Daten wurden mittels One Way Analysis of Variance (Anova) auf signifikante Unterschiede getestet. (*, $\mathrm{p}<0,05$ vs. Ko; ${ }^{* *}, \mathrm{p}<0,01$ vs. Ko), $\mathrm{n}=3$

B: Repräsentativer Blot für die Konzentrationsabhängige Reduktion der GPR30-Expression nach 96 h Cetrorelix-Einwirkzeit unter dem Kontrolllauf von GAPDH

\subsubsection{Darstellung der GPR30-Expression in Abhängigkeit von der Cetrorelix-Inkubationszeit}

Darstellung, der unter 3.4.2.1 genannten Ergebnisse in Abhängigkeit von der Einwirkzeit.

\subsection{Cetrorelix $10^{-7} \mathrm{M}$}

Bei der Zugabe von $10^{-7} \mathrm{M}$ wurde, nach $24 \mathrm{~h}$ eine signifikante Senkung der GPR30Expression von $1,00 \pm 0,00$ (Kontrolle) auf 0,78 $\pm 0,06\left(^{*}, \mathrm{p}<0,05\right.$, im unpaired t-Test) erreicht. 48 h nach Zugabe stieg die GPR30-Proteinexpression an. Nach 96 h kam es zur signifikanten Reduktion der GPR30-Expression auf 0,62 $\pm 0,11(*, \mathrm{p}<0,05$, im One-way ANOVA). 


\subsection{Cetrorelix $10^{-6} \mathrm{M}$}

24 Stunden nach Zugabe von Cetrorelix $10^{-6} \mathrm{M}$ sank die GPR30-Proteinexpression auf $0,55 \pm 0,11\left(^{*}, \mathrm{p}<0,05\right.$, im unpaired t-Test). $48 \mathrm{~h}$ nach der Zugabe stieg die GPR30Proteinexpression an. Nach 96 h konnte eine signifikante Hemmung GPR30-Expression auf 0,68 $\pm 0,09(*, p<0,05$, im One- way ANOVA) erreicht werden.

\subsection{Cetrorelix $10^{-5} \mathrm{M}$}

96 Stunden nach Zugabe von Cetrorelix zeigten sich folgende Ergebnisse:

Bei Zugabe von $10^{-5} \mathrm{M}$ Cetrorelix wurde nach $24 \mathrm{~h}$ eine signifikante Senkung der GPR30Expression von $1,00 \pm 0,00$ (Kontrolle) auf 0,38 $\pm 0,20(*, p<0,05$, im One-way ANOVA) beobachtet.

$48 \mathrm{~h}$ nach Zugabe sank die Expression von 1,00 \pm 0,00 (Kontrolle) auf 0,77 \pm 0,22 (n.s.). Nach 96 h konnte die GPR30-Expression von 1,00 $\pm 0,00$ (Kontrolle) auf 0,36 \pm 0,033 $(* \mathrm{p}<0,05$, im One-way ANOVA) erreicht werden.

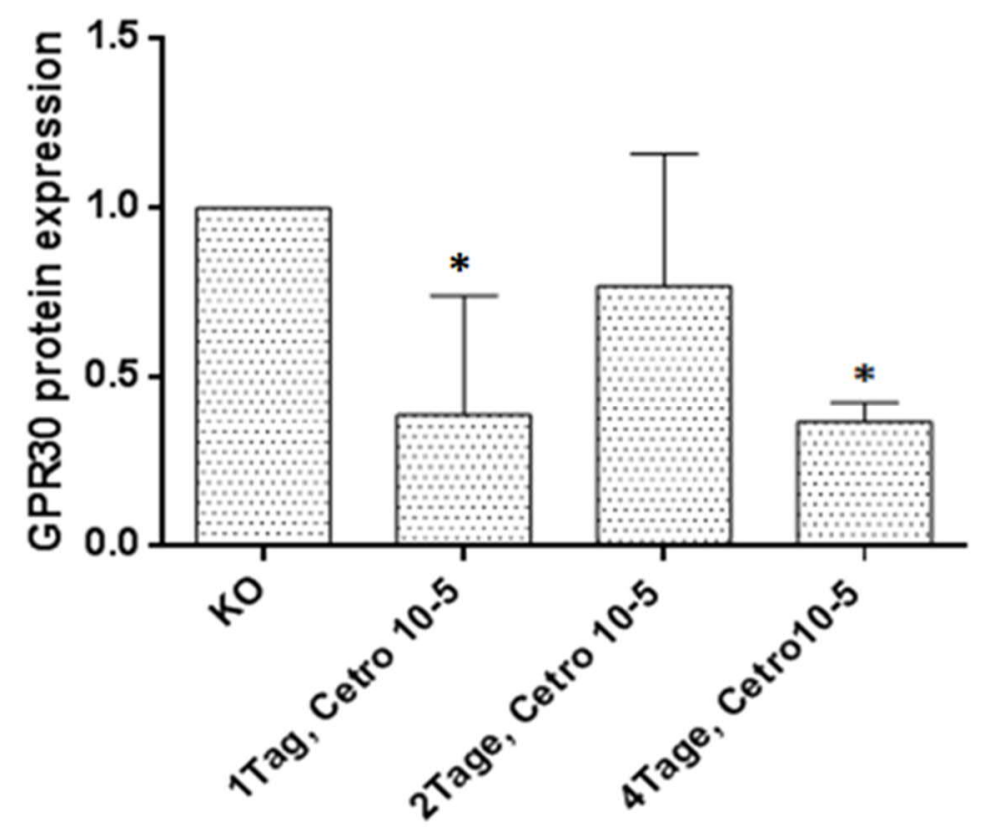

Abbildung 24: Darstellung der Wirkung von Cetrorelix $10^{-5} \mathrm{M}$ auf die GPR30Proteinexpression in Abhängigkeit von der Inkubationszeit bei der Zelllinie HCC1806

Signifikante Reduktion der GPR30-Expression durch Cetrorelix $10^{-5} \mathrm{M}$ nach $24 \mathrm{~h}$ und nach $96 \mathrm{~h}$. Die Reduktion der GPR30-Expression nach $48 \mathrm{~h}$ zeigte sich nicht signifikant. Angegeben sind MW \pm SEM, die Daten wurden mittels One Way Analysis of Variance (ANOVA) auf signifikante Unterschiede geprüft. (* $\mathrm{p}<0,05$ vs. Ko), $\mathrm{n}=3$ 


\subsubsection{Zusammenfassung}

Zusammenfassend kann man bei der Wirkung von Cetrorelix auf die GPR30-Expression in HCC70 und HCC1806 Mammakarzinomzellen Folgendes beobachten:

In Abhängigkeit von der einwirkenden Konzentration des GnRH-I-Antagonisten Cetrorelix kommt es, nach 24 Stunden, bei den HCC1806 zu einer konzentrationsabhängigen Reduktion der GPR30-Expression zwischen 78\% (in der niedrigsten Konzentration) und 38\% (in der höchsten Konzentration). Bei den HCC70 zeigt sich, nach 24 h, ein ähnliches Ergebnis bei der mittleren und höchsten Konzentration des Cetrorelix (Rückgang auf 60\% und $51 \%)$. Bei der niedrigsten Konzentration kam es, nach 24 h, zu einem leichten Anstieg der GPR30-Expression. Bei beiden Zelllinien kommt es nach $48 \mathrm{~h}$ Einwirkzeit bei der niedrigsten und mittleren Konzentrationsstufe zu einem deutlichen Anstieg der GPR30Expression. Nur in der Höchstdosierung von $10^{-5} \mathrm{M}$ kommt es zu einer Reduktion auf 77\% (HCC1806) und 56\% (HCC70). Nach $96 \mathrm{~h}$ kam es bei beiden Zelllinien zu einer konzentrationsabhängigen Hemmung der GPR30-Expression. Eine Gesamtübersicht der Ergebnisse zur Senkung der GPR30-Expression zeigt die Tabelle 17.

In Abhängigkeit von der einwirkenden Zeit des GnRH-I-Antagonisten Cetrorelix kommt es bei der niedrigsten Konzentration von $10^{-7} \mathrm{M}$ nach $24 \mathrm{~h}$ zunächst zu einer geringen Hemmung (HCC1806) bzw. zu einem leichten Anstieg (HCC70) der GPR30-Expression. Nach $48 \mathrm{~h}$ kommt es zu einem deutlichen Anstieg und nach $96 \mathrm{~h}$ zu einem deutlichen Abfall der GPR30-Expression in beiden Zelllinien. Bei der Konzentration von $10^{-6} \mathrm{M}$ zeigt sich bei beiden Zelllinien das gleiche Ergebnis: nach 24h ein Rückgang, nach 48h ein Anstieg und nach 96 h ein erneuter Rückgang der GPR30-Expression. Bei einer Cetrorelix- Konzentration von $10^{-5} \mathrm{M}$ kommt es beiden Zelllinien bei jeder Einwirkdauer ( $24 \mathrm{~h}, 48 \mathrm{~h}$ und $96 \mathrm{~h}$ ) zu einer Hemmung der GPR30-Expression. Nach $96 \mathrm{~h}$ Inkubationszeit wurde bei der Zelllinien HCC1806 eine Reduktion auf 36\% und bei der Zelllinie HCC70 auf 57\% erreicht (Tab.17). 
Tabelle 17: Gesamtübersicht der Ergebnisse zur Senkung der GPR30-Proteinexpression

\begin{tabular}{|l|l|l|l|l|}
\hline & Tage & Cetro $10^{-7} \mathrm{M}$ & Cetro $10^{-6} \mathrm{M}$ & Cetro10 $0^{-5} \mathrm{M}$ \\
\hline HCC1806 & 1 & $0,78 \pm 0,06(78 \%)$ & $0,55 \pm 0,11(55 \%)$ & $0,38 \pm 0,20(38 \%)$ \\
\hline & 2 & $1,23 \pm 0,25(123 \%)$ & $1,72 \pm 0,77(172 \%)$ & $0,77 \pm 0,22(77 \%)$ \\
\hline & 4 & $0,62 \pm 0,11(62 \%)$ & $0,68 \pm 0,09(68 \%)$ & $0,36 \pm 0,03(36 \%)$ \\
\hline HCC70 & 1 & $1,16 \pm 0,27(116 \%)$ & $0,60 \pm 0,36(60 \%)$ & $0,51 \pm 0,09(51 \%)$ \\
\hline & 2 & $3,86 \pm 2,06(386 \%)$ & $1,31 \pm 0,42(131 \%)$ & $0,56 \pm 0,20(56 \%)$ \\
\hline & 4 & $0,89 \pm 0,07(89 \%)$ & $0,63 \pm 0,10(63 \%)$ & $0,57 \pm 0,21(57 \%)$ \\
\hline
\end{tabular}

(Angegeben sind die MW $\pm \mathrm{SEM}$, sowie Prozent-Werte in Klammern) 


\subsection{Zusammenfassung der Ergebnisse}

Das primäre Ziel der Versuche war, herauszufinden, welches der GnRH-Analoga bei welcher Zelllinie die größtmögliche Hemmung der durch 17ß-Östradiol ausgelösten Proliferationssteigerung bewirkt und inwieweit sich die GPR30-Expression unter Behandlung mit GnRH-Analoga verändert.

Bei der Zelllinie HCC70 konnte durch alle vier GnRH-Analoga eine Reduktion der Proliferation erreicht werden. Die höchste signifikante Reduktion bei dieser Zelllinie ergab sich durch Cetrorelix $10^{-5} \mathrm{M}$.

Bei den Zellen der Linie HCC1806 konnte lediglich durch Cetrorelix in der Konzentration $10^{-5} \mathrm{M}$ eine signifikante Senkung der Proliferation erzielt werden. Diese Reduktion war mit $35 \%$ unter allen durchgeführten Versuchen die größtmöglich zu erreichende Hemmung. 


\section{Diskussion}

Die heterogene Gruppe von triple negativen Mammakarzinomen besitzt weder einen Östrogenrezeptor $\alpha(\mathrm{ER} \alpha)$, noch einen Progesteronrezeptor (PR) und exprimiert auch den humanen epidermalen Wachstumsrezeptor 2 (HER-2) nicht. Aufgrund dieses negativen Rezeptorstatus sind diese Karzinome weder einer antihormonellen noch einer speziellen Therapie mit Trastuzumab (Herzeptin) zugänglich.

Das klinische Outcome für diese Patienten ist immer noch schlecht. Bis auf eine Chemotherapie mit zytotoxischen platinhaltigen Substanzen gibt es aktuell keine spezifische Behandlungsmöglichkeit.

Seit Jahren versucht man, andere Therapiemöglichkeiten zu finden. Unter anderem wurden folgende Optionen getestet:

Zum einen wurde das DNA-Reparationsenzym Poly-ADP Ribose Polymerase (PARP) als vielversprechende Zielstruktur in der Therapie des TNBC entdeckt. PARP Inhibitoren, wie Talazoperib werden angewendet, wenn aufgrund einer BRCA1 Mutation eine gestörte DNA-Reparatur vorliegt.

Bei Überexpression des EGF 1-Rezeptors in triple negativen Mammakarzinomzellen kann ein spezifischer EGF-Rezeptor Antikörper (Cetuximab) angewendet werden (Baselga et al. 2013; Carey et al. 2012).

Mit der Möglichkeit, die GPR30-Rezeptor Expression zu senken, wurde ein weiterer Weg entdeckt, die Zellproliferation zu hemmen. Forschungen ergaben, dass die Hemmung der Zellproliferation durch eine direkte Inhibierung des GPR30-Rezeptors sowohl durch Estriol (Girgert et al. 2014; Lappano et al. 2010) als auch durch eine GPR30 spezifische siRNA (Girgert et al. 2012) möglich ist. Aufgrund der Undurchführbarkeit der Therapie mit einer siRNA in vivo wurde nach Möglichkeiten gesucht, den GPR30-Rezeptor indirekt zu hemmen. Zurzeit sind zwei unterschiedliche Wege der Hemmung bekannt, die auf der gegenseitigen Einflussnahme zwischen dem GPR30- und dem EGF-Rezeptor beruhen.

Einerseits besteht die Möglichkeit, den GPR30-Rezeptor über die Hemmung des EGF1Rezeptors zu inhibieren. Der EGF1-Rezeptor wird, im Gegensatz zum EGF2-Rezeptor = HER2-Rezeptor, in triple negativen Mammakarzinomzellen häufig überexprimiert (Nielsen et al. 2004; Reis-Filho und Tutt 2008). Die Inhibierung dieses Rezeptors erfolgt entweder 
durch einen spezifischen Antikörper (Cetuximab) (EMA 2020, Erbitux) oder durch den Tyrosinkinaseinhibitor (Gefitinib) (Girgert et al. 2017), welcher an die Tyrosinkinaseeinheit des EGF1-Rezeptors bindet und ihn dadurch blockiert.

Andererseits kann, wie in der vorliegenden Arbeit beschrieben, der GPR30-Rezeptor auch durch GnRH-Analoga indirekt gehemmt werden. Durch Bindung an den GnRH-Rezeptor erfolgt die Aktivierung der PTP. Diese inhibiert den EGF-1 Rezeptor (Emons et al. 1997; Gründker et al. 2001). Dies führt zur Senkung der Zellproliferationsrate und auch zur Downregulation von GPR30.

GnRH-Rezeptoren wurden in allen Zelllinien, die in dieser Arbeit verwendet wurden nachgewiesen (Buchholz et al. 2009; Föst et al. 2011; Schubert et al. 2008).

\subsection{Die Beeinflussung der Proliferationsraten von vier TNBC- Zellpopulationen durch verschiedene Konzentrationen von 17ß-Östradiol $\left(\mathbf{E}_{2}\right)$}

Unter dem Einfluss von 17ß-Östradiol kam es zu Zellproliferationssteigerungen aller vier TNBC-Zelllinien. Der größte Effekt wurde bei einer Konzentration von $10^{-8} \mathrm{M}$ erreicht. Höhere Östradiolkonzentrationen führten zu keiner weiteren Proliferationssteigerung bzw. zu einer Abnahme der Proliferationsrate. Eine mögliche Erklärung dafür wäre eine Sättigung der GPR30-Rezeptorbindungsstellen.

Trotz Fehlens des Östrogen $\alpha$ Rezeptors ist eine Stimulation mit 17ß-Östradiol möglich. Sie verläuft über den nichtgenomischen Weg, über die Bindung des 17ß-Östradiols an den GPR30-Rezeptor (Filardo et al. 2000; Revankar et al. 2005). Auch Girgert et al. (2012; 2014) untersuchte die Proliferationssteigerung von triple negativen Zellen unter 17ßÖstradioleinfluss, und kam zu ähnlichen Ergebnissen. Es kam bei diesen Untersuchungen zu unterschiedlich starken Proliferationsraten, bei verschiedenen Zelllinien. Die Autoren führten dieses Ergebnis auf eine unterschiedliche Expressionsstärke von GPR30Rezeptoren zurück. 


\subsection{Vergleich der Wachstumsraten von $\mathrm{E}_{2}$-stimulierten und nicht $\mathbf{E}_{2}$ - stimulierten TNBC-Zellen (zwei verschiedene Zellpopulationen) unter Reduzierung des FCS-Gehaltes}

Es wurde untersucht, ob die, durch Stimulation mit 17 $\beta$-Östradiol hervorgerufene Proliferationssteigerung, weiter gesteigert werden kann. Dieser Effekt sollte durch Optimierung des Nährmediums erreicht werden. Die Reduktion der Konzentration von gestripptem FCS (,Aktivkohle gefiltertes FCS“) sollte den Einfluss von darin eventuell noch vorhandenen Steroidhormonen (die den GPR30-Rezeptor unspezifisch besetzen) minimieren. Dennoch sollte die Konzentration des gestrippten FCS, eine bestimmte Mindestmenge nicht unterschreiten, um die Lebensfähigkeit der Zellen (Viability) nicht negativ zu beeinflussen.

Unter Reduzierung des FCS Gehaltes kam es zu keiner zusätzlichen Proliferationssteigerung von $\mathrm{E}_{2}$-stimulierten und nicht stimulierten TNBC-Zellen der Zelllinien HCC70 und 1806. Da keine Verbesserung durch die Reduzierung von FCS erreicht werden konnte, wurde die anfängliche Zusammensetzung des Nährmediums mit 1\% FCS Gehalt in den weiteren Versuchen beibehalten.

Die Zellproliferationssteigerung der HCC1806-Zellpopulation lag, bei einer 1\%-igen FCS Konzentration zwischen $13 \%$ und 44\% der Kontrolle. Girgert et al. (2017) erreichten ähnliche Proliferationssteigerungen. In seiner Arbeit über die Reduktion der GPR30Expression durch Gefitinib konnte anfangs eine Proliferationssteigerung durch 17ßÖstradiol bei HCC70-Zellen um $10 \pm 8 \%$ und bei HCC1806-Zellen um $45 \pm 29 \%$ erreicht werden (Girgert et al. 2017).

\subsection{Wirkung der GnRH-Analoga Triptorelin, Cetrorelix, D-Lysin ${ }^{6}$ GnRH II und $\mathbf{N} 4$ auf die relative Zellzahl der Zelllinien MDA-MB-435S, MDA-MB-453, HCC70, HCC1806}

Um herauszufinden, ob bei den TNBC-Zellen GnRH-Agonisten oder -Antagonisten eine stärkere Proliferationshemmung hervorrufen, wurden in der vorliegenden Arbeit GnRHAgonisten und Antagonisten verwendet.

GnRH-Analoga aktivieren durch Bindung an den GnRH-Rezeptor eine ProteinTyrosinphosphatase (Emons et al. 1996b; Furui et al. 1995; Gründker et al. 2001; Imai et al. 1996; Lee et al. 1991). Die aktivierte Protein-Tyrosinphosphatase dephosphoryliert den 
EGF-Rezeptor und inaktiviert ihn, durch Hemmung der Autophosphorylierung (Gründker et al. 2001).

Die vorliegenden Versuche sollten zeigen, ob es durch die Hemmung der EGFSignaltransduktion durch GnRH-Analoga in TNBC-Zellen zu einer Reduktion der GPR30Expression kommt.

Von mehreren Autoren wurde in verschiedenen Studien bereits nachgewiesen, dass systemische GnRH-Agonisten und Antagonisten bei verschiedenen Tumorarten, z. B. bei Brustkrebs, sowie bei Ovarial- und Endometriumkarzinome (Emons et al. 1996a; Gründker et al. 2000) eine Dosis-Zeit-abhängige, inhibierende Wirkung auf die Proliferation haben (Emons et al. 2003; Gründker et al. 2002b).

In der vorliegenden Arbeit wurde dieser Effekt nun bei triple negativen Karzinomzellen (Zelllinien HCC1806, HCC70, MDA-MB-435S und MDA-MB-453) untersucht. Verwendet wurde der GnRH-I-Agonist (Triptorelin), der GnRH-I-Antagonist (Cetrorelix), der GnRH-II-Agonist (D-Lysin ${ }^{6}$ GnRH II) und der GNRH-II-Antagonist (N4). Bei der Zelllinie MDA-MB-435S zeigte sich keine wachstumshemmende Reaktion auf GnRH-Analoga. Bei der Zelllinie MDA-MB-453 kam es unter dem GnRH-I-Antagonisten Cetrorelix in einer Konzentration von $10^{-5} \mathrm{M}$ zu einer geringen Proliferationshemmung. Dagegen zeigte sich bei den Zelllinien HCC70 und HCC1806 eine deutliche Proliferationshemmung durch GnRH-Analoga.

\subsubsection{Vergleich der Zelllinien MDA-MB-453, MDA-MB-435S, HCC70, HCC1806}

GnRH-I-Rezeptoren wurden in den verwendeten Zelllinien MDA-MB-453, MDA-MB-435S und HCC70 von Schubert et al. (2008) und in HCC1806 von Buchholz et al. (2009) und Föst et al. (2011) nachgewiesen.

In der vorliegenden Arbeit kam es, im Gegensatz zu den Zelllinien HCC1806 und HCC70, bei den Zelllinien MDA-MB-435S und MDA-MB-453 zu keiner wesentlichen Proliferationshemmung durch GnRH-Analoga.

Zu ähnlichen Ergebnissen kamen auch Schubert (2010 Math.-Nat. Diss. Göttingen).

Bei ihren in vivo Versuchen mit Zellen der Zelllinie MDA-MB-435S ergab sich ebenfalls kein signifikanter wachstumshemmender Effekt auf das Tumorwachstum durch GnRH-IAnaloga (Triptorelin und Cetrorelix) (Schubert 2010 Math.-Nat. Diss. Göttingen). Fehlen- 
de GnRH-Rezeptoren können nicht die Ursache für diese Reaktion sein, denn 2010 wurde von Schubert unter anderem bei den Zelllinien MDA-MB-453 und MDA-MB-435S die Expression von GnRH-Rezeptoren nachgewiesen. Eine semiquantitative Auswertung der einzelnen Zelllinien wurde in dieser Arbeit nicht durchgeführt. Jedoch konnte eine Verringerung des Tumorvolumens nach einer fünfwöchigen Therapie beobachtet werden (Schubert 2010 Math.-Nat. Diss. Göttingen). Daraus folgerte die Autorin ein Ansprechen der Mammakarzinomzellen auf die GnRH-I-Analoga (Schubert 2010 Math.-Nat. Diss. Göttingen). Eine mögliche Erklärung für die unterschiedlich ausgeprägte Wirkung könnte eine unterschiedliche Anzahl an exprimierten GnRH-Rezeptoren sein.

Weiterhin könnte die verschiedene Gewebeabstammung der verwendeten Karzinomzellen ein Grund für das unterschiedliche Hemmverhalten sein. Die Zellen der Zelllinien HCC70/1806 stammen aus primären Mammakarzinomherden (ATCC HCC70, ATCC HCC1806). Die Zellen der Zelllinien MDA-MB-453 stammen aus, durch TNBC Metastasen verursachten Perikardergüssen (ATCC MDA-MB-453). Möglicherweise exprimieren die Primariusherde mehr GPR30-Rezeptoren als Metastasen. In der Studie über die GPR30-Inhibition untersuchten Girgert et al. (2014) mittels Western Blot die GPR30Expression von triple negativen Mammakarzinomzellen. Bei Zelllinien, die aus primären Tumorzellen (HCC70/HCC1806) gewonnen wurden, konnte der GPR30-Rezeptor nachgewiesen werden. Bei der Zelllinie MDA-MB 231, die aus Pleurametastasen eines Mammakarzinoms gewonnen wurde (ATCC MDA-MB 231), wurde der GPR30-Rezeptor nicht nachgewiesen (Girgert et al. 2014). Somit könnte es sein, dass, trotz Vorhandensein von GnRH-Rezeptoren, die Proliferationshemmung ohne GPR30-Rezeptor nicht eintreten kann.

Die Ergebnisse der Ziellinie MDA-MB-435S müssen kritisch gesehen werden. Die Herkunft der Zelllinie MDA-MB-435S ist schon länger umstritten. Zum Zeitpunkt der Versuchsdurchführung der vorliegenden Arbeit wurde die Abstammung der Zellen MDA-MB-435S aus Pleuraergüssen durch Metastasen eines triple negativen Mammakarzinoms gewertet. 2018 wurde eine Arbeit über die Fehlbestimmung von MDA-MB-435S als Mammakarzinomzelllinie und Nachweis einer molekularen Übereinstimmung mit der Melanom-Zelllinie M14 veröffentlicht (Korch et al. 2018) (ATCC MDA-MB-435S). 


\subsubsection{Vergleich der Wirkung der GnRH-Analoga GnRH I vs. GnRH II}

Beim Vergleich der GnRH-I- und GnRH-II-Analoga zeigt sich bei den GnRH-I-Analoga ein deutlich stärkerer proliferationshemmender Effekt als bei den GnRH-II-Analoga. Auch bei Gründker et al, der die Wirkung von GnRH-I- und -II-Analoga bei Endometrium- und Ovarialkarzinom untersuchte, zeigte sich ein unterschiedliches Ergebnis bezogen auf die Wirksamkeit. Bei diesen Karzinomen war der antiproliferative Effekt der GnRH-IIAnaloga deutlicher ausgeprägt, als der der GnRH-I-Analoga (Gründker et al. 2002a).

Die Rezeptor-Bindungsfähigkeiten unterscheiden sich in der Hypophyse und in den Tumorzellen. In Tumorzellen existieren zwei Arten von GnRH-Bindungsstellen. Diese unterscheiden sich anhand der Affinität und der Kapazität. Die eine GnRH Rezeptorbindungsstelle charakterisiert sich durch eine niedrige Affinität, jedoch durch eine hohe Kapazität und ähnelt der GnRH-Rezeptorbindestelle, wie sie auch in der Placenta und im Corpus luteum gefunden wurde (Eidne et al. 1987). Die andere Rezeptorbindungsstelle besitzt eine hohe Affinität, jedoch eine niedrige Kapazität und ähnelt der GnRH-Rezeptorbindestelle der Hypophyse (Emons und Schally 1994; Gründker und Emons 2017; Gründker et al. 2002b).

Eine unterschiedliche Bindungsaffinität der unterschiedlichen Analoga wäre außerdem zu diskutieren (Emons et al. 1993a; 1997; 1989; Gründker und Emons 2017; Pahwa et al. 1991; Srkalovic et al. 1998).

\subsubsection{Vergleich der Wirksamkeit des GnRH-I-Agonisten Triptorelin vs. den GnRH-I-Antagonisten Cetrorelix}

Da die GnRH-II-Analoga in der vorliegenden Arbeit keinen oder einen nicht signifikanten antiproliferativen Effekt zeigten, wurden zur weiteren Selektion in den weiterführenden Versuchen nur noch die GnRH-I-Analoga Triptorelin und Cetrorelix eingesetzt. Cetrorelix, der GnRH-I-Antagonist zeigte sich bei den Zelllinien HCC70 und HCC1806 in höheren Konzentrationen proliferationshemmend. Triptorelin bewirkte nur bei der Zelllinie HCC70 in verschiedenen Konzentrationen eine signifikante Proliferationshemmung. Bei der Zelllinie HCC1806 konnte Triptorelin bei keiner der verwendeten Konzentrationen einen antiproliferativen Effekt erzielen. Aufgrund dieser Ergebnisse wurde im weiteren Verlauf nur Cetrorelix bei den Versuchen zur GPR30-Expressionsbestimmung verwendet. 
Dieses Ergebnis der guten antiproliferativen Wirkung der GnRH-I-Analoga stimmt mit den Untersuchungsergebnissen verschiedener anderer Autoren überein (Emons und Schally 1994; Miller et al. 1985; Yano et al. 1994b).

Zu diesem Ergebnis kamen auch Studien von Emons et al (1993a, b), welche sowohl für Triptorelin als auch für Cetrorelix antiproliferative Effekte in gynäkologischen Tumoren nachweisen konnten.

2009 veröffentlichten Buchholz et al. Ergebnisse, welche die antiproliferativen Effekte von Cetrorelix bei triple negativen Mammakarzinomen der Zelllinien HCC1806 und HCC 1937 in vitro und in vivo darstellten. In vitro konnten signifikante antiproliferative Wirkungen bei beiden Zelllinien erzielt werden. In vivo führte die Injektion von je $3 \mathrm{mg}$ Cetrorelix an Tag eins und Tag $21 \mathrm{zu}$ einer signifikanten Inhibition des Tumorwachstums bei mit HCC1806 xenotransplantierten Nacktmäusen (Buchholz et al. 2009). Gründker et al. wiesen bereits 2004 die proliferationshemmende Wirkung der GnRH-Analoga Triptorelin und Cetrorelix in Ovarial- und Endometriumkarzinomzellen nach. Dabei wurde, nach Ausschaltung der GnRH-I-Rezeptoren eine Persistenz der antiproliferativen Wirkung von Cetrorelix nachgewiesen. Im Gegensatz dazu bewirkte Triptorelin, nach Ausschaltung der GnRH-I-Rezeptoren keine Wachstumshemmung mehr (Gründker et al. 2004). Es könnte sein, dass Triptorelin seine antiproliferative Wirkung nur über den GnRH-I-Rezeptor vermittelt, Cetrorelix sowohl über den GnRH-I- als auch über den GnRH-II-Rezeptor. Auch Yano et al. (1994a) bewiesen die wachstumshemmende Wirkung von Cetrorelix. Sie führten Versuche an Nacktmäusen durch, welche mit Ovarialkarzinomzellen beimpft wurden. Durch Cetrorelix wurde, im Gegensatz zu Triptorelin das Tumorzellwachstums signifikant gehemmt (Yano et al. 1994a). Der Autor vermutete damals eine zusätzliche antitumoröse Wirkung von Cetrorelix an der Tumorzelle.

Emons at al. (2003) untersuchten in einer klinischen Phase-II-Studie die Wirkung des GnRH-Antagonisten Cetrorelix auf das Ovarialkarzinom. Hierbei wurden 17 Patientinnen mit einem Ovarialkarzinom, welches refraktär auf eine Platinchemotherapie war, täglich mit 10 mg Cetrorelix (Plasmakonzentration 30-60 ng/ml = 20-40 nM) behandelt. Drei Patientinnen (18\%) erreichten eine partielle Remission für zwei bis sechs Monate und sechs Patientinnen (35\%) erreichten eine stabile Krankheitsphase für ein Jahr (Emons et al. 2003). 


\subsection{Dosis-Zeit abhängige Wirkung des GnRH-I-Antagonisten Cetrorelix auf die GPR30-Expression bei den Zelllinien HCC70 und HCC1806}

Für den Nachweis einer Dosis-Zeit-Abhängigkeit wurden die Zellen der Zelllinien HCC70 und HCC1806 mit dem GnRH-I-Antagonisten Cetrorelix in verschiedenen Konzentrationen $\left(10^{-7} \mathrm{M}, 10^{-6} \mathrm{M}, 10^{-5} \mathrm{M}\right)$ inkubiert. Mittels Western Blot wurde die GPR30-Expression zeitabhängig (nach 24, 48 und 96 Stunden) ermittelt. Um die direkte Stimulation des EGFRezeptors durch EGF aus dem Kulturmedium auszuschließen, wurden diese Versuche in serumfreiem Medium durchgeführt.

Zusammenfassend zeigte sich eine deutliche Konzentrationsabhängigkeit. Bei der höchsten Konzentration von Cetrorelix $\left(10^{-5} \mathrm{M}\right)$ ergab sich bei beiden Zelllinien eine signifikante Hemmung der GPR30-Expression, unabhängig von der Zeit.

Auch eine Zeitabhängigkeit konnte nachgewiesen werden. Bei der längsten Inkubationszeit (96 h) zeigte sich bei beiden Zelllinien eine signifikante Hemmung der GPR30-Expression unabhängig von der Konzentration.

Girgert et al. veröffentlichten 2012, dass der GPR30-Rezeptor in TNBC-Zellen durch eine GPR30-spezifische siRNA gehemmt werden kann. 2014 zeigten die gleichen Autoren, dass die Signaltransduktion des GPR30-Rezeptors sowie die Zellproliferation der triple negativen Mammakarzinomzellen durch Estriol ( $\left.E_{3}\right)$ gehemmt werden kann (Girgert et al. 2014). 2017 folgte eine weitere Studie in der die Zellproliferation von triple negativen Mammakarzinomzellen, die GPR30-Proteinexpression sowie die Expression proliferationsrelevanter Gene (cfos, Cyclin D1) durch den Antikörper Gefitinib Dosis-Zeit abhängig gehemmt wurde (Girgert et al. 2017). Die Ergebnisse dieser Studien stützen die Annahme, dass der GPR30-Rezeptor eine vielversprechende Zielstruktur zur Behandlung von TNBC ist. Die Proteinexpression von GPR30 konnte in der Studie von Girgert et al. (2017) durch 200 nM Gefitinib nach vier Tagen Inkubationszeit bei der Zelllinie 1806 auf 39\% und bei der Zelllinie HCC70 auf 15\%, gesenkt werden.

Dies ist vergleichbar mit den erhobenen Daten der vorliegenden Arbeit. Hier wurde durch die Behandlung mit Cetrorelix $10^{-5} \mathrm{M}$ für vier Tage die GPR30-Expression bei der Zelllinie HCC1806 auf 36\% und bei der Zelllinie HCC70 auf 57\% gesenkt. Auffallend war bei den Versuchen, dass es bei der niedrigsten Konzentration von Cetrorelix bei den HCC70Zellen nach $24 \mathrm{~h}$ und $48 \mathrm{~h}$ zunächst zu einem Anstieg der GPR30-Expression kam. Auch die Zellen der Zelllinie HCC1806 zeigten nach 48 h, bei einer Cetrorelixkonzentration von 
$10^{-7} \mathrm{M}$, einen vorübergehenden Anstieg der GPR30-Expression. Zudem konnte man beobachten, dass es nach der mittleren Zeit von $48 \mathrm{~h}$ bei beiden Zelllinien bei einer Cetrorelix Konzentration von $10^{-6} \mathrm{M}$ zu einem vorübergehenden Anstieg kam. Dieser vorübergehende Anstieg der GPR30-Expression könnte eine Gegenregulation der Zelle auf das einwirkende Agens sein. Die maximale Wirkung von Cetrorelix in der höchsten Konzentration bzw. nach der längsten Einwirkzeit könnte dadurch erklärt werden, dass der GnRH-Antagonist irreversibel an die Rezeptoren bindet. Niedrige Konzentrationen würden dazu führen, dass nicht alle Rezeptoren besetzt sind und eine Gegenregulation der Zelle eintritt (GPR30Anstieg). Im Laufe der Zeit würden dann auch die restlichen GnRH-Rezeptoren besetzt werden und so kommt es nach $96 \mathrm{~h}$ zu einer deutlichen GPR30-Reduktion. Bei der höchsten Konzentration von Cetrorelix könnten in kurzer Zeit alle Rezeptoren besetzt werden und somit zu einer zeitunabhängigen Reduktion der GPR30-Expression führen.

Für eine eventuelle Therapie wäre vermutlich eine hohe Anfangsdosierung mit nachfolgender Dosisreduktion sinnvoll.

Ein ähnliches Beispiel der Dosierung zeigt sich bei der Therapie des fortgeschrittenen Prostatakarzinoms mit Degarelin. Degarelin ist, wie Cetrorelix, ein GnRH-Antagonist. Die Behandlung beginnt mit einer initialen Dosis von $240 \mathrm{mg}$ am Tag eins der Behandlung. Im Anschluss werden monatlich $80 \mathrm{mg}$ Degarelin sub cutan verabreicht (Doehn et al. 2009; Steinberg 2009) (EMA 2020, Firmagon). 


\section{Zusammenfassung}

In der vorliegenden Arbeit sollte ein neues Target zur spezifischen Therapie triple negativer Mammakarzinome näher untersucht werden.

Da TNBC-Zellen keinen Östrogenrezeptor $\alpha$ und keinen Progesteronrezeptor besitzen und Her-2 nicht überexprimieren, existiert aktuell keine spezifische endokrine Therapie. In TNBC-Zellen wurden EGFR-1-, GPR30- und GnRH-Rezeptoren nachgewiesen. Der GPR30-Rezeptor, der in den meisten gynäkologischen Tumoren exprimiert wird, soll durch seine Beziehung zum EGF-Rezeptor über GnRH-Analoga indirekt gehemmt werden.

GnRH-Analoga binden an den GnRH-Rezeptor der Tumorzelle, dadurch wird eine PTP aktiviert, welche die Autophosphorylierung und somit die Aktivierung des EGF-Rezeptors hemmt. Durch die bekannte Korrelation zwischen dem EGFR und dem GPR30 lässt sich eine Reduktion der GPR30-Expression durch GnRH-Analoga erklären.

In der vorliegenden Arbeit wurden drei verschiedene triple negative Zelllinien MDA-MB453, HCC70 und HCC1806, sowie die Zelllinie MDA-MB-435S (aus einem Melanom), die zum Zeitpunkt der Versuchsdurchführung der Arbeit als triple negative Mammakarzinomzelllinie deklariert war, verwendet.

Zunächst erfolgte die Stimulierung der Proliferation über 17ß-Östradiol. Mittels Alamar Blue Assay wurde die Proliferationsrate der TNBC-Zellen in Abhängigkeit der Konzentration von 17ß-Östradiol ermittelt. Bei drei der vier verwendeten Zelllinien kam es bei einer Konzentration von $10^{-8} \mathrm{M}$ zu einer signifikanten Proliferationssteigerung bis zu $24 \%$ (bei HCC70).

Des Weiteren wurden die vier Zelllinien, welche zuvor mit $10^{-8} \mathrm{M} 17 ß$-Östradiol für $24 \mathrm{~h}$ stimuliert wurden, mit den GnRH-Analoga Triptorelin (GnRH-I-Agonist), Cetrorelix (GnRH-I-Antagonist), D-Lysin ${ }^{6} \mathrm{GnRH}$ II Agonist (GnRH-II-Agonist), GnRH-IIAntagonist (N4 GnRH-II-Antagonist) in verschiedenen Konzentrationen inkubiert. Unter Auswertung der Proliferationsrate nach fünf Tagen mittels Alamar Blue Assay zeigte sich, dass vor allem bei den Zelllinien HCC70 und HCC1806 eine signifikante Reduktion der Proliferationsrate durch den GnRH-I-Antagonisten Cetrorelix erreicht wurde. Schon bei diesen Untersuchungen zeigte sich, dass es durch Cetrorelix in der höchsten verwendeten Konzentration $\left(10^{-5} \mathrm{M}\right)$ zu einer signifikanten Hemmung der Proliferationsrate kam. 
Der GPR30 als vermutetes Therapie-Target wurde weiter untersucht. Mittels Western Blot wurde die Reduktion der GPR30-Expression unter Cetrorelix zeit- und dosisabhängig ermittelt. Dabei ergab sich bei der höchsten Konzentration von Cetrorelix $\left(10^{-5} \mathrm{M}\right)$ bei beiden Zelllinien eine signifikante Hemmung der GPR30-Expression, unabhängig von der Zeit. Bei der längsten Inkubationszeit von $96 \mathrm{~h}$ zeigte sich eine signifikante Hemmung der GPR30-Expression unabhängig von der Cetrorelixkonzentration.

Der GnRH-I-Antagonist zeigte in der vorliegenden Arbeit eine wirksame dosis- zeitabhängige Hemmung der GPR30-Expression und damit der Proliferationsrate der triple negativen Mammakarzinomzellen.

Weitere Untersuchungen sollten folgten, um eine Wirksamkeit von Cetrorelix bei triple negativen Mammakarzinomen in vivo zu untersuchen. 


\section{Literaturverzeichnis}

Albanito L, Sisci D, Aquila S, Brunelli E, Vivacqua A, Madeo A, Lappano R, Pandey DP, Picard D, Mauro L et al. (2008): Epidermal growth factor induces G protein-coupled receptor 30 expression in estrogen receptor-negative breast cancer cells. Endocrinology 149, 3799-3808

Amoss M, Burgus R, Blackwell R, Vale W, Fellows R, Guillemin R (1971): Purification, amino acid composition and $\mathrm{N}$-terminus of the hypothalamic luteinizing hormone releasing factor (LRF) of ovine origin. Biochem Biophys Res Commun 44, 205-210

Anderson NG, Ahmad T, Chan K, Dobson R, Bundred NJ (2001): ZD1839 (Iressa), a novel epidermal growth factor receptor (EGFR) tyrosine kinase inhibitor, potently inhibits the growth of EGFR-positive cancer cell lines with or without erbB2 overexpression. Int J Cancer 94, 774-782

ATCC HCC70: American Type Culture Collection (ATCC) in Partnership with Laboratory of the Government Chemist (LGC) Standards, HCC70 (ATCC ${ }^{\circledR}$ CRL-2315 ${ }^{\mathrm{TM}}$ ) https://www.lgcstandardsatcc.org/Products/All/CRL-2315.aspx?geo_country=de\#generalinformation abgerufen am 21.04.2020 um 17:13

ATCC HCC1806: American Type Culture Collection (ATCC) in Partnership with Laboratory of the Government Chemist (LGC) Standards, HCC1806 (ATCC ${ }^{\circledR}$ CRL-2335 ${ }^{\text {TM }}$ ) https://www.lgcstandards-atcc.org/Products/All/CRL-

2335.aspx?geo_country=de\#generalinformation abgerufen am 21.04.2020 um 17:13

ATCC MDA-MB-453: American Type Culture Collection (ATCC), MDA-MB453 (ATCC ${ }^{\circledR}$ HTB- $^{-}$ $131^{\mathrm{TM}}$ ) https://www.atcc.org/Products/All/HTB-131.aspx?geo_country=de.\#generalinformation abgerufen am 21.04.2020 um 17:13

ATCC MDA-MB 231: American Type Culture Collection (ATCC) in Partnership with Laboratory of the Government Chemist (LGC) Standards, MDA-MB231 (ATCC ${ }^{\circledR}$ HTB-26 $6^{\text {TM }}$ ) https://www.lgcstandards-atcc.org/Products/All/HTB-26.aspx?geo_country=de\#generalinformation abgerufen am 21.04.2020 um 17:14

ATCC MDA-MB-435S: American Type Culture Collection (ATCC) in Partnership with Laboratory of the Government Chemist (LGC) Standards, MDA-MB 435S (ATCC ${ }^{\circledR}$ HTB-129 $9^{\mathrm{TM}}$ ) https://www.lgcstandards-atcc.org/Products/All/HTB-

129.aspx?geo_country=de\#generalinformation abgerufen am 21.04.2020 um 17:17 
Baselga J, Albanell J, Ruiz A, Lluch A, Gascon P, Guillem V, Gonzalez S, Sauleda S, Marimon I, Tabernero JM et al. (2005): Phase II and tumor pharmacodynamic study of gefitinib in patients with advanced breast cancer. J Clin Oncol 23, 5323-5333

Baselga J, Gomez P, Greil R, Braga S, Climent MA, Wardley AM, Kaufman B, Stemmer SM, Pego A, Chan A et al. (2013): Randomized phase II study of the anti-epidermal growth factor receptor monoclonal antibody cetuximab with cisplatin versus cisplatin alone in patients with metastatic triple-negative breast cancer. J Clin Oncol $\underline{31}$, 2586-2592

Bauer KR, Brown M, Cress RD, Parise CA, Caggiano V (2007): Descriptive analysis of estrogen receptor (ER)-negative, progesterone receptor (PR)-negative, and HER2-negative invasive breast cancer, the so-called triple-negative phenotype: a population-based study from the California cancer. Registry Cancer 109, 1721-1728

Baumann KH, Kiesel L, Kaufmann M, Bastert G, Runnebaum B (1993): Characterization of binding sites for a GnRH-agonist (buserelin) in human breast cancer biopsies and their distribution in relation to tumor parameters. Breast Cancer Res Treat 25, 37-46

Bernsdorf M, Ingvar C, Jorgensen L, Tuxen MK, Jakobsen EH, Saetersdal A, Kimper-Karl ML, Kroman N, Balslev E, Ejlertsen B (2011): Effect of adding gefitinib to neoadjuvant chemotherapy in estrogen receptor negative early breast cancer in a randomized phase II trial. Breast Cancer Res Treat $\underline{126}, 463-470$

Berridge MJ (1993): Inositol trisphosphate and calcium signalling. Nature $\underline{361}$, 315-325

Blankenstein MA, Henkelman MS, Klijn JG (1985): Direct inhibitory effect of a luteinizing hormone-releasing hormone agonist on MCF-7 human breast cancer cells. Eur J Cancer Clin Oncol 21, 1493-1499

Bokser L, Bajusz S, Groot K, Schally AV (1990): Prolonged inhibition of luteinizing hormone and testosterone levels in male rats with the luteinizing hormone-releasing hormone antagonist SB-75. Proc Natl Acad Sci U S A $\underline{87}, 7100-7104$

Bonfil D, Chuderland D, Kraus S, Shahbazian D, Friedberg I, Seger R, Naor Z (2004): Extracellular signal-regulated kinase, Jun N-terminal kinase, p38, and c-Src are involved in gonadotropin-releasing hormone-stimulated activity of the glycoprotein hormone folliclestimulating hormone beta-subunit promoter. Endocrinology 145, 2228-2244

Buchholz S, Seitz S, Schally AV, Engel JB, Rick FG, Szalontay L, Hohla F, Krishan A, Papadia A, Gaiser $\mathrm{T}$ et al. (2009): Triple-negative breast cancers express receptors for luteinizing hormonereleasing hormone (LHRH) and respond to LHRH antagonist cetrorelix with growth inhibition. Int J Oncol $\underline{35}$, 789-796

Carey LA, Dees EC, Sawyer L, Gatti L, Moore DT, Collichio F, Ollila DW, Sartor CI, Graham ML, Perou CM (2007): The triple negative paradox: primary tumor chemosensitivity of breast cancer subtypes. Clin Cancer Res $\underline{13}$, 2329-2334 
Carey LA, Rugo HS, Marcom PK, Mayer EL, Esteva FJ, Ma CX, Liu MC, Storniolo AM, Rimawi MF, Forero-Torres A et al. (2012): TBCRC 001: randomized phase II study of cetuximab in combination with carboplatin in stage IV triple-negative breast cancer. J Clin Oncol $\underline{30}$, 2615-2623

Chegini N, Rong H, Dou Q, Kipersztok S, Williams RS (1996): Gonadotropin-releasing hormone $(\mathrm{GnRH})$ and $\mathrm{GnRH}$ receptor gene expression in human myometrium and leiomyomata and the direct action of $\mathrm{GnRH}$ analogs on myometrial smooth muscle cells and interaction with ovarian steroids in vitro. J Clin Endocrinol Metab 81, 3215-3221

Chen A, Yahalom D, Ben-Aroya N, Kaganovsky E, Okon E, Koch Y (1998): A second isoform of gonadotropin-releasing hormone is present in the brain of human and rodents. FEBS Lett 435, 199203

Chen JQ, Russo J (2009): ERalpha-negative and triple negative breast cancer: molecular features and potential therapeutic approaches. Biochim Biophys Acta 1796, 162-175

Cheng KW, Leung PC (2000): The expression, regulation and signal transduction pathways of the mammalian gonadotropin-releasing hormone receptor. Can J Physiol Pharmacol 78, 1029-1052

Dawson SJ, Provenzano E, Caldas C (2009): Triple negative breast cancers: clinical and prognostic implications. Eur J Cancer 45 Suppl 1, 27-40

Dent R, Trudeau M, Pritchard KI, Hanna WM, Kahn HK, Sawka CA, Lickley LA, Rawlinson E, Sun P, Narod SA (2007): Triple-negative breast cancer: clinical features and patterns of recurrence. Clin Cancer Res $\underline{13}$, 4429-4434

Deutzmann R: Zelluläre Kommunikation: Mechanismen der Signaltransduktion. In: Rassow J, Hauser K, Netzker R, Deutzmann R (Hrsg.): Duale Reihe Biochemie. 3. Auflage; Thieme, Stuttgart 2012, 534-556

Deutzmann R: Zelluläre Kommunikation: Hormone. In: Rassow J, Hauser K, Netzker R, Deutzmann R (Hrsg.): Duale Reihe Biochemie. 3. Auflage; Thieme, Stuttgart 2012, 557-626

Deutzmann R: Zelluläre Kommunikation: Zytokine. In: Rassow J, Hauser K, Netzker R, Deutzmann R (Hrsg.): Duale Reihe Biochemie. 3. Auflage; Thieme, Stuttgart 2012, 645-650 
DGVS (2019): Kolorektales Karzinom. S3-Leitlinie der Deutschen Gesellschaft für Gastroenterologie, Verdauungs- und Stoffwechselkrankheiten https://www.awmf.org/uploads/tx_szleitlinien/021-007OLk_S3_Kolorektales-KarzinomKRK_2019-01.pdf; abgerufen am 21.4.2020

Doehn C, Sommerauer M, Jocham D (2009): Degarelix and its therapeutic potential in the treatment of prostate cancer. Clin Interv Aging $\underline{4}$, 215-223

Dondi D, Limonta P, Moretti RM, Marelli MM, Garattini E, Motta M (1994): Antiproliferative effects of luteinizing hormone-releasing hormone (LHRH) agonists on human androgenindependent prostate cancer cell line DU 145: evidence for an autocrine-inhibitory LHRH loop. Cancer Res $\underline{54}, 4091-4095$

Dowsett M, Cuzick J, Ingle J, Coates A, Forbes J, Bliss J, Buyse M, Baum M, Buzdar A, Colleoni $M$ et al. (2010): Meta-analysis of breast cancer outcomes in adjuvant trials of aromatase inhibitors versus tamoxifen. J Clin Oncol 28, 509-518

Eicke N, Gunthert AR, Emons G, Gründker C (2006): GnRH-II agonist [D-Lys6]GnRH-II inhibits the EGF-induced mitogenic signal transduction in human endometrial and ovarian cancer cells. Int J Oncol 29, 1223-1229

Eicke N, Gunthert AR, Viereck V, Siebold D, Behe M, Becker T, Emons G, Gründker C (2005): GnRH-II receptor-like antigenicity in human placenta and in cancers of the human reproductive organs. Eur J Endocrinol 153, 605-612

Eidne KA, Flanagan CA, Harris NS, Millar RP (1987): Gonadotropin-releasing hormone (GnRH)binding sites in human breast cancer cell lines and inhibitory effects of GnRH antagonists. J Clin Endocrinol Metab 64, 425-432

EMA 2019, Iressa: European Medicines Agency, Sciene Medicines Health, Iressa Stand 28.05.2019, https://www.ema.europa.eu/en/medicines/human/EPAR/iressa abgerufen am 21.04.2020 um 10:17

EMA 2020, Erbitux: European Medicines Agency, Sciene Medicines Health, Erbitux Stand 20.01.2020, https://www.ema.europa.eu/en/medicines/human/EPAR/erbitux abgerufen am 21.04.2020 um 12:43

EMA 2019, Cetrolide: European Medicines Agency, Sciene Medicines Health, Cetrolide Stand 19.01.2019, https://www.ema.europa.eu/en/medicines/human/EPAR/cetrotide abgerufen am 21.04.2020 um 12.52 
EMA 2020, Firmagon: European Medicines Agency, Sciene Medicines Health, Firmagon Stand 10.01.2020 https://www.ema.europa.eu/en/medicines/human/EPAR/firmagon abgerufen am 21.04.2020 um 14.10

Emons G, Gründker C, Gunthert AR, Westphalen S, Kavanagh J, Verschraegen C (2003): GnRH antagonists in the treatment of gynecological and breast cancers. Endocr Relat Cancer 10, 291-299

Emons G, Muller V, Ortmann O, Grossmann G, Trautner U, Stuckrad B, Schulz K, Schally A (1996a): Luteinizing hormone-releasing hormone agonist triptorelin antagonizes signal transduction and mitogenic activity of epidermal growth factor in human ovarian and endometrial cancer cell lines. Int J Oncol 9, 1129-1137

Emons G, Ortmann O, Becker M, Irmer G, Springer B, Laun R, Holzel F, Schulz KD, Schally AV (1993a): High affinity binding and direct antiproliferative effects of LHRH analogues in human ovarian cancer cell lines. Cancer Res 53, 5439-5446

Emons G, Ortmann O, Schulz KD, Schally AV (1997): Growth-inhibitory actions of analogues of Luteinizing Hormone Releasing Hormone on tumor cells. Trends Endocrinol Metab $\underline{8}$, 355-362

Emons G, Ortmann O, Teichert HM, Fassl H, Lohrs U, Kullander S, Kauppila A, Ayalon D, Schally A, Oberheuser F (1996b): Luteinizing hormone-releasing hormone agonist triptorelin in combination with cytotoxic chemotherapy in patients with advanced ovarian carcinoma. A prospective double blind randomized trial. Decapeptyl Ovarian Cancer Study Group Cancer $\underline{78}$, $1452-1460$

Emons G, Pahwa GS, Brack C, Sturm R, Oberheuser F, Knuppen R (1989): Gonadotropin releasing hormone binding sites in human epithelial ovarian carcinomata. Eur J Cancer Clin Oncol $25,215-221$

Emons G, Schally AV (1994): The use of luteinizing hormone releasing hormone agonists and antagonists in gynaecological cancers. Hum Reprod $\underline{9}, 1364-1379$

Emons G, Schroder B, Ortmann O, Westphalen S, Schulz KD, Schally AV (1993b): High affinity binding and direct antiproliferative effects of luteinizing hormone-releasing hormone analogs in human endometrial cancer cell lines. J Clin Endocrinol Metab 7, 1458-1464

Filardo EJ, Quinn JA, Bland KI, Frackelton AR, Jr. (2000): Estrogen-induced activation of Erk-1 and Erk-2 requires the G protein-coupled receptor homolog, GPR30, and occurs via transactivation of the epidermal growth factor receptor through release of HB-EGF. Mol Endocrinol 14, $1649-1660$

Filardo EJ, Quinn JA, Frackelton AR, Jr., Bland KI (2002): Estrogen action via the G proteincoupled receptor, GPR30: stimulation of adenylyl cyclase and cAMP-mediated attenuation of the epidermal growth factor receptor-to-MAPK signaling axis. Mol Endocrinol $\underline{16}, 70-84$ 
Fister S, Gunthert AR, Aicher B, Paulini KW, Emons G, Gründker C (2009): GnRH-II antagonists induce apoptosis in human endometrial, ovarian, and breast cancer cells via activation of stressinduced MAPKs p38 and JNK and proapoptotic protein Bax. Cancer Res $\underline{69}$, 6473-6481

Fister S, Gunthert AR, Emons G, Gründker C (2007): Gonadotropin-releasing hormone type II antagonists induce apoptotic cell death in human endometrial and ovarian cancer cells in vitro and in vivo. Cancer Res $\underline{67}, 1750-1756$

Föst C, Duwe F, Hellriegel M, Schweyer S, Emons G, Gründker C (2011): Targeted chemotherapy for triple-negative breast cancers via LHRH receptor. Oncol Rep 25, 1481-1487

Foulkes WD, Stefansson IM, Chappuis PO, Begin LR, Goffin JR, Wong N, Trudel M, Akslen LA (2003): Germline BRCA1 mutations and a basal epithelial phenotype in breast cancer. J Natl Cancer Inst 95, 1482-1485

Furui T, Imai A, Takagi H, Horibe S, Fuseya T, Tamaya T (1995): Phosphotyrosine phosphataseactivity in membranes from endometrial carcinoma. Oncol Rep 2 , 1055-1057

Girgert R, Emons G, Gründker C (2012): Inactivation of GPR30 reduces growth of triple-negative breast cancer cells: possible application in targeted therapy. Breast Cancer Res Treat 134, 199-205

Girgert R, Emons G, Gründker C (2014): Inhibition of GPR30 by estriol prevents growth stimulation of triple-negative breast cancer cells by 17beta-estradiol. BMC Cancer 14, 935

Girgert R, Emons G, Gründker C (2017): 17beta-estradiol-induced growth of triple-negative breast cancer cells is prevented by the reduction of GPER expression after treatment with gefitinib. Oncol Rep 그, 1212-1218

Green MD, Francis PA, Gebski V, Harvey V, Karapetis C, Chan A, Snyder R, Fong A, Basser R, Forbes JF (2009): Gefitinib treatment in hormone-resistant and hormone receptor-negative advanced breast cancer. Ann Oncol 20, 1813-1817

Gründker C, Emons G (2017): The Role of Gonadotropin-Releasing Hormone in Cancer Cell Proliferation and Metastasis. Front Endocrinol (Lausanne) $\underline{8}, 187$

Gründker C, Gunthert AR, Millar RP, Emons G (2002a): Expression of gonadotropin-releasing hormone II (GnRH-II) receptor in human endometrial and ovarian cancer cells and effects of GnRH-II on tumor cell proliferation. J Clin Endocrinol Metab 87, 1427-1430

Gründker C, Gunthert AR, Westphalen S, Emons G (2002b): Biology of the gonadotropinreleasing hormone system in gynecological cancers. Eur J Endocrinol 146, 1-14 
Gründker C, Schlotawa L, Viereck V, Eicke N, Horst A, Kairies B, Emons G (2004): Antiproliferative effects of the GnRH antagonist cetrorelix and of GnRH-II on human endometrial and ovarian cancer cells are not mediated through the GnRH type I receptor. Eur J Endocrinol 151, 141-149

Gründker C, Volker P, Emons G (2001): Antiproliferative signaling of luteinizing hormonereleasing hormone in human endometrial and ovarian cancer cells through $\mathrm{G}$ protein alpha(I)mediated activation of phosphotyrosine phosphatase. Endocrinology 142, 2369-2380

Gründker C, Volker P, Schulz KD, Emons G (2000): Luteinizing hormone-releasing hormone agonist triptorelin and antagonist cetrorelix inhibit EGF-induced c-fos expression in human gynecological cancers. Gynecol Oncol $\underline{78}, 194-202$

Haffty BG, Yang Q, Reiss M, Kearney T, Higgins SA, Weidhaas J, Harris L, Hait W, Toppmeyer D (2006): Locoregional relapse and distant metastasis in conservatively managed triple negative early-stage breast cancer. J Clin Oncol 24, 5652-5657

Harris D, Bonfil D, Chuderland D, Kraus S, Seger R, Naor Z (2002): Activation of MAPK cascades by GnRH: ERK and Jun N-terminal kinase are involved in basal and GnRH-stimulated activity of the glycoprotein hormone LHbeta-subunit promoter. Endocrinology 143, 1018-1025

Imai A, Takagi H, Furui T, Horibe S, Fuseya T, Tamaya T (1996): Evidence for coupling of phosphotyrosine phosphatase to gonadotropin-releasing hormone receptor in ovarian carcinoma membrane. Cancer 77, 132-137

Irmer G, Burger C, Muller R, Ortmann O, Peter U, Kakar SS, Neill JD, Schulz KD, Emons G (1995): Expression of the messenger RNAs for luteinizing hormone-releasing hormone (LHRH) and its receptor in human ovarian epithelial carcinoma. Cancer Res 55, 817-822

Irmer G, Burger C, Ortmann O, Schulz KD, Emons G (1994): Expression of luteinizing hormone releasing hormone and its mRNA in human endometrial cancer cell lines. J Clin Endocrinol Metab $\underline{79}, 916-919$

Kakar SS, Grizzle WE, Neill JD (1994): The nucleotide sequences of human GnRH receptors in breast and ovarian tumors are identical with that found in pituitary. Mol Cell Endocrinol 106, 145149

Kakar SS, Musgrove LC, Devor DC, Sellers JC, Neill JD (1992): Cloning, sequencing, and expression of human gonadotropin releasing hormone $(\mathrm{GnRH})$ receptor. Biochem Biophys Res Commun 189, 289-295

Karten MJ, Rivier JE (1986): Gonadotropin-releasing hormone analog design. Structure-function studies toward the development of agonists and antagonists: rationale and perspective. Endocr Rev 7, 44-66 
Keizer J, Li YX, Stojilkovic S, Rinzel J (1995): InsP3-induced Ca2+ excitability of the endoplasmic reticulum. Mol Biol Cell $\underline{6}, 945-951$

Kenakin T (1995): Agonist-receptor efficacy. I: Mechanisms of efficacy and receptor promiscuity. Trends Pharmacol Sci 16, 188-192

Kim MJ, Ro JY, Ahn SH, Kim HH, Kim SB, Gong G (2006): Clinicopathologic significance of the basal-like subtype of breast cancer: a comparison with hormone receptor and Her2/neuoverexpressing phenotypes. Hum Pathol $\underline{37}$, 1217-1226

Knobil E (1990): The GnRH pulse generator. Am J Obstet Gynecol 163, 1721-1727

Koch Y, Baram T, Hazum E, Fridkin M (1977): Resistance to enzymic degradation of LH-RH analogues possessing increased biological activity. Biochem Biophys Res Commun 74, 488-491

Konecny G, Pauletti G, Pegram M, Untch M, Dandekar S, Aguilar Z, Wilson C, Rong HM, Bauerfeind I, Felber M et al. (2003): Quantitative association between HER-2/neu and steroid hormone receptors in hormone receptor-positive primary breast cancer. J Natl Cancer Inst $\underline{95}$, 142 153

Korch C, Hall EM, Dirks WG, Ewing M, Faries M, Varella-Garcia M, Robinson S, Storts D, Turner JA, Wang Y et al. (2018): Authentication of M14 melanoma cell line proves misidentification of MDA-MB-435 breast cancer cell line. Int J Cancer 142, 561-572

Kraus S, Naor Z, Seger R (2001): Intracellular signaling pathways mediated by the gonadotropinreleasing hormone $(\mathrm{GnRH})$ receptor. Arch Med Res $\underline{32}$, 499-509

Lappano R, Rosano C, De Marco P, De Francesco EM, Pezzi V, Maggiolini M (2010): Estriol acts as a GPR30 antagonist in estrogen receptor-negative breast cancer cells. Mol Cell Endocrinol 320, $162-170$

Lee MT, Liebow C, Kamer AR, Schally AV (1991): Effects of epidermal growth factor and analogues of luteinizing hormone-releasing hormone and somatostatin on phosphorylation and dephosphorylation of tyrosine residues of specific protein substrates in various tumors. Proc Natl Acad Sci U S A $\underline{88}, 1656-1660$

Leitlinie Kolorektales Karzinom 2019: siehe DGVS 2019

Levi NL, Hanoch T, Benard O, Rozenblat M, Harris D, Reiss N, Naor Z, Seger R (1998): Stimulation of Jun N-terminal kinase (JNK) by gonadotropin-releasing hormone in pituitary alpha T3-1 cell line is mediated by protein kinase C, c-Src, and CDC42. Mol Endocrinol 12, 815-824 
Limonta P, Montagnani Marelli M, Moretti RM (2001): LHRH analogues as anticancer agents: pituitary and extrapituitary sites of action. Expert Opin Investig Drugs 10, 709-720

Luttrell LM, Daaka Y, Lefkowitz RJ (1999): Regulation of tyrosine kinase cascades by G-proteincoupled receptors. Curr Opin Cell Biol 11, 177-183

Maggiolini M, Vivacqua A, Fasanella G, Recchia AG, Sisci D, Pezzi V, Montanaro D, Musti AM, Picard D, Ando S (2004): The G protein-coupled receptor GPR30 mediates c-fos up-regulation by 17beta-estradiol and phytoestrogens in breast cancer cells. J Biol Chem $\underline{279}$, 27008-27016

Mangia A, Tommasi S, Reshkin SJ, Simone G, Stea B, Schittulli F, Paradiso A (2002): Gonadotropin releasing hormone receptor expression in primary breast cancer: comparison of immunohistochemical, radioligand and Western blot analyses. Oncol Rep $\underline{9}, 1127-1132$

McArdle CA, Franklin J, Green L, Hislop JN (2002): Signalling, cycling and desensitisation of gonadotrophin-releasing hormone receptors. J Endocrinol 173, 1-11

Millar R, Lowe S, Conklin D, Pawson A, Maudsley S, Troskie B, Ott T, Millar M, Lincoln G, Sellar R et al. (2001): A novel mammalian receptor for the evolutionarily conserved type II GnRH. Proc Natl Acad Sci U S A $\underline{98}, 9636-9641$

Millar RP (2003): GnRH II and type II GnRH receptors. Trends Endocrinol Metab 14, 35-43

Millar RP, Lu ZL, Pawson AJ, Flanagan CA, Morgan K, Maudsley SR (2004): Gonadotropinreleasing hormone receptors. Endocr Rev 25, 235-275

Miller WR, Scott WN, Morris R, Fraser HM, Sharpe RM (1985): Growth of human breast cancer cells inhibited by a luteinizing hormone-releasing hormone agonist. Nature $\underline{313}, 231-233$

Minaretzis D, Jakubowski M, Mortola JF, Pavlou SN (1995): Gonadotropin-releasing hormone receptor gene expression in human ovary and granulosa-lutein cells. J Clin Endocrinol Metab $\underline{80}$, 430-434

Miyamoto K, Hasegawa Y, Nomura M, Igarashi M, Kangawa K, Matsuo H (1984): Identification of the second gonadotropin-releasing hormone in chicken hypothalamus: evidence that gonadotropin secretion is probably controlled by two distinct gonadotropin-releasing hormones in avian species. Proc Natl Acad Sci U S A $\underline{81}$, 3874-3878 
Morris GJ, Naidu S, Topham AK, Guiles F, Xu Y, McCue P, Schwartz GF, Park PK, Rosenberg AL, Brill $\mathrm{K}$ et al. (2007): Differences in breast carcinoma characteristics in newly diagnosed African-American and Caucasian patients: a single-institution compilation compared with the National Cancer Institute's Surveillance, Epidemiology, and End Results database. Cancer 110, 876-884

Murase M, Uemura T, Gao M, Inada M, Funabashi T, Hirahara F (2005): GnRH antagonistinduced down-regulation of the mRNA expression of pituitary receptors: comparisons with $\mathrm{GnRH}$ agonist effects. Endocr J 2, 131-137

Naor Z (1990): Signal transduction mechanisms of Ca2+ mobilizing hormones: the case of gonadotropin-releasing hormone. Endocr Rev $\underline{11}$, 326-353

Neill JD (2002): GnRH and GnRH receptor genes in the human genome. Endocrinology 143, 737743

Neill JD, Duck LW, Sellers JC, Musgrove LC (2001): A gonadotropin-releasing hormone (GnRH) receptor specific for GnRH II in primates. Biochem Biophys Res Commun 282, 1012-1018

Netzker R: Zellzyklus und molekulare Genetik: Genexpression. In: Rassow J, Hauser K, Netzker R, Deutzmann R (Hrsg.): Duale Reihe Biochemie. 3. Auflage; Thieme, Stuttgart 2012, 432- 472

Nielsen TO, Hsu FD, Jensen K, Cheang M, Karaca G, Hu Z, Hernandez-Boussard T, Livasy C, Cowan D, Dressler L et al. (2004): Immunohistochemical and clinical characterization of the basallike subtype of invasive breast carcinoma. Clin Cancer Res $\underline{10}$, 5367-5374

Ohno T, Imai A, Furui T, Takahashi K, Tamaya T (1993): Presence of gonadotropin-releasing hormone and its messenger ribonucleic acid in human ovarian epithelial carcinoma. Am J Obstet Gynecol 169, 605-610

Pahwa GS, Kullander S, Vollmer G, Oberheuser F, Knuppen R, Emons G (1991): Specific low affinity binding sites for gonadotropin-releasing hormone in human endometrial carcinomata. Eur $\mathrm{J}$ Obstet Gynecol Reprod Biol 41, 135-142

Petrelli F, Cabiddu M, Ghilardi M, Barni S (2009): Current data of targeted therapies for the treatment of triple-negative advanced breast cancer: empiricism or evidence-based? Expert Opin Investig Drugs $\underline{18}, 1467-1477$

Podo F, Buydens LM, Degani H, Hilhorst R, Klipp E, Gribbestad IS, Van Huffel S, van Laarhoven HW, Luts J, Monleon D et al. (2010): Triple-negative breast cancer: present challenges and new perspectives. Mol Oncol $\underline{4}, 209-229$

Rakha EA, El-Sayed ME, Green AR, Lee AH, Robertson JF, Ellis IO (2007): Prognostic markers in triple-negative breast cancer. Cancer 109, 25-32 
Razandi M, Oh P, Pedram A, Schnitzer J, Levin ER (2002): ERs associate with and regulate the production of caveolin: implications for signaling and cellular actions. Mol Endocrinol 16, 100-115

Reis-Filho JS, Tutt AN (2008): Triple negative tumours: a critical review. Histopathology $\underline{52}$, 108118

Reissmann T, Schally AV, Bouchard P, Riethmiiller H, Engel J (2000): The LHRH antagonist cetrorelix: a review. Hum Reprod Update $\underline{6}, 322-331$

Revankar CM, Cimino DF, Sklar LA, Arterburn JB, Prossnitz ER (2005): A transmembrane intracellular estrogen receptor mediates rapid cell signaling. Science $\underline{307}, 1625-1630$

Roberson MS, Zhang T, Li HL, Mulvaney JM (1999): Activation of the p38 mitogen-activated protein kinase pathway by gonadotropin-releasing hormone. Endocrinology 140, 1310-1318

Ruf F, Fink MY, Sealfon SC (2003): Structure of the GnRH receptor-stimulated signaling network: insights from genomics. Front Neuroendocrinol 24, 181-199

Schally AV, Arimura A, Kastin AJ, Matsuo H, Baba Y, Redding TW, Nair RM, Debeljuk L, White WF (1971): Gonadotropin-releasing hormone: one polypeptide regulates secretion of luteinizing and follicle-stimulating hormones. Science $\underline{173}$, 1036-1038

Schubert A, Schulz H, Emons G, Gründker C (2008): Expression of osteoprotegerin and receptor activator of nuclear factor-kappaB ligand (RANKL) in HCC70 breast cancer cells and effects of treatment with gonadotropin-releasing hormone on RANKL expression. Gynecol Endocrinol 24, $331-338$

Schubert A: Einfluss von GnRH Analoga auf die Metastasierung humaner Mammakarzinomzellen in vitro und in vivo. Math.-Nat. Diss. Göttingen 2010

Sealfon SC, Weinstein H, Millar RP (1997): Molecular mechanisms of ligand interaction with the gonadotropin-releasing hormone receptor. Endocr Rev 18, 180-205

Sorlie T, Tibshirani R, Parker J, Hastie T, Marron JS, Nobel A, Deng S, Johnsen H, Pesich R, Geisler S et al. (2003): Repeated observation of breast tumor subtypes in independent gene expression data sets. Proc Natl Acad Sci U S A $\underline{100}$, 8418-8423

Srkalovic G, Schally AV, Wittliff JL, Day TG, Jr., Jenison EL (1998): Presence and characteristics of receptors for [D-Trp6]luteinizing hormone releasing hormone and epidermal growth factor in human ovarian cancer. Int J Oncol 12, 489-498

Srkalovic G, Wittliff JL, Schally AV (1990): Detection and partial characterization of receptors for [D-Trp6]-luteinizing hormone-releasing hormone and epidermal growth factor in human endometrial carcinoma. Cancer Res $\underline{50}$, 1841-1846 
Steiman J, Peralta EA, Louis S, Kamel O (2013): Biology of the estrogen receptor, GPR30, in triple negative breast cancer. Am J Surg 206, 698-703

Steinberg M (2009): Degarelix: a gonadotropin-releasing hormone antagonist for the management of prostate cancer. Clin Ther $\underline{31 \mathrm{Pt} 2}$, 2312-2331

Stern DF (2000): Tyrosine kinase signalling in breast cancer: ErbB family receptor tyrosine kinases. Breast Cancer Res $\underline{2}$, 176-183

Stojilkovic SS, Reinhart J, Catt KJ (1994): Gonadotropin-releasing hormone receptors: structure and signal transduction pathways. Endocr Rev $\underline{15}$, 462-499

Vivacqua A, Lappano R, De Marco P, Sisci D, Aquila S, De Amicis F, Fuqua SA, Ando S, Maggiolini M (2009): G protein-coupled receptor 30 expression is up-regulated by EGF and TGF alpha in estrogen receptor alpha-positive cancer cells. Mol Endocrinol 23, 1815-1826

Volker P, Gründker C, Schmidt O, Schulz KD, Emons G (2002): Expression of receptors for luteinizing hormone-releasing hormone in human ovarian and endometrial cancers: frequency, autoregulation, and correlation with direct antiproliferative activity of luteinizing hormonereleasing hormone analogues. Am J Obstet Gynecol 186, 171-179

von Minckwitz G, Jonat W, Fasching P, du Bois A, Kleeberg U, Luck HJ, Kettner E, Hilfrich J, Eiermann W, Torode $\mathrm{J}$ et al. (2005): A multicentre phase II study on gefitinib in taxane- and anthracycline-pretreated metastatic breast cancer. Breast Cancer Res Treat 89, 165-172

Wakeling AE, Guy SP, Woodburn JR, Ashton SE, Curry BJ, Barker AJ, Gibson KH (2002): ZD1839 (Iressa): an orally active inhibitor of epidermal growth factor signaling with potential for cancer therapy. Cancer Res 62, 5749-5754

White RB, Eisen JA, Kasten TL, Fernald RD (1998): Second gene for gonadotropin-releasing hormone in humans. Proc Natl Acad Sci U S A 95, 305-309

Yano T, Pinski J, Halmos G, Szepeshazi K, Groot K, Schally AV (1994a): Inhibition of growth of OV-1063 human epithelial ovarian cancer xenografts in nude mice by treatment with luteinizing hormone-releasing hormone antagonist SB-75. Proc Natl Acad Sci U S A $\underline{91}$, 7090-7094

Yano T, Pinski J, Radulovic S, Schally AV (1994b): Inhibition of human epithelial ovarian cancer cell growth in vitro by agonistic and antagonistic analogues of luteinizing hormone-releasing hormone. Proc Natl Acad Sci U S A 91, 1701-1705

Zhang T, Roberson MS (2006): Role of MAP kinase phosphatases in GnRH-dependent activation of MAP kinases. J Mol Endocrinol 36, 41-50 


\section{DANKSAGUNG}

Ich bedanke mich bei Herrn Prof. Dr. med. Günter Emons sowie bei Frau Univ.-Prof. Dr. med. Julia Gallwas für die Möglichkeit, dass ich die vorliegende Arbeit im Forschungslabor der Universitätsfrauenklinik Göttingen unter der Leitung von Prof. Dr. Carsten Gründker anfertigen konnte.

Mein besonderer Dank gilt Herrn Prof. Dr. Carsten Gründker, der mich stets förderte und durch seine lehrreiche, engagierte Betreuung wesentlich zum Erfolg dieser Arbeit beitrug. Dafür und auch für die persönlichen Gespräche möchte ich ihm hiermit besonderen Dank aussprechen.

Außerdem danke ich Herrn PD Dr. Rainer Girgert für die wissenschaftliche Unterstützung im Labor in allen erdenklichen Situationen.

Besonders großer Dank gilt auch Frau Sonja Blume für die Hilfe zur Einarbeitung, für die Unterstützung während meiner ganzen Laborzeit, für das offene Ohr bei jeglichen Problemen und für die lustigen Momente, die wir gemeinsam hatten.

Für die schönen, produktiven aber auch lustigen Stunden im Labor der Molekularen Gynäkologie bedanke ich mich recht herzlich. Das tolle Arbeitsklima und die stets zur Verfügung stehende Schokolade führten zu dem gewissen Wohlfühlfaktor im Labor.

Ich hoffe, dass wir auch nach Abgabe der Dissertation weiterhin in Verbindung bleiben. Bleibt so wie ihr seid! 